\title{
Baseline household survey: Lasbela district
}

Pakistan Initiative for Mothers and Newborns (PAIMAN)

Follow this and additional works at: https://knowledgecommons.popcouncil.org/departments_sbsr-rh

Part of the Family, Life Course, and Society Commons, and the Maternal and Child Health Commons How does access to this work benefit you? Let us know!

\section{Recommended Citation}

Pakistan Initiative for Mothers and Newborns (PAIMAN). 2006. "Baseline household survey: Lasbela district." Islamabad: Population Council. 


\section{Baseline Household Survey Lasbola DISTRICT}



Pakistan Initiative for Mothers and Newborns (PAIMAN)

\section{Lasbela}

\section{Baseline Household Survey}




\section{(1) Population Council}

The Population Council, an international, non-profit, non-governmental organization established in 1952, seeks to improve the well-being and reproductive health of current and future generations around the world and to help achieve a humane, equitable, and sustainable balance between people and resources.

The Council analyzes population issues and trends; conducts research in the reproductive sciences; develops new contraceptives; works with public and private agencies to improve the quality and outreach of family planning and reproductive health services; helps governments design and implement effective population policies; communicates the results of research in the population field to diverse audiences; and helps strengthen professional resources in developing countries through collaborative research and programs, technical exchanges, awards, and fellowships.

\section{For inquiries, please contact:}

Population Council

\#7, Street 62, F-6/3, Islamabad, Pakistan

Tel: 92512277439

Fax: 92512821401

Email: info@pcpak.org

web: http://www.popcouncil.org

Layout \& Design : Ali Ammad

Printed by: Crystal Printers, Islamabad

Disclaimer:

"This study/report is made possible by the generous support of the American people through the United States Agency for International Development (USAID). The contents are the responsibility of JSI Research \& Training Institute, Inc. and do not necessarily reflect the views of USAID or the United States Government." 


\section{Contents}

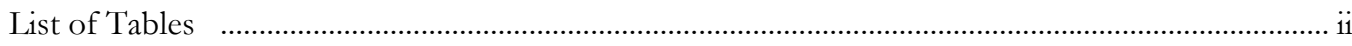

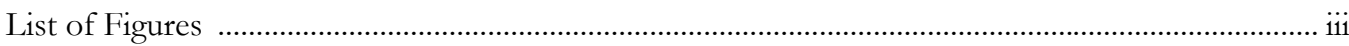

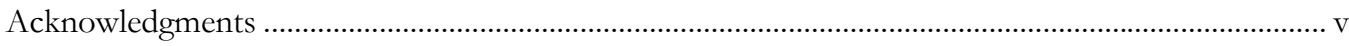

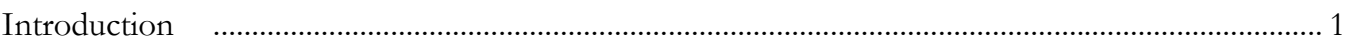

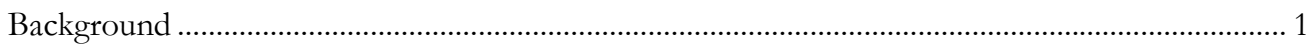

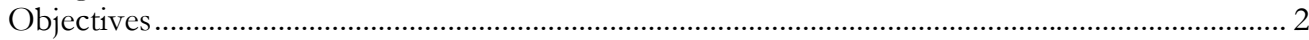

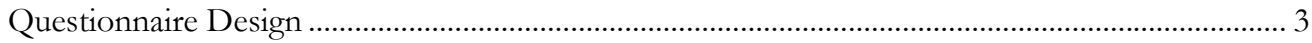

Hiring of Interviewers and Supervisors.......................................................................................... 4

Training of Interviewers and Supervisors ……………………………………………………….... 4

Data Entry and Edit Procedures ............................................................................................ 4

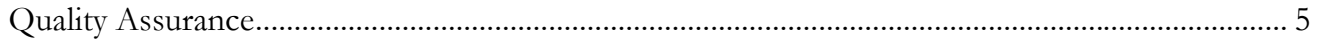

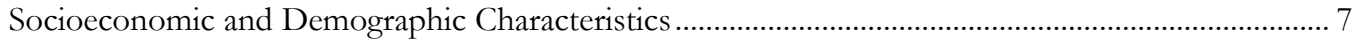

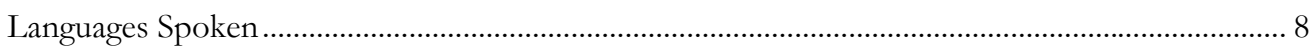

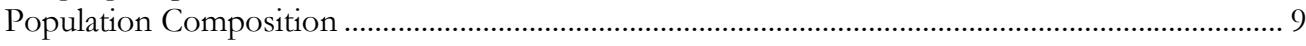

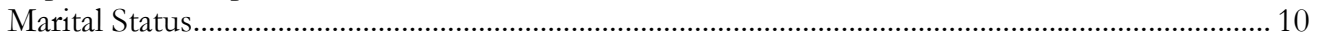

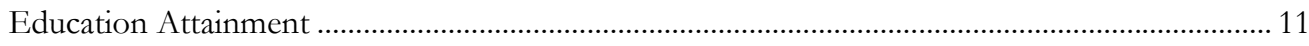

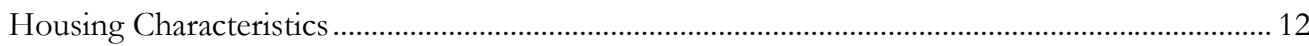

Fuel Used for Cooking ……………………………………………………………………. 13

Materials used for the Roof............................................................................................................ 14

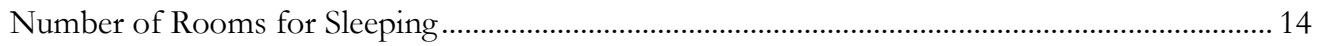

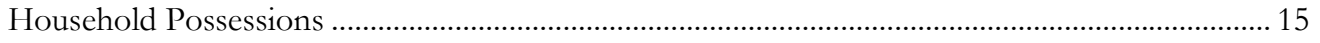

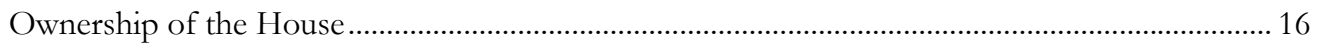

Background Characteristics of Married Women of Reproductive Age............................................ 17

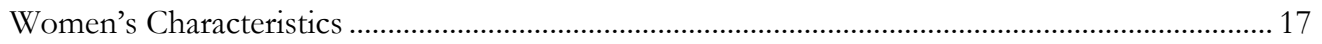

Age Distribution of Married Women ............................................................................................ 17

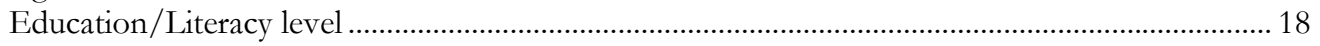

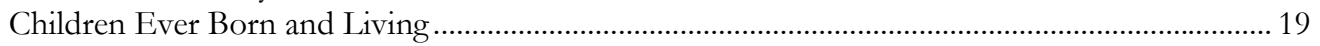

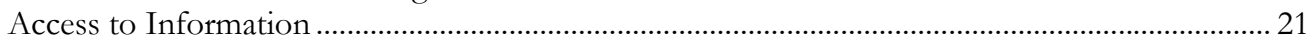

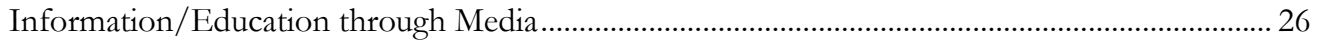

Knowledge of Safe Motherhood, Birth Preparedness and Community Resources............................... 29

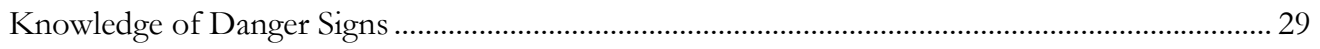

Source of Information Regarding Danger Signs ............................................................................... 35

Knowledge of Community Schemes for the Welfare of Women and Newborns............................ 36

Attitudes Towards Pregnancy, Delivery and Postpartum Period............................................................ 37

Attitudes Towards Age at Marriage ………………………………………………………….... 37

Attitudes Towards Antenatal Care ................................................................................................ 38

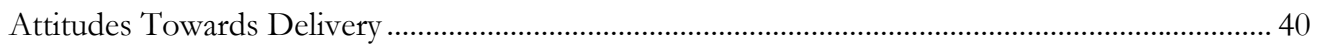

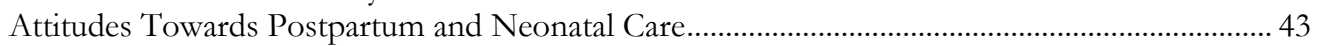

Coverage of Lady Health Workers.................................................................................................. 44

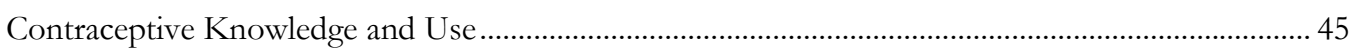

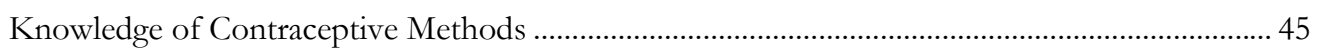

Ever Use of Contraception ....................................................................................................... 46

Behavior Regarding Maternal and Newborn Health.......................................................................... 49

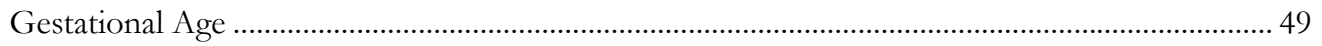

Antenatal Care ……………………………………………………………………………... 50

Experience of Complications and Birth Preparedness ................................................................... 55 


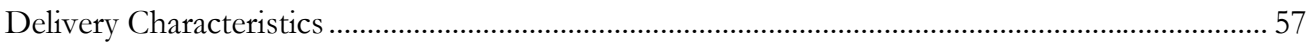

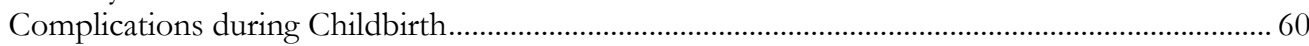

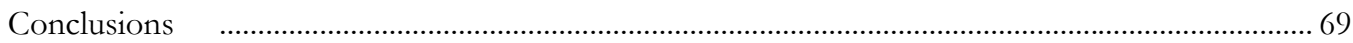

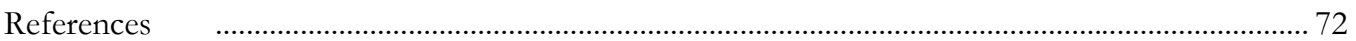

\section{List of Tables}

Table 1.1: Number of blocks/villages and households selected for the sample population .......... 2

Table 2.1: Household results by place of residence .............................................................................. 7

Table 2.2: $\quad$ Language mostly spoken in the HH by place of residence ............................................... 8

Table 2.3: Age-sex distribution of population ............................................................................ 9

Table 2.4: Household population by age (15 years and above), sex and marital status................ 10

Table 2.5: Household population by age (10 years and above), sex and educational level........... 11

Table 2.6 : Main source of drinking water by place of residence ......................................................... 12

Table 2.7: Type of toilet facility used by HH members and place of residence............................. 13

Table 2.8: $\quad$ Main type of fuel used in the HH for cooking by place of residence ........................... 13

Table 2.9: $\quad$ Number of rooms used for sleeping by place of residence ........................................... 15

Table 2.10: Ownership of household commodities/land by place of residence............................. 15

Table 2.11: Status of house by place of residence .................................................................................. 16

Table 3.1: Current age and age at marriage by place of residence................................................. 17

Table 3.2: $\quad$ Education level and literacy of married women and their husbands............................ 19

Table 3.3: $\quad$ Percentage distribution of married women by number of children ever born, mean number of children ever born, living children and age group, compared to the 1998 population census ......................................................................................................... 20

Table 3.4: $\quad$ Percentage distribution of married women by length of preceding birth interval...... 20

Table 3.5: Frequency of watching television ................................................................................... 22

Table 3.6: Place where respondent usually watches television ..................................................... 22

Table 3.7: Frequency of listening to radio ...................................................................................... 23

Table 3.8 : Place where respondent listens to the radio....................................................................... 24

Table 4.1: Knowledge of existence and importance of transport, blood and finances by the community at the time of delivery by place of residence ................................................ 36

Table 5.1: Percentage of respondents who believe girls should be married soon after puberty

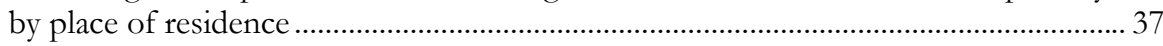

Table 5.2: Antenatal check-up by place of residence ....................................................................... 38

Table 5.3: $\quad$ Month of the pregnancy when women should go for antenatal care by place of

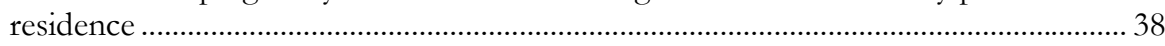

Table 5.4: Number of antenatal visits believed necessary by place of residence........................... 39

Table 5.5: Believe that women should receive delivery services from health professional by place of residence ................................................................................................................ 40

Table 5.6: Person who should make decisions regarding health of a pregnant woman............... 42

Table 5.7: Belief in necessity of postnatal care by place of residence............................................ 43

Table 5.8: Number of postnatal care visits women should have in the community by place of

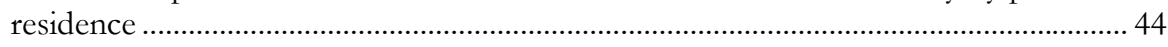

Table 5.9: $\quad$ Presence of lady health worker in the community by place of residence ..................... 44 
Table 5.10: $\quad$ LHW ever visited home during last three months by place of residence ................... 44

Table 6.1: $\quad$ Ever used FP method by contraceptive and place of residence ................................... 46

Table 6.2: Current use of specific contraceptive method................................................................ 47

Table 6.3 : Source of contraception by place of residence ................................................................... 48

Table 7.1: Pregnancy outcome by gestational age ............................................................................. 50

Table 7.2: Status of the antenatal check-ups who went for the services by place of residence.... 51

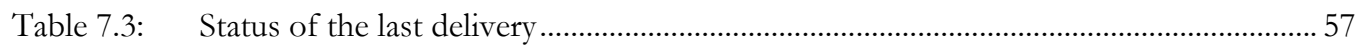

Table 7.4: Experienced complications during last delivery by place of residence......................... 60

Table 7.5: Person who made decision to seek health care/mode of transport used to reach

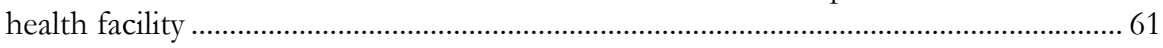

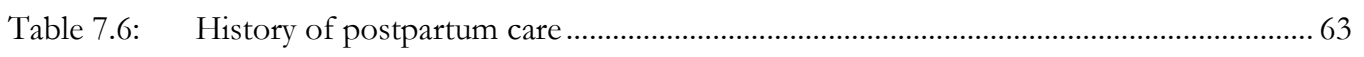

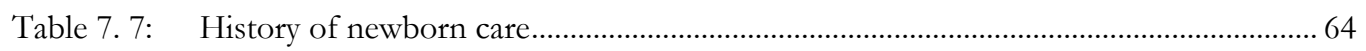

\section{List of Figures}

Figure 2.1: Languages spoken by place of residence ...................................................................... 8

Figure 2.2: $\quad$ Material used for construction of roof by place of residence.......................................... 14

Figure 3.1: Age distribution ......................................................................................................... 18

Figure 3.2: Percentage of women who watch television or listen to radio..................................... 21

Figure 3.3: Influence of television programs on health behaviors of people.................................. 23

Figure 3.4: Influence of radio on health behaviors........................................................................ 24

Figure 3.5: Frequency of reading newspaper.................................................................................. 25

Figure 3.6: Exposure to mass media (radio, television or newspaper)............................................. 25

Figure 3.7: Most trustworthy form of media..................................................................................... 26

Figure 3.8: Percentage of married women who had heard/read about maternal and newborn messages during the last 3 months ............................................................................... 27

Figure 4.1: Knowledge of danger signs during pregnancy which require medical attention ......... 30

Figure 4.2: $\quad$ Percentage distribution of women by number of known danger signs of pregnancy. 30

Figure 4.3: Distribution of respondents, who had knowledge about complications during

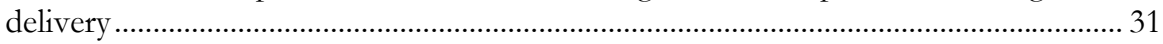

Figure 4.4: Percentage distribution of women by number of known danger signs of delivery ..... 32

Figure 4.5: Percent of married women who had knowledge about complications during postpartum period by place of residence .............................................................................. 32

Figure 4.6: Percentage distribution of women by number of known danger signs during

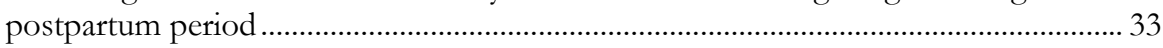

Figure 4.7: Distribution of respondents who had knowledge about danger signs in newborns ... 34

Figure 4.8: Percentage distribution of women by number of known danger signs in newborns.. 34

Figure 4.9: $\quad$ Source of information about pregnancy by place of residence ..................................... 35

Figure 5.1: Percentage of married women who thought they should have TT shots and take

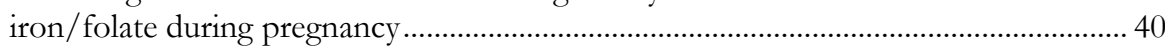

Figure 5.2: Percentage of women who thought women in their community went for skilled

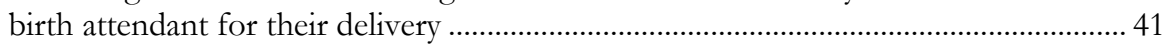

Figure 5.3: Percentage of women by their perception where should delivery take place.............. 41 
Figure 5.4: Percentage of married women by mode of transport they would use to reach a health facility .....

Figure 6.1: Percentage of married women by knowledge of specific contraceptive methodrural Lasbela

Figure 6.2: $\quad$ Percentage of married women by knowledge of specific contraceptive method urban Lasbela ................................................................................................................... 46

Figure 6.3: Percentage of married women by future intention to use contraceptives ................... 48

Figure 7.1: Percentage of pregnant women by their antenatal care status for the pregnancy three years preceding the baseline survey..... 51

Figure 7.2: $\quad$ Percentage distribution of married women by persons who accompanied them to

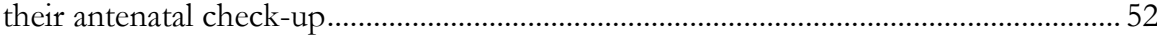

Figure 7.3 : Services performed/asked during antenatal check-up................................................... 53

Figure 7.4: Percentage of pregnant women by issues discussed during antenatal check-up.......... 53

Figure 7.5: Percentage of married women by status of TT injections during the last pregnancy. 54

Figure 7.6: Percentage of married women by status of iron/folate tablets during the last

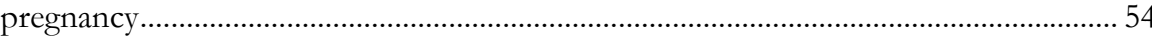

Figure 7.7: Percentage of married women who experienced complications during their last

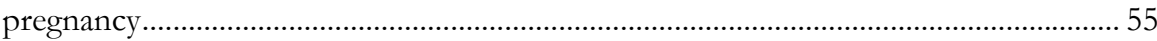

Figure 7.8: Percentage of married women who made arrangements for their last delivery ........... 56

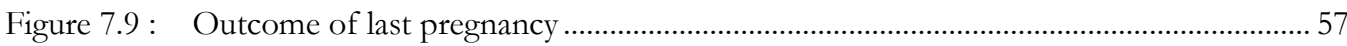

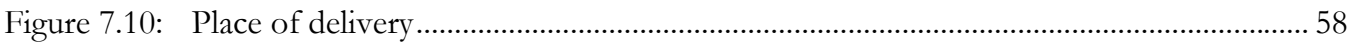

Figure 7.11: Percentage of married women who delivered their last child at home by delivery

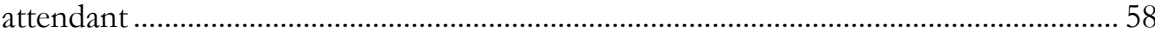

Figure 7.12: Main reason for choosing a TBA/dai as delivery attendant ........................................ 59

Figure 7.13: Percentage of delivery attendants who reportedly washed hands before conducting the delivery and type of thread used to tie the cord ...................................................... 59

Figure 7.14: Percentage of delivery attendants who reported instruments for cutting the cord ..... 60

Figure 7.15: Time taken to reach the health facility for childbirth ....................................................6 62

Figure 7.16: Median time to get the transport, reach the health facility, and to receive the treatment after reaching the facility

Figure 7.17: Percentage of live birth by their size (small, normal and big) at birth.......................... 64

Figure 7.18: Duration between the time of birth and the first bath given to a newborn ................. 65

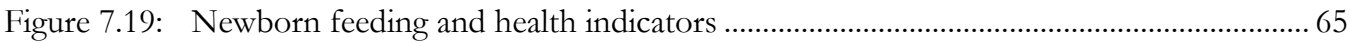

Figure 7.20: Percentage of newborns with danger signs/symptoms soon after delivery ................. 66

Figure 7.21: Percent of newborns with danger signs/symptoms within 7-days after last delivery . 67

Figure 7.22: Place where treatment was sought for newborn complications .................................. 67

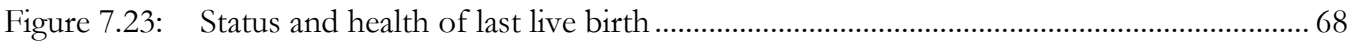




\section{Acknowledgments}

The PAIMAN Baseline Household Survey is a collaborative effort involving many partners, and will be the foundation of the PAIMAN project as a whole. Firstly, we would like to acknowledge our major partners. The United States Agency for International Development (USAID), in particular Mr. Chris McDermott, made funding available for this activity. Dr. Nabeela Ali, Chief of Party for PAIMAN, encouraged the study in general, and greatly facilitated the partnership between the Population Council and NIPS. The role of NIPS was supported under a separate agreement with PAIMAN. The comments, suggestions and feedback received from PAIMAN partners with regard to the design of this activity greatly contributed towards the success of the household survey.

The National Institute of Population Studies (NIPS) ably carried out the fieldwork for this study and were responsible for the completion of a clean dataset. We would like to appreciate the efforts of the Executive Director, Dr. Saeed Shafqat; and the Director Mr. Mahboob Sultan for the execution of the fieldwork; Computer Programmer, Mr. Fateh-uddin, who managed the entry and cleaning of the data and the numerous NIPS staff members who carried out the study.

The Population Council was primarily responsible for designing the study, overseeing the data collection, analysis of data, and writing the reports. Dr. Arshad Mahmood, Director of Monitoring and Evaluation for PAIMAN, used his capable technical and managerial skills to oversee the entire study with enthusiasm and energy. Mr. Peter Miller, Deputy Country Director, contributed substantially in the design phase, and Dr. Zeba Sathar and Mr. Miller contributed towards the report preparation.

The essential work of the study was carried out by several Council staff members at all phases. During the design and pre-testing phases, we would particularly like to acknowledge Shagufta Naheed, Bushra Bano, Irfan Masood, Tayyaba Gul, and Saima Pervaiz for monitoring field work and ensuring quality data collection in the field. Saman Naz and Muhammad Ashraf assisted in preparing graphs and tables as well as with the writing process. Dr. Arshad Mahmood and Reem Khan jointly prepared the first draft of the baseline survey report, which served as the template for all ten district reports. Shafique Arif, Azeema Faizunisa and Nadia Abid also contributed to the report writing and reviewing process. Reem Khan completed the initial editing of the district reports, Mehdi Ali Khan designed their layout, Ali Ammad was responsible for the formatting, and Ms. Mary DeSouza carried out the final proofreading of the reports.

Finally, we must express our gratitude to the women of Lasbela, who gave their time freely and cooperated with us in order to make this study possible. We hope to repay them by using the information obtained from them to improve maternal and neonatal health services in the district of Lasbela. 



\section{Chapter}

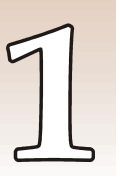

\section{Introduction}

\section{Background}

The Pakistan Initiative for Mothers and Newborns (PAIMAN) is a five-year project funded by the United States Agency for International Development (USAID). PAIMAN is committed to assisting the Government of Pakistan (GoP) in the implementation of the full spectrum of interventions necessary to address maternal and neonatal health $(\mathrm{MNH})$ issues.

The consortium is led by John Snow Incorporated (JSI), with partners from Pakistani and international organizations including Aga Khan University, Contech, Greenstar Social Marketing, Johns Hopkins University Center for Communication Program (JHU), PAVHNA, Population Council and Save the Children USA.

USAID has provided a grant to implement PAIMAN in 10 districts of Pakistan's four provinces. These districts are: Rawalpindi, Jhelum, Khanewal, and DG Khan in Punjab; Dadu and Sukkur in Sindh; Jafarabad and Lasbela in Balochistan; and Upper Dir and Buner in the North West Frontier Province. The goal of the project is to reduce maternal, newborn and child mortality in Pakistan. The project is based on the "Pathway to Care and Survival" framework. The five major strategic objectives are to:

- Increase awareness and promote positive maternal and neonatal health behaviors

- Increase access (including essential obstetric care) to and community involvement in maternal and child health services, while ensuring that services are successfully delivered through health and ancillary health services

- Improve service quality in both the public and private sectors, particularly related to management of obstetrical complications

- Increase the capacity of Maternal and Newborn Health (MNH) managers and care providers

- Improve the management and integration of services at all levels

The PAIMAN Project will promote skilled attendants as the long-term goal for all deliveries in Pakistan while acknowledging that maternal and neonatal health outcomes are influenced by factors other than health care. The PAIMAN Project calls for a multi-pronged and integrated strategic approach, combining individual health care with public health and community-based interventions.

To ensure that the success of PAIMAN is properly attained and that the appropriate lessons are learned, PAIMAN has developed a Monitoring and Evaluation Plan. Included in this plan is the establishment of baseline measures for a set of indicators, which will be used to evaluate the success 
of the project. This baseline report explores the level of knowledge of, as well as the attitudes and behaviors towards maternal and newborn health in the Lasbela district. The specific objectives of the baseline survey were as follows.

\section{Objectives}

- To measure the Intermediate Result 7 indicators necessary as part of PAIMAN's obligation to USAID.

- To measure PAIMAN indicators for which household survey data are appropriate for measurement, and for which sample sizes are feasible.

- To obtain information on maternal and neonatal health along with related issues, which may be of use to district Departments of Health for health management purposes.

- To obtain information needed for the detailed design of the PAIMAN project and, in particular, behavior change communication, public/private partnerships, and health systems strengthening.

\section{Methodology}

\section{Study Population}

PAIMAN is primarily a district-level project, intended to improve the health of all pregnant women, women with neonatal children, as well as all neonates of the district over the course of the project. To this end, the study covers community residents - notably mothers and prospective mothers - in order to understand and measure general knowledge and practice in relation related to pregnancy, delivery, obstetric and neonatal emergencies etc.

Hence, the study population for the baseline includes all currently married women of reproductive age (15-49 years) living in the selected districts. More specifically, it includes women who have experienced a pregnancy during the last three years.

\section{Sample Design}

The sampling design adopted for the survey is a stratified, systematic sample of households. The universe consists of all urban and rural areas of the district. The numbers of blocks selected in urban areas, along with the number of villages selected in rural areas, are presented in table 1.1 .

Table 1.1:Number of blocks/villages and households selected for the sample population

$\begin{array}{lccc} & \text { Area } & \begin{array}{c}\text { Number of Sample } \\ \text { Blocks/Villages }\end{array} & \text { Number of Households Selected } \\ \text { Urban } & & 15 & 360 \\ \text { Rural } & 25 & 600 \\ \text { Total } & 40 & 960\end{array}$




\section{Urban Sample}

Keeping in view the heterogeneity of the city of Lasbela, the sampling procedure was carried out to capture the full range of the socio-economic conditions of the urban population. For this purpose, we utilized the literacy rate, which was obtained from the 1998 Population Census as an indicator of the socio-economic status of each of the Census Enumeration Circles.

The required numbers of enumeration blocks were selected with probability proportional to size (number of circles). The "Enumeration Circle" was the smallest unit available in the 1998 Population District Census Reports as demarcated by the Population Census organizations. The maps of these circles were obtained from the Population Census Organization. The areas were already divided into blocks of approximately 250-300 households depending upon the number of households in each circle. Later, blocks were randomly selected with probability proportional to size from the list of total blocks in that circle. The enumeration teams then updated the listing of each block before selecting the sampled households. A fixed number of 24 households has been drawn from each sample enumeration block by using systematic random technique.

\section{Rural Sample}

The 1998 Population Census list of villages was used as the sampling frame for the selection of the rural sample. Villages in rural areas have been treated as primary sampling units (PSU). Sample PSUs have been selected with probability proportional to size (number of households). Households within the sample PSUs were considered secondary sampling units. The enumeration teams then updated the listing of each village before selecting the sampled households. A fixed number of 24 households has been drawn from each sample enumeration village by the systematic random technique.

\section{Questionnaire Design}

The questionnaire has been developed by the Population Council, based on a combination of current general Demographic and Health Survey methodologies and the questionnaire developed by the Population Council for the Safe Motherhood Applied Research and Training (SMART) Project. The questionnaire contains data sufficient to estimate all PAIMAN indicators.

Information on the following is included in the questionnaire:

- Households Information

- Socio-economic status of women

- Fertility, pregnancy history and reproductive intentions

- Attitude towards, as well as knowledge and practice of contraceptive methods

- Attitude towards pregnancy, delivery and the postpartum period

- Current birth preparedness/complications readiness (BP/CR) and knowledge of newborn care

- Current birth practices

- Health seeking behaviors

- Future BP/CR intentions

- Personal beliefs regarding pregnancy, delivery and the postpartum period 
- Common perceptions pertaining to women who are pregnant, delivering or in their postpartum period

- Facilities regarding BP/CR available in the community

- Factors that facilitate or hinder behaviors related to BP/CR

- Media habits

\section{Pre-testing of Questionnaire}

The questionnaire was reviewed by the PAIMAN's M\&E thematic group and other interested stakeholders, and was pre-tested in non-PAIMAN districts. The main objective of the pre-testing was to examine the suitability and effectiveness of questions in eliciting adequate responses, and to find out if there were any linguistic problems faced either by interviewers or by respondents. Finally, the pre-testing also helped determine the approximate time required to complete a questionnaire. The pre-tests were carried out by the Population Council's female staff members, who recorded their experiences with regard to each question. These records were then used to revise and finalize the questionnaire.

\section{Hiring of Interviewers and Supervisors}

Since the respondents in the baseline were to be MWRA and married men, it was decided that female interviewers would be used to interview women and male interviewers for men. Based on the constitution of each team, the required number of female interviewers were hired by NIPS according to its own internal procedures.

\section{Training of Interviewers and Supervisors}

The quality of training received by interviewers is reflected in the quality of data they record. In order to ensure that interviews were of a high and uniform quality and that interviewers understood the definitions and concepts behind the language of the questions, training was conducted by the Population Council in collaboration with NIPS. The training took place in Islamabad over two weeks and interviewers were schooled in questionnaire and survey procedures. Interviewers visited 3-4 households to conduct practice interviews.

It was very important for the interviewers to thoroughly understand the methodology and statistical importance of the sampled households. Training regarding the importance of the criterion for the selection of primary sampling units, mapping and listing procedure, sample selection, field operation procedures, as well as the selection of the particular households and respondents was also provided by experts.

\section{Data Entry and Edit Procedures}

Data processing was started from the field level with the checking of the questionnaires. Each team leader completed on-the-spot checks and preliminary editing of questionnaires during the enumeration period. Editing instructions were provided to the team leaders, and emphasis was laid on the importance of completing each questionnaire, correctly identifying each eligible respondent, and the completeness of household composition. 


\section{Quality Assurance}

To ensure the quality of the data, Population Council staff monitored the fieldwork accompanying the field teams. While supervising the fieldwork, the Population Council supervisory staff was also available to provide on-the-spot guidance to interviewers in the event that any part of the questionnaire was unclear to them. This ensured the completeness and accuracy of each questionnaire. 



\section{Socioeconomic and Demographic Characteristics}

This chapter presents the demographic and socioeconomic characteristics of the population in the sampled households of Lasbela. Information was collected on some demographic and socioeconomic characteristics such as the condition of the households, including the source of drinking water, availability of electricity, sanitation facilities, building materials, and possession of household durable goods. This information on the characteristics of the households is essential for the interpretation of survey findings. The definition of the household used for the baseline survey was "a person or a group of persons, related or unrelated, who live together in the same dwelling unit and share a common source of food".

\section{Urban/Rural Sample Population}

Table 2.1 shows the number of households selected in both urban and rural areas of Lasbela, as well as the interview status upon completion of the survey. A total sample of 960 households was selected from Lasbela. This number includes 600 households from rural areas along with 360 households from urban areas of Lasbela.

Table 2.1 shows that the completion rate of interviews was very high. Almost 99.8 percent of the interviews were completed in rural areas, while the figure was 98.9 percent in urban areas.

Table 2.1: $\quad$ Housebold results by place of residence

\begin{tabular}{lrrrrrr}
\multicolumn{1}{c}{ Result } & \multicolumn{2}{c}{ Rural } & \multicolumn{2}{c}{ Urban } & \multicolumn{2}{c}{ Total } \\
\cline { 2 - 7 } Completed & Percent & Number & Percent & Number & Percent & \multicolumn{1}{c}{ Number } \\
Incomplete & 99.8 & 599 & 98.9 & 356 & 99.5 & 955 \\
Refused & & & 0.3 & 1 & 0.1 & 1 \\
Total & 0.2 & 1 & 0.8 & 3 & 0.4 & 4 \\
\hline
\end{tabular}




\section{Languages Spoken}

Table 2.2 presents the distribution of households with respect to the languages spoken by the inhabitants. Sindhi was the most widely spoken language both in urban and rural areas of Lasbela, while second most widely spoken was Balochi. Barahvi was spoken by about 7 percent of the sample population of Lasbela.

Table 2.2: $\quad$ Language mostly spoken in the HH by place of residence

\begin{tabular}{lrrrrrr}
\multicolumn{1}{c}{ Language } & \multicolumn{2}{c}{ Rural } & \multicolumn{2}{c}{ Urban } & \multicolumn{2}{c}{ Total } \\
Urdu & Percent & Number & Percent & Number & Percent & Number \\
\hline Punjabi & & & 1.7 & 6 & 0.6 & 6 \\
\hline Sindhi & 0.2 & 1 & 2.8 & 10 & 1.2 & 11 \\
\hline Pushto & 77.6 & 465 & 48.9 & 174 & 66.9 & 639 \\
\hline Hindko & & & 0.6 & 2 & 0.2 & 2 \\
\hline Balochi & 13.2 & 79 & 39.0 & 139 & 22.8 & 218 \\
\hline Barahvi & 8.7 & 52 & 4.8 & 17 & 7.2 & 69 \\
\hline Saraiki & & & 1.7 & 6 & 0.6 & 6 \\
\hline Others & 0.3 & 2 & 0.3 & 1 & 0.3 & 3 \\
Total & 100.0 & 599 & 100.0 & 356 & 100.0 & 955
\end{tabular}

Figure 2.1: $\quad$ Languages spoken by place of residence

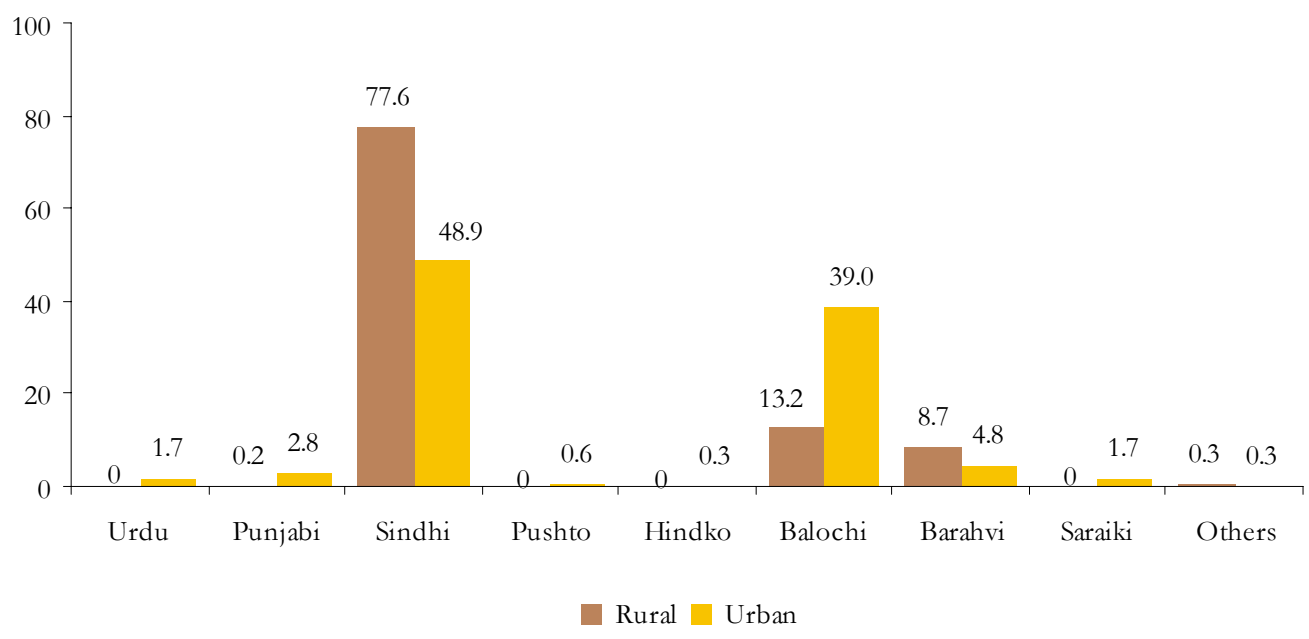




\section{Population Composition}

Table 2.3 shows the population in the baseline survey with regard to age and sex composition. Age and sex are important demographic variables and are the primary basis of demographic analysis. They are also important variables in the study of reproductive health, mortality and fertility.

In table 2.3, the age-sex distribution shows that about 15 percent of the population is currently less than 5 years of age, which indicates a high fertility rate. It also shows that 45.3 percent of the population in Lasbela appears to be under the age of 15. The sex ratio in the baseline survey is 105 males per 100 females. The sex ratio obtained in the 1998 Population Census was 115.32 males per 100 females. The marked difference between the two could be the result of a reporting error, or an improvement in the overall enumeration of females in the area.

Table 2.3: $\quad$ Age-sex distribution of population

\begin{tabular}{lcccccc}
\multicolumn{1}{c}{ Age } & \multicolumn{2}{c}{ Females } & \multicolumn{2}{c}{ Both Sexes } \\
\cline { 2 - 5 } Group & Number & Percent & Number & Percent & Number & Percent \\
Less than 5 & 570 & 15.3 & 520 & 14.6 & 1090 & 15.0 \\
\hline $5-9$ & 607 & 16.3 & 591 & 16.6 & 1198 & 16.4 \\
\hline $10-14$ & 522 & 14.0 & 490 & 13.8 & 1012 & 13.9 \\
\hline $15-19$ & 395 & 10.6 & 369 & 10.4 & 764 & 10.5 \\
\hline $20-24$ & 268 & 7.2 & 326 & 9.2 & 594 & 8.2 \\
\hline $25-29$ & 276 & 7.4 & 303 & 8.5 & 579 & 7.9 \\
\hline $30-34$ & 216 & 5.8 & 206 & 5.8 & 422 & 5.8 \\
\hline $35-39$ & 223 & 6.0 & 169 & 4.8 & 392 & 5.4 \\
\hline $40-44$ & 146 & 3.9 & 104 & 2.9 & 250 & 3.4 \\
\hline $45-49$ & 94 & 2.5 & 87 & 2.4 & 181 & 2.5 \\
\hline $50-54$ & 84 & 2.3 & 179 & 5.0 & 263 & 3.6 \\
\hline $55-59$ & 100 & 2.7 & 52 & 1.5 & 152 & 2.1 \\
\hline $60-64$ & 110 & 2.9 & 69 & 1.9 & 179 & 2.5 \\
\hline 65 and older & 118 & 3.2 & 90 & 2.5 & 208 & 2.9 \\
Total & 3729 & 100.0 & 3555 & 100.0 & 7284 & 100.0 \\
\hline
\end{tabular}




\section{Marital Status}

All individuals aged 15 years and older enumerated in the baseline survey were classified according to their marital status, as shown in table 2.4. The proportion of married women in the 15 to 19 year age group and the 20 to 24 year age group is much higher than the proportion of married men within the same age groups. When compared to the 1998 Population Census however, the proportion of married people in the aforementioned age groups appears to have fallen for both sexes, therefore suggesting an increase in the average age at marriage.

Table 2.4: $\quad$ Housebold population by age (15 years and above), sex and marital status

\begin{tabular}{|c|c|c|c|c|c|c|}
\hline \multirow[b]{2}{*}{ Age } & \multicolumn{3}{|c|}{ Males } & \multicolumn{3}{|c|}{ Females } \\
\hline & Never & Currently & Widow/ & Never & Currently & Widow/ \\
\hline Group & Married & Married & Divorced & Married & Married & Divorced \\
\hline \multicolumn{7}{|c|}{ PAIMAN Baseline 2005} \\
\hline $15-19$ & 97.7 & 2.3 & 0.0 & 86.4 & 13.6 & 0.0 \\
\hline $20-24$ & 72.8 & 26.5 & 0.7 & 44.2 & 55.2 & 0.3 \\
\hline $25-29$ & 27.9 & 72.1 & 0.0 & 12.5 & 86.8 & 0.3 \\
\hline $30-34$ & 11.1 & 88.9 & 0.0 & 5.3 & 93.7 & 1.0 \\
\hline $35-39$ & 1.8 & 96.4 & 1.3 & 1.8 & 97.6 & 0.6 \\
\hline $40-44$ & 3.4 & 96.6 & 0.0 & 0.0 & 96.2 & 3.8 \\
\hline $45-49$ & 2.1 & 97.9 & 0.0 & 0.0 & 97.7 & 1.1 \\
\hline $50-54$ & 1.2 & 94.0 & 4.8 & 1.1 & 82.7 & 15.6 \\
\hline $55-59$ & 0.0 & 92.0 & 7.0 & 1.9 & 82.7 & 15.4 \\
\hline $60-64$ & 0.0 & 92.7 & 7.3 & 2.9 & 50.7 & 43.5 \\
\hline 65 and older & 1.7 & 87.3 & 10.2 & 1.1 & 44.4 & 53.3 \\
\hline Total & 34.3 & 63.8 & 1.8 & 26.7 & 66.6 & 6.3 \\
\hline \multicolumn{7}{|c|}{ Population census 1998} \\
\hline $15-19$ & 93.0 & 6.7 & 0.4 & 76.7 & 22.9 & 0.4 \\
\hline $20-24$ & 64.4 & 34.9 & 0.7 & 31.4 & 67.5 & 1.2 \\
\hline $25-29$ & 32.1 & 66.7 & 1.2 & 10.2 & 87.9 & 2.0 \\
\hline $30-34$ & 14.5 & 83.6 & 1.9 & 5.3 & 91.5 & 3.2 \\
\hline $35-39$ & 8.6 & 88.4 & 3.0 & 2.8 & 92.5 & 4.7 \\
\hline $40-44$ & 6.3 & 89.8 & 3.9 & 2.1 & 90.0 & 7.9 \\
\hline $45-49$ & 4.3 & 91.1 & 4.6 & 1.7 & 88.2 & 10.1 \\
\hline $50-54$ & 3.9 & 89.3 & 6.8 & 2.6 & 77.1 & 20.3 \\
\hline $55-59$ & 2.9 & 89.3 & 7.7 & 2.8 & 72.0 & 25.2 \\
\hline $60-64$ & 3.9 & 85.5 & 10.7 & 3.9 & 56.6 & 39.4 \\
\hline 65 and older & 4.8 & 77.7 & 17.4 & 6.1 & 38.8 & 55.1 \\
\hline Total & 35.4 & 61.3 & 3.3 & 22.2 & 68.8 & 8.9 \\
\hline
\end{tabular}




\section{Education Attainment}

Education is a major factor influencing social status. Education is important for the social and economic development of a country. Males tend to be better educated than females for all age groups in Lasbela. According to table 2.5, more than half of the males, and four out of five females were uneducated. Table 2.5 shows that at the time of survey, the number of women interviewed aged 40 and above with a college education was very low, while 3.7 percent of the women in the $20-24$ year age group claimed to have had a college education.

Table 2.5: $\quad$ Household population by age (10 years and above), sex and educational level

\begin{tabular}{|c|c|c|c|c|c|}
\hline $\begin{array}{l}\text { Age } \\
\text { Group }\end{array}$ & $\begin{array}{c}\text { No } \\
\text { Schooling }\end{array}$ & $\begin{array}{c}1-5 \\
\text { Years }\end{array}$ & $\begin{array}{l}6-10 \\
\text { Years }\end{array}$ & $\begin{array}{c}11 \text { and } \\
\text { More years }\end{array}$ & Total \\
\hline \multicolumn{6}{|l|}{ Males } \\
\hline $10-14$ & 41.4 & 45.2 & 13.4 & 0.0 & 522 \\
\hline $15-19$ & 40.0 & 18.7 & 37.7 & 3.5 & 395 \\
\hline $20-24$ & 42.9 & 13.4 & 36.9 & 6.7 & 268 \\
\hline $25-29$ & 47.5 & 9.8 & 35.1 & 7.6 & 276 \\
\hline $30-34$ & 60.2 & 10.6 & 19.9 & 9.3 & 216 \\
\hline $35-39$ & 63.2 & 9.0 & 19.3 & 8.5 & 223 \\
\hline $40-44$ & 67.1 & 11.6 & 15.1 & 6.2 & 146 \\
\hline $45-49$ & 60.6 & 9.6 & 24.5 & 5.3 & 94 \\
\hline $50-54$ & 70.2 & 9.5 & 15.5 & 4.8 & 84 \\
\hline $55-59$ & 82.0 & 8.0 & 7.0 & 3.0 & 100 \\
\hline $60-64$ & 85.5 & 10.0 & 4.5 & 0.0 & 110 \\
\hline 65 and older & 86.4 & 6.8 & 5.9 & 0.8 & 118 \\
\hline Total & 54.2 & 18.7 & 22.6 & 4.5 & 2552 \\
\hline \multicolumn{6}{|l|}{ Females } \\
\hline $10-14$ & 60.8 & 33.9 & 5.3 & 0.0 & 490 \\
\hline $15-19$ & 67.5 & 16.5 & 13.0 & 3.0 & 369 \\
\hline $20-24$ & 76.4 & 11.7 & 8.3 & 3.7 & 326 \\
\hline $25-29$ & 88.4 & 5.0 & 4.0 & 2.6 & 303 \\
\hline $30-34$ & 95.1 & 1.9 & 1.5 & 1.5 & 206 \\
\hline $35-39$ & 91.7 & 0.6 & 5.3 & 2.4 & 169 \\
\hline $40-44$ & 96.2 & 1.0 & 2.9 & 0.0 & 104 \\
\hline $45-49$ & 96.6 & 0.0 & 3.4 & 0.0 & 87 \\
\hline $50-54$ & 96.1 & 2.8 & 0.6 & 0.6 & 179 \\
\hline $55-59$ & 94.2 & 3.8 & 1.9 & 0.0 & 52 \\
\hline $60-64$ & 100.0 & 0.0 & 0.0 & 0.0 & 69 \\
\hline 65 and older & 95.6 & 1.1 & 2.2 & 1.1 & 90 \\
\hline Total & 80.8 & 12.0 & 5.5 & 1.6 & 2444 \\
\hline
\end{tabular}




\section{Housing Characteristics}

\section{Source of Drinking Water}

In order to obtain a clear understanding of the living conditions of the population, it is necessary to record the source of drinking water available to respondents and their families. The source of drinking water is a very good indicator of a household's socio-economic status. By the source of drinking water the level of hygiene of the household can also be assessed. With regard to pregnancy and neonatal care, the source of drinking water indicates a level of hygiene and comfort available to an expectant mother or a newborn child.

Table 2.6 presents the types of water sources available to the residents of Lasbela in the baseline survey. In urban areas, about half of the respondents had access to tap water inside their homes, while only 5 percent in rural areas had the same advantage. About one third of the respondents in rural areas cited wells as their main source of drinking water. Overall, more than 10 percent remain dependent on surface water such as rivers/canals/streams or pooled/pond water.

Table 2.6 : $\quad$ Main source of drinking water by place of residence

\begin{tabular}{lrrrrrrr} 
& \multicolumn{2}{c}{ Rural } & \multicolumn{2}{c}{ Urban } & \multicolumn{2}{c}{ Total } \\
\cline { 2 - 7 } Source & Percent & Number & Percent & Number & Percent & Number \\
\hline Govt. supply (tap water inside) & 4.8 & 29 & 48.3 & 172 & 21.0 & 201 \\
\hline Govt. supply (communal) & 11.7 & 70 & 10.7 & 38 & 11.3 & 108 \\
\hline Motorized/hand pump (inside) & 2.5 & 15 & 5.1 & 18 & 3.5 & 33 \\
\hline Motorized/hand pump (outside) & 8.7 & 52 & 7.6 & 27 & 8.3 & 79 \\
\hline Well (inside) & 2.5 & 15 & 0.8 & 3 & 1.9 & 18 \\
\hline Well (outside) & 30.9 & 185 & 3.1 & 11 & 20.5 & 196 \\
\hline Tube-well & 13.4 & 80 & 8.4 & 30 & 11.5 & 110 \\
\hline River/canal/stream & 6.3 & 38 & 6.7 & 24 & 6.5 & 62 \\
\hline Pooled/pond water & 6.0 & 36 & & & 3.8 & 36 \\
\hline Others & 13.2 & 79 & 9.3 & 33 & 11.7 & 112 \\
\hline Total & 100.0 & 599 & 100.0 & 356 & 100.0 & 955
\end{tabular}

\section{Toilet Facilities}

The type of toilet facility available is yet another important indicator of household socio-economic status, as well as of hygiene/sanitation levels. Similar to the source of drinking water, the residents of households with open-concept toilet facilities or no toilet facilities at all are at a higher risk of catching diseases than households with closed flush systems. 
In rural areas of Lasbela, 69 percent of the respondents in rural areas, along with more than 20 percent in urban areas have no toilet facilities, therefore forcing them to use open fields. In rural areas, only 1 percent have access to a flush connected to sewerage system, while 24 percent have access to a flush connected to a septic tank, and 4.2 percent have access to a flush connected to an open drain. In urban areas, 21 percent of sampled households have access to a flush connected to the sewerage system while 37 percent have access to a flush connected to a septic tank and 15 percent have access to a flush connected to an open drain (table 2.7).

Table 2.7: $\quad$ Type of toilet facility used by $\mathrm{HH}$ members and place of residence

\begin{tabular}{lrrrrrrr}
\multirow{2}{*}{\multicolumn{1}{c}{ Toilet facility }} & \multicolumn{2}{c}{ Rural } & \multicolumn{2}{c}{ Urban } & \multicolumn{2}{c}{ Total } \\
\cline { 2 - 7 } & Percent & Number & Percent & Number & Percent & Number \\
\hline Flush to sewerage & 1.2 & 7 & 21.1 & 75 & 8.6 & 82 \\
\hline Flush connected to septic tank & 23.9 & 143 & 36.8 & 131 & 28.7 & 274 \\
\hline Flush connected to open drain & 4.2 & 25 & 14.9 & 53 & 8.2 & 78 \\
\hline Raised latrine & 0.7 & 4 & & & 0.4 & 4 \\
\hline Pit latrine & 1.5 & 9 & 6.7 & 24 & 3.5 & 33 \\
\hline In fields & 68.6 & 411 & 20.5 & 73 & 50.7 & 484 \\
Total & 100.0 & 599 & 100.0 & 356 & 100.0 & 955
\end{tabular}

\section{Fuel Used for Cooking}

The fuel used in a household for cooking purposes is yet another important indicator of the socioeconomic status of that household. Table 2.8 shows that more than 98 percent of the respondents in rural areas and 68 percent of the respondents in urban areas use firewood for the purpose of cooking. In urban areas, more than 28 percent of the sampled households use natural gas.

Table 2.8: $\quad$ Main type of fuel used in the HH for cooking by place of residence

\begin{tabular}{lr|r|r|rrr}
\multirow{2}{*}{\multicolumn{1}{c}{ Type of fuel }} & \multicolumn{2}{c}{ Rural } & \multicolumn{2}{c}{ Urban } & \multicolumn{2}{c}{ Total } \\
\cline { 2 - 7 } & Percent & Number & Percent & Number & Percent & Number \\
\hline Fire wood & 98.2 & 588 & 68.0 & 242 & 86.9 & 830 \\
\hline Kerosene oil & 1.5 & 9 & & & 0.9 & 9 \\
\hline Gas cylinder & 0.3 & 2 & 3.1 & 11 & 1.4 & 13 \\
\hline Natural gas (Sui gas) & & & 28.4 & 101 & 10.6 & 101 \\
\hline Dry dung & & & 0.6 & 2 & 0.2 & 2 \\
\hline Total & 100.0 & 599 & 100.0 & 356 & 100.0 & 955
\end{tabular}




\section{Materials used for the Roof}

The materials used for the construction of roof and walls of a household are major indicators of the socio-economic status of that household, as well as the living standards of the people residing there. The more secure the materials, the higher the level of comfort and living standard of residents, and the lower the risk of disease and infection.

According to figure 2.2, more than three quarters (78 percent) of the households in rural areas of Lasbela had constructed the roofs of their houses with wood/bamboo and mud. In urban areas, more than a quarter ( 27 percent) of the sampled households had used girder and T-iron for the construction of roofs of their houses, while another quarter had used concrete. About 26 percent of the households in rural areas had used wood/bamboo and mud for constructing the roof. Another 20 percent of the respondents in urban areas and 7.5 percent of respondents in rural areas had constructed the roofs of their houses with corrugated iron.

Figure 2.2: $\quad$ Material used for construction of roof by place of residence

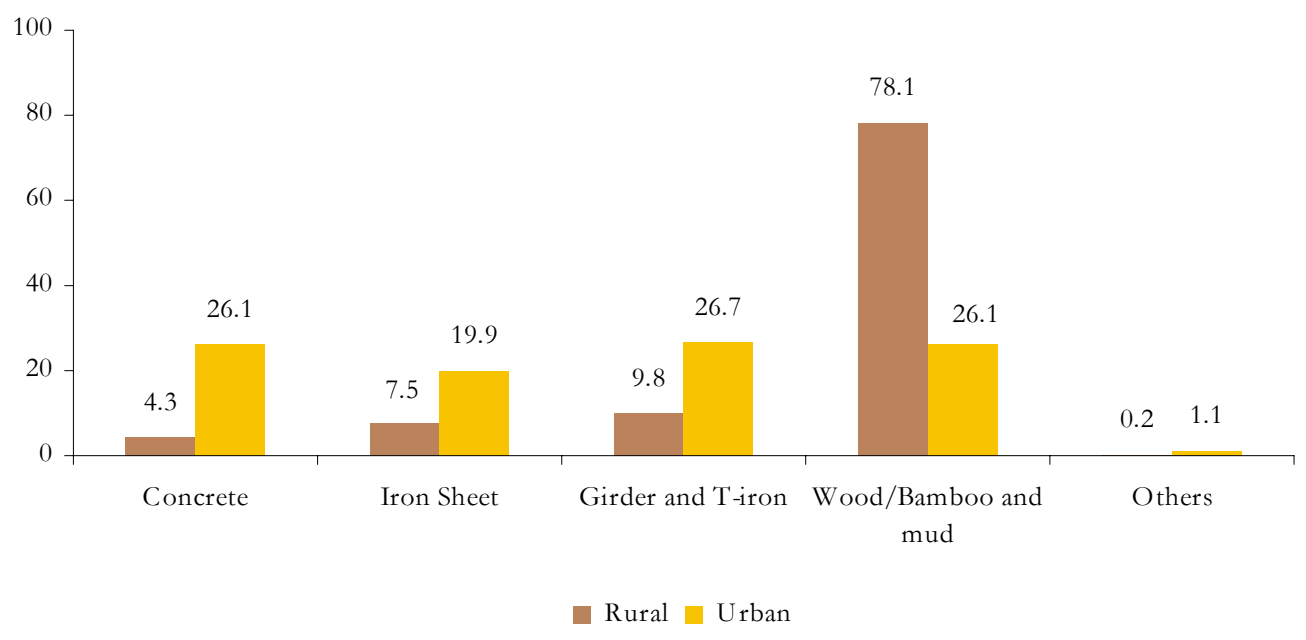

\section{Number of Rooms for Sleeping}

Respondents were asked to provide information regarding the number of rooms used for sleeping in their households. More than half of the families in rural areas and a quarter of the families in urban areas of Lasbela live in single room houses. About 35 percent of the families in rural areas, and 46 percent in urban areas live in double room houses. Only 28 percent and 11 percent of the households in rural and urban areas respectively have three or more rooms for the purpose of sleeping. In urban areas, there are an average of 4.2 persons per room compared to 5 persons per room in rural areas. 
Table 2.9: Number of rooms used for sleeping by place of residence

\begin{tabular}{lrrrrrrr}
\multirow{2}{*}{ Number of rooms } & \multicolumn{2}{c}{ Rural } & \multicolumn{2}{c}{ Urban } & \multicolumn{2}{c}{ Total } \\
\cline { 2 - 9 } 0 & Percent & Number & Percent & Number & Percent & Number \\
\hline 1 & 0.5 & 3 & & & 0.3 & 3 \\
\hline 2 & 53.2 & 318 & 25.6 & 91 & 42.9 & 409 \\
\hline 3 & 34.9 & 209 & 46.1 & 164 & 39.1 & 373 \\
\hline 4 & 8.0 & 48 & 15.7 & 56 & 10.9 & 104 \\
\hline $5+$ & 1.8 & 11 & 8.1 & 29 & 4.2 & 40 \\
\hline Total & 1.5 & 9 & 4.5 & 16 & 2.6 & 25 \\
\hline & 100.0 & 598 & 100.0 & 356 & 100.0 & 954
\end{tabular}

\section{Household Possessions}

Household possessions are perhaps one of the most effective ways of determining the socioeconomic status of a household. Often, it is easier to obtain information regarding household possessions than to ask for details about the household income, which respondents may be less willing to provide for various reasons.

Table 2.10: $\quad$ Ownership of household commodities/land by place of residence

\begin{tabular}{|c|c|c|c|c|}
\hline \multirow{2}{*}{ Household items } & \multirow{2}{*}{ Rural } & \multirow{2}{*}{ Urban } & \multicolumn{2}{|c|}{ Total } \\
\hline & & & Percentage & Number \\
\hline Electric iron & 13.7 & 62.6 & 31.9 & 305 \\
\hline Electric fan & 20.9 & 85.4 & 44.9 & 429 \\
\hline Sewing machine & 21.5 & 49.7 & 32.0 & 306 \\
\hline Radio or cassette player & 22.9 & 44.7 & 31.0 & 296 \\
\hline Chair/table & 4.0 & 21.1 & 10.4 & 99 \\
\hline Television & 6.8 & 50.8 & 23.2 & 222 \\
\hline Telephone & 3.7 & 30.3 & 13.6 & 130 \\
\hline Watch/clock & 33.1 & 61.5 & 43.7 & 417 \\
\hline VCR/VCP/VCD/CD player & 1.8 & 16.0 & 7.1 & 68 \\
\hline Refrigerator/deep freezer & 3.3 & 24.2 & 11.1 & 106 \\
\hline Air cooler & 0.2 & 1.4 & 0.6 & 6 \\
\hline Air conditioner & 0.3 & 3.1 & 1.4 & 13 \\
\hline Computer & 0.2 & 4.8 & 1.9 & 18 \\
\hline Bicycle & 7.5 & 13.2 & 9.6 & 92 \\
\hline Motorcycle & 8.7 & 11.5 & 9.7 & 93 \\
\hline Car/jeep & 2.5 & 4.8 & 3.4 & 32 \\
\hline Tractor/truck & 1.3 & 3.1 & 2.0 & 19 \\
\hline Ownership of agriculture land by $\mathrm{HH}$ & 45.1 & 24.2 & 37.3 & 356 \\
\hline $\begin{array}{l}\text { Agriculture major source of } \\
\text { livelihood }\end{array}$ & 25.4 & 14.3 & 21.3 & 203 \\
\hline
\end{tabular}


In order to obtain information regarding the socio-economic status of household, respondents were asked if specific household goods were present in their homes. The presence of durable goods such as a radio, television, telephone, refrigerator, motorcycle, and private car is another indicator of the household's socioeconomic status. Moreover, particular goods have specific benefits; for example, the ownership of a radio or television is a measure of access to mass media and exposure to innovative ideas; telephone ownership measures access to an efficient means of communication; refrigerator ownership means the life of wholesomeness food is prolonged and ownership of private transport allows greater access to many services away from the local area.

According to table 2.10, the socio-economic conditions of the households surveyed in rural areas of Lasbela were very poor. In urban areas, half of the households had television sets compared to only 6.8 percent of the rural population.

Table 2.10 also shows that 45 percent of the rural households own agricultural land, as compared to 24 percent of the households in urban areas. According to the findings, agriculture is the major source of livelihood for about 25 percent of the households in rural areas, as compared to only around 14 percent of the households in urban areas of Lasbela.

\section{Ownership of the House}

Table 2.11 shows the ownership status of the respondents' households. In rural areas of Lasbela, 96 percent of the respondents claimed to own the houses they were currently living in. Only about 1.3 percent of the respondents live in rented homes. In urban areas, 89 percent of the respondents live in their own houses, and 10 percent live in rented houses.

Table 2.11: $\quad$ Status of house by place of residence

\begin{tabular}{l|r|rrrrr}
\multirow{2}{*}{ Status } & \multicolumn{2}{c}{ Rural } & \multicolumn{2}{c}{ Urban } & \multicolumn{2}{c}{ Total } \\
\cline { 2 - 7 } & Percent & Number & Percent & Number & Percent & Number \\
\hline Owner occupied & 96.0 & 575 & 89.0 & 317 & 93.4 & 892 \\
\hline Rented & 1.3 & 8 & 10.1 & 36 & 4.6 & 44 \\
\hline Rent free & 2.7 & 16 & 0.3 & 1 & 1.8 & 17 \\
\hline Others & & & 0.6 & 2 & 0.2 & 2 \\
\hline Total & 100.0 & 599 & 100.0 & 356 & 100.0 & 955 \\
\hline
\end{tabular}




\section{Chapter

\section{Background Characteristics of Married Women of Reproductive Age}

Information regarding the basic background characteristics of respondents is essential for the interpretation of survey findings. This chapter describes the basic background characteristics including age, education level, and place of residence of the respondents. It also describes detailed information on the educational status of respondents and their husbands, literacy levels, and exposure to mass media. Only currently married women aged 15-49 were interviewed for this portion of the survey.

\section{Women's Characteristics}

\section{Age Distribution of Married Women}

Table 3.1 indicates the number of married women of reproductive age in each age group for the households surveyed. In both rural and urban areas, the largest proportion of women surveyed were in the 25 to 29 year age group, whereas the lowest proportions were in the 15 to 19 year age group. However, the percentage of married women aged 15 to 19 was slightly higher in the rural areas of Lasbela than in the urban areas (5.1 percent versus 3.8 percent). Overall the mean age of respondents in Lasbela is estimated to be 32.3 years.

Table 3.1:

Current age and age at marriage by place of residence

\begin{tabular}{|c|c|c|c|c|c|c|c|}
\hline \multirow{2}{*}{\multicolumn{2}{|c|}{ Background profile }} & \multicolumn{2}{|c|}{ Rural } & \multicolumn{2}{|c|}{ Urban } & \multicolumn{2}{|c|}{ Total } \\
\hline & & Percent & Number & Percent & Number & Percent & Number \\
\hline \multirow{7}{*}{ Age of respondent } & $15-19$ & 5.1 & 33 & 3.8 & 13 & 4.7 & 46 \\
\hline & $20-24$ & 17.6 & 113 & 17.2 & 59 & 17.4 & 172 \\
\hline & $25-29$ & 26.9 & 173 & 22.2 & 76 & 25.3 & 249 \\
\hline & $30-34$ & 19.6 & 126 & 18.1 & 62 & 19.1 & 188 \\
\hline & $35-39$ & 14.5 & 93 & 19.2 & 66 & 16.1 & 159 \\
\hline & $40-44$ & 8.9 & 57 & 12.5 & 43 & 10.1 & 100 \\
\hline & $45-49$ & 7.5 & 48 & 7.0 & 24 & 7.3 & 72 \\
\hline \multirow{4}{*}{ Age at marriage } & $<15$ & 18.7 & 120 & 23.0 & 79 & 20.2 & 199 \\
\hline & $15-19$ & 61.2 & 393 & 59.5 & 204 & 60.6 & 597 \\
\hline & $20-24$ & 16.8 & 108 & 15.2 & 52 & 16.2 & 160 \\
\hline & $25+$ & 3.3 & 21 & 2.3 & 8 & 2.9 & 29 \\
\hline
\end{tabular}

Figure 3.1 shows a graph of the age distribution of currently married women in rural and urban areas of Lasbela. The mean age at marriage in Lasbela is 16.5 years. The percentage of married women in early age groups is very similar in both urban and rural areas. If the age at marriage is low, then the 
education level of that woman also tends to be low. According to table 3.1, more than 20 percent of the women surveyed in Lasbela were married before the age of fifteen. As a result, many of these women may not have the opportunity to obtain an education before becoming pregnant, and therefore may not have a solid understanding of birth preparedness and complication readiness.

Figure 3.1: $\quad$ Age distribution

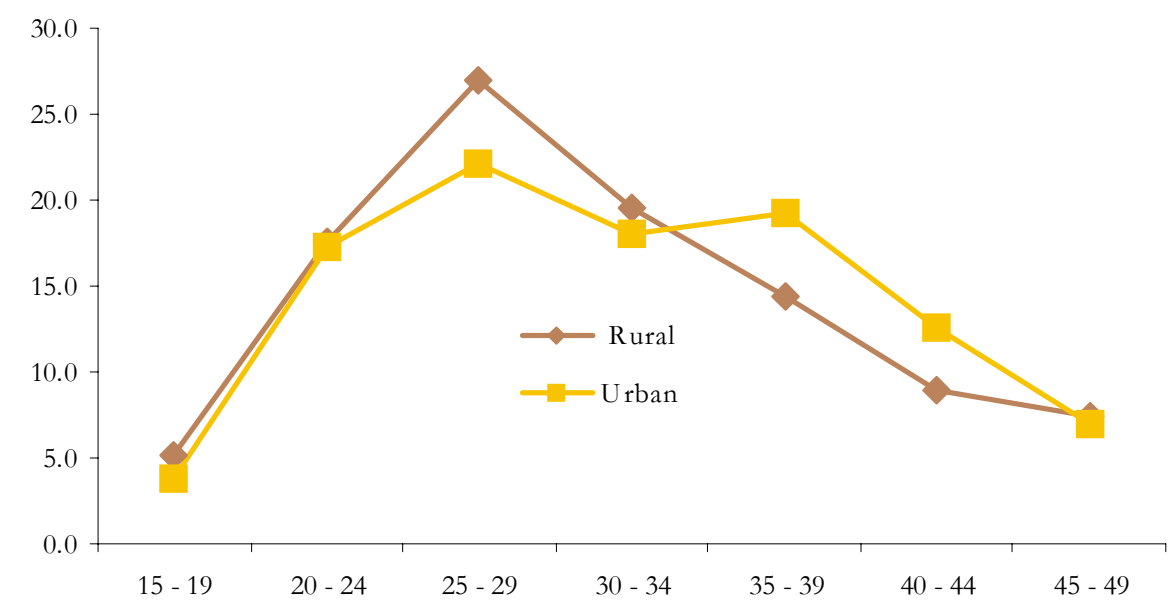

\section{Education/Literacy level}

The level of education obtained by a woman can be a good indicator of her status in society, as well as the independent decision-making power available to her. It is presumed that the higher the level of education obtained by a woman, the more say she has in matters concerning her health and that of her children. With regard to maternal health, a higher literacy rate in women would result in an increased use of contraceptives, higher awareness of complications during and after pregnancy, a strong understanding of neonatal and newborn health, and finally, a more complete understanding of safe birth practices.

Table 3.2 shows that 95 percent of the women interviewed in rural areas were illiterate. Only 2.6 percent of married women had education up to primary school. In urban areas of Lasbela, more than 82 percent of women were illiterate. Only 8.2 percent went up to primary school, 3.2 percent up to secondary school, and 3.2 percent completed studies past secondary school. 
Table 3.2:

Education level and literacy of married women and their husbands

\begin{tabular}{|c|c|c|c|c|c|c|c|}
\hline \multirow{2}{*}{\multicolumn{2}{|c|}{ Background profile }} & \multicolumn{2}{|c|}{ Rural } & \multicolumn{2}{|c|}{ Urban } & \multicolumn{2}{|c|}{ Total } \\
\hline & & Percent & Number & Percent & Number & Percent & Number \\
\hline \multirow{5}{*}{$\begin{array}{l}\text { Level of } \\
\text { education }\end{array}$} & No education & 96.0 & 617 & 81.9 & 281 & 91.1 & 898 \\
\hline & Up to primary & 2.6 & 17 & 8.2 & 28 & 4.6 & 45 \\
\hline & Up to middle & 0.9 & 6 & 3.5 & 12 & 1.8 & 18 \\
\hline & Up to secondary & 0.3 & 2 & 3.2 & 11 & 1.3 & 13 \\
\hline & Secondary + & 0.2 & 1 & 3.2 & 11 & 1.2 & 12 \\
\hline \multirow{2}{*}{$\begin{array}{l}\text { Respondent's } \\
\text { literacy }\end{array}$} & Literate & 5.1 & 33 & 17.8 & 61 & 9.5 & 94 \\
\hline & Illiterate & 94.9 & 610 & 82.2 & 282 & 90.5 & 892 \\
\hline \multirow{6}{*}{$\begin{array}{l}\text { Husband's } \\
\text { Level of } \\
\text { education }\end{array}$} & No education & 71.7 & 461 & 48.4 & 166 & 63.6 & 627 \\
\hline & Up to primary & 7.5 & 48 & 13.1 & 45 & 9.4 & 93 \\
\hline & Up to middle & 5.9 & 38 & 7.0 & 24 & 6.3 & 62 \\
\hline & Up to secondary & 10.6 & 68 & 21.0 & 72 & 14.2 & 140 \\
\hline & Secondary + & 3.7 & 24 & 10.5 & 36 & 6.1 & 60 \\
\hline & Don't know & 0.6 & 4 & & & 0.4 & 4 \\
\hline \multirow{2}{*}{$\begin{array}{l}\text { Husband's } \\
\text { literacy }\end{array}$} & Literate & 28.0 & 180 & 51.6 & 177 & 36.2 & 357 \\
\hline & Illiterate & 72.0 & 463 & 48.4 & 166 & 63.8 & 629 \\
\hline
\end{tabular}

The ability to read is an important personal asset allowing women and their husbands increased access to various opportunities. By gathering information regarding the distribution of literacy among the respondents surveyed, maternal and newborn health communicators are better able to reach their target population with their messages. About 63.8 percent of the husbands were illiterate in Lasbela.

\section{Children Ever Born and Living}

Table 3.3 presents the distribution of married women by the number of children ever born (CEB). This table also shows the mean number of children ever born and the mean number of living children for each five-year age group. Overall in Lasbela, there was an average of 3.8 children ever born and 3.5 surviving children. When these results are compared with the 1998 Population Census results, some changes can be noted. The overall average number of children ever born has decreased from 4.5 to 3.8. This reduction can be noted in all age groups except for the $45-49$ year age cohort. The number of living children has increased from 3.4 to 3.5 . 
Table 3.3: $\quad$ Percentage distribution of married women by number of children ever born, mean number of children ever born, living children and age group, compared to the 1998 population census

\begin{tabular}{|c|c|c|c|c|c|c|c|c|c|c|}
\hline \multirow{3}{*}{$\begin{array}{l}\text { Age } \\
\text { Group }\end{array}$} & \multicolumn{5}{|c|}{ Number of Children Ever Born } & \multirow{3}{*}{$\begin{array}{l}\text { No. of } \\
\text { Women }\end{array}$} & \multirow{2}{*}{\multicolumn{4}{|c|}{$\begin{array}{l}\text { Mean Number of Children } \\
\text { AN Baseline } 1998 \text { Population Census }\end{array}$}} \\
\hline & 0 & $1-2$ & $3-4$ & 5 or & Total & & & & & \\
\hline & & & & More & & & Ever born & Living & Ever born & Living \\
\hline $15-19$ & 50.0 & 45.7 & 4.3 & 0.0 & 100 & 46 & 0.7 & 0.6 & 1.5 & 0.8 \\
\hline $20-24$ & 31.4 & 50.0 & 15.1 & 3.5 & 100 & 172 & 1.4 & 1.3 & 2.2 & 1.5 \\
\hline $25-29$ & 8.4 & 34.9 & 41.4 & 15.3 & 100 & 249 & 2.8 & 2.7 & 3.3 & 2.7 \\
\hline $30-34$ & 4.8 & 14.4 & 33.5 & 47.3 & 100 & 188 & 4.3 & 3.9 & 5.5 & 3.9 \\
\hline $35-39$ & 3.1 & 9.4 & 24.5 & 62.9 & 100 & 159 & 5.4 & 5.0 & 6.1 & 4.7 \\
\hline $40-44$ & 3.0 & 9.0 & 10.0 & 78.0 & 100 & 100 & 6.5 & 5.9 & 6.6 & 5.2 \\
\hline $45-49$ & 4.2 & 2.8 & 11.1 & 81.9 & 100 & 72 & 6.9 & 6.1 & 6.6 & 5.2 \\
\hline Total & 12.0 & 25.1 & 25.5 & 37.5 & 100 & 986 & 3.8 & 3.5 & 4.5 & 3.4 \\
\hline
\end{tabular}

\section{Preceding Birth Interval}

The length of the preceding birth interval is very important, as it directly affects the health and mortality of both mother and child. A mother with repeated pregnancies, especially at short intervals, does not have sufficient time for recovery both physically and nutritionally and is therefore more likely to have pregnancy losses and babies of a lower birth weight. Table 3.4 shows that almost 21.9 percent of the last births occurred at an interval of less than 19 months, 22.3 percent after an interval of19-24 months, while 18.7 percent of the respondents had a 25-36 month interval between their last two births.

Table 3.4: $\quad$ Percentage distribution of married women by length of preceding birth interval

\begin{tabular}{lcc} 
Length of Preceding Birth Interval & Number & Percent \\
\hline Less than 12 Months & 6 & 1.2 \\
\hline 13-18 Months & 103 & 20.7 \\
\hline 19-24 Months & 111 & 22.3 \\
\hline 25-36 Months & 93 & 18.7 \\
\hline More than 36 Months & 184 & 37 \\
Total & 497 & 100
\end{tabular}




\section{Access to Information}

In the baseline survey, respondents were asked several questions regarding access and exposure to television, radio and newspapers. One of the main objectives of the baseline survey was to determine the knowledge of married women on different maternal and newborn health issues, and the source of that knowledge. This information is useful in determining which media channels should be employed in the dissemination of maternal and newborn health information to target audiences. Moreover, it is important to measure the likelihood of reaching target audiences, as well as to determine which media channel is most effective when it comes to reaching that target audience.

\section{Access to Media (Television, Radio and Newspaper)}

Mass media is regularly used to campaign various issues, including those related to the health of mothers and newborns. In the past, radio was the most popular form of communication (Syed, 1979). However, according to the survey findings, television seems to have become a more popular source of information.

\section{Television}

Figure 3.2 shows the percentage of respondents who watch television and listen to the radio. In rural areas of Lasbela only 6.4 percent of respondents watch television, whereas the figure for urban areas is 46.6 percent. This difference may be due to the socioeconomic disparities between urban and rural areas of Lasbela, urban areas being typically better off socio-economically.

Since access to television is synonymous with access to information, women in urban areas have more access to information through television. As a result, they are able to make informed decisions, based on the knowledge made available to them through television. Women in rural areas therefore, may not have this privilege.

Figure 3.2: $\quad$ Percentage of women who watch television or listen to radio

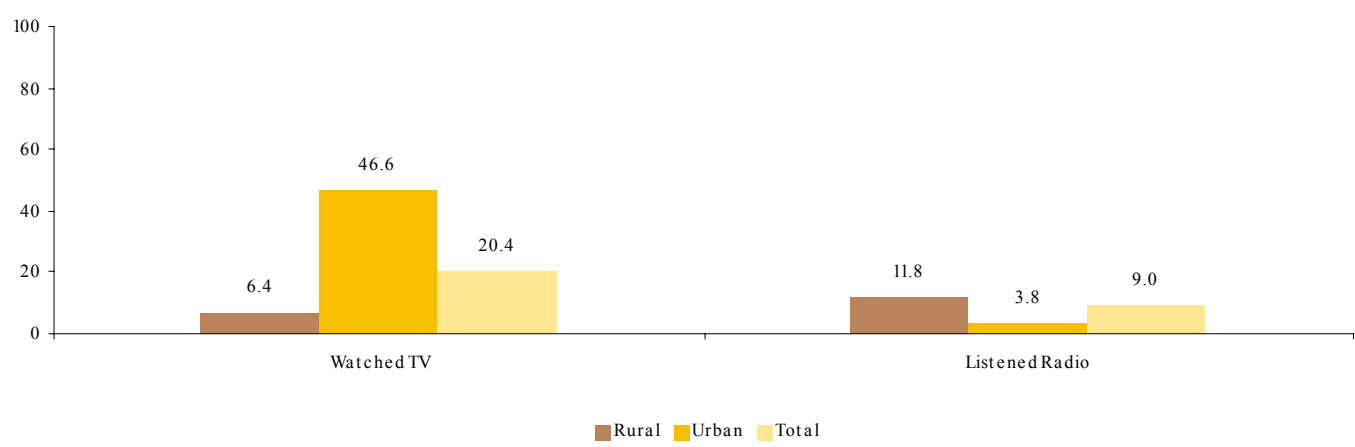

Table 3.5 indicates the frequency of watching television for those respondents who do watch TV. In rural areas, 61 percent reportedly watch TV on a frequent basis, while the figure is 75.6 percent in urban areas. More than one-third (37 percent) of the respondents in rural areas, along with less than one-quarter (23 percent) of women in urban areas watch TV rarely. 
Table 3.5:

Frequency of watching television

\begin{tabular}{lr|rrrrr}
\multicolumn{1}{c}{ Frequency } & \multicolumn{2}{c}{ Rural } & \multicolumn{2}{c}{ Urban } & \multicolumn{2}{c}{ Total } \\
\cline { 2 - 7 } & Percent & Number & Percent & Number & Percent & Number \\
Almost daily & 61.0 & 25 & 75.6 & 121 & 72.6 & 146 \\
At least once a week & & & 1.9 & 3 & 1.5 & 3 \\
At least once a month & 2.4 & 1 & & & 0.5 & 1 \\
Rarely & 36.6 & 15 & 22.5 & 36 & 25.4 & 51 \\
Total & 100.0 & 41 & 100.0 & 160 & 100.0 & 201
\end{tabular}

Respondents were asked to indicate the place where they most often watch television. More than 90 percent of those who watch TV, reportedly watch at home. About 7.3 percent of the respondents in rural areas and 6.3 percent in urban areas of Lasbela indicate that they watch TV at a relative's house.

Table 3.6: $\quad$ Place where respondent usually watches television

\begin{tabular}{lcccc|cc} 
& \multicolumn{2}{c}{ Rural } & \multicolumn{2}{c}{ Urban } & \multicolumn{2}{c}{ Total } \\
\cline { 2 - 7 } \multicolumn{1}{c}{ Place } & Percent & Number & Percent & Number & Percent & Number \\
\hline At home & 90.2 & 37 & 91.9 & 147 & 91.5 & 184 \\
\hline At relative's house & 7.3 & 3 & 6.3 & 10 & 6.5 & 13 \\
\hline At neighbor's house & 2.4 & 1 & 1.9 & 3 & 2.0 & 4 \\
\hline Total & 100.0 & 41 & 100.0 & 160 & 100.0 & 201 \\
\hline
\end{tabular}

When asked if they thought television has an impact on the health behavior of people, a very low percentage of the respondents both in urban and rural areas agreed. This shows that television may not be a very effective source of information in a society like Lasbela. 
Figure 3.3:

Influence of television programs on health behaviors of people

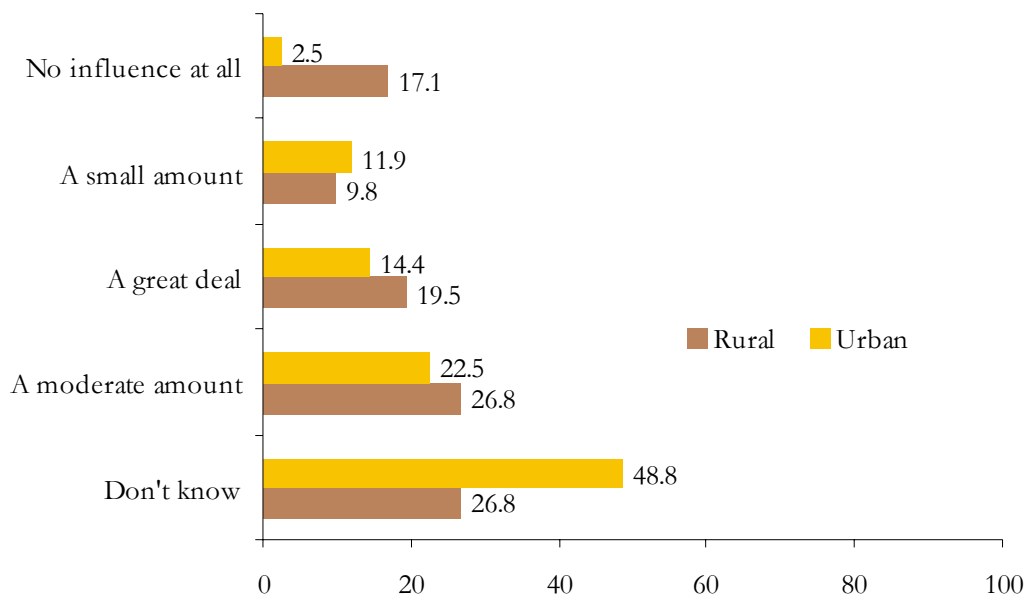

\section{Radio}

Much like television, radio is also a tool through which messages may be relayed to a relatively large audience. A very low percentage of respondents both in urban and rural areas answered in the affirmative when asked if they listen to the radio. Only 12 percent in rural areas and 3.8 percent in urban areas of Lasbela indicated that they listen to the radio.

Approximately 58 percent of the respondents in rural areas, and more than 77 percent of the respondents in urban areas who indicated that they listen to the radio, stated that they did so everyday. More than one-third of the women surveyed ( 37 percent) in rural areas and less than one-quarter (23 percent) in urban areas rarely listen to the radio.

Table 3.7:

Frequency of listening to radio

\begin{tabular}{lrrrrrrr} 
& \multicolumn{2}{c}{ Rural } & \multicolumn{2}{c}{ Urban } & \multicolumn{2}{c}{ Total } \\
\cline { 2 - 7 } \multicolumn{1}{c}{ Frequency } & Percent & Number & Percent & Number & Percent & Number \\
\hline Almost daily & 57.9 & 44 & 76.9 & 10 & 60.7 & 54 \\
\hline Alt least once a week & 3.9 & 3 & & & 3.4 & 3 \\
\hline At least once a month & 1.3 & 1 & & 3 & 34.8 & 31 \\
\hline Rarely & 36.8 & 28 & 23.1 & 13 & 100.0 & 89 \\
\hline Total & 100.0 & 76 & 100.0 & 13 & 1 \\
\hline
\end{tabular}


Table 3.8 shows that in rural areas, 92 percent of women listen to the radio in their homes and 6.6 percent at their work place. In urban areas, all women who listen to the radio do so at home.

Table 3.8: $\quad$ Place where respondent listens to the radio

\begin{tabular}{lrrrrrr}
\multirow{2}{*}{ Place } & \multicolumn{2}{c}{ Rural } & \multicolumn{2}{c}{ Urban } & \multicolumn{2}{c}{ Total } \\
\cline { 2 - 7 } & Percent & Number & Percent & Number & Percent & Number \\
\hline At home & 92.1 & 70 & 100.0 & 13 & 93.3 & 83 \\
\hline At work place & 6.6 & 5 & & & 5.6 & 5 \\
\hline At relative's house & 1.3 & 1 & & 1.1 & 1 \\
Total & 100.0 & 76 & 100.0 & 13 & 100.0 & 89
\end{tabular}

Respondents were asked to indicate the level of influence radio programs have on the health behaviors of people. Figure 3.4 shows that more than 23 percent of those who listen to the radio in urban areas indicated that radio has a great deal of influence on the health behaviors of people, whereas more than 15 percent indicated that it has a small amount of influence. In rural areas, about 30 percent of those with access to a radio indicated that radio is very influential, whereas 2.6 percent stated that it has no influence at all. In urban areas 46 percent reported that radio has a moderate amount of influence on health behaviors of individuals compared to 34 percent of rural respondents.

Figure 3.4: $\quad$ Influence of radio on health behaviors

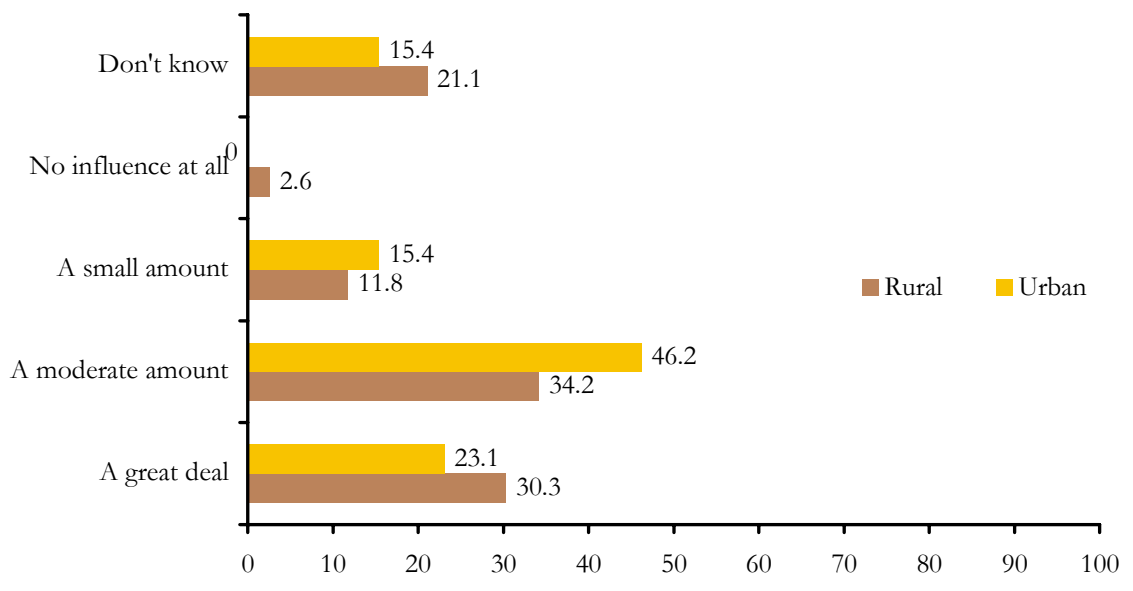




\section{Newspapers}

About 98 percent of the respondents in rural areas indicated that they never read the newspaper, while 88 percent said the same in urban areas of Lasbela. Only 2 percent in urban areas and 0.2 percent in rural areas read a newspaper on a daily basis, while 6.7 percent and 1.2 percent in urban and rural areas respectively indicated that they read newspapers rarely (Figure 3.5).

Figure 3.5: $\quad$ Frequency of reading newspaper

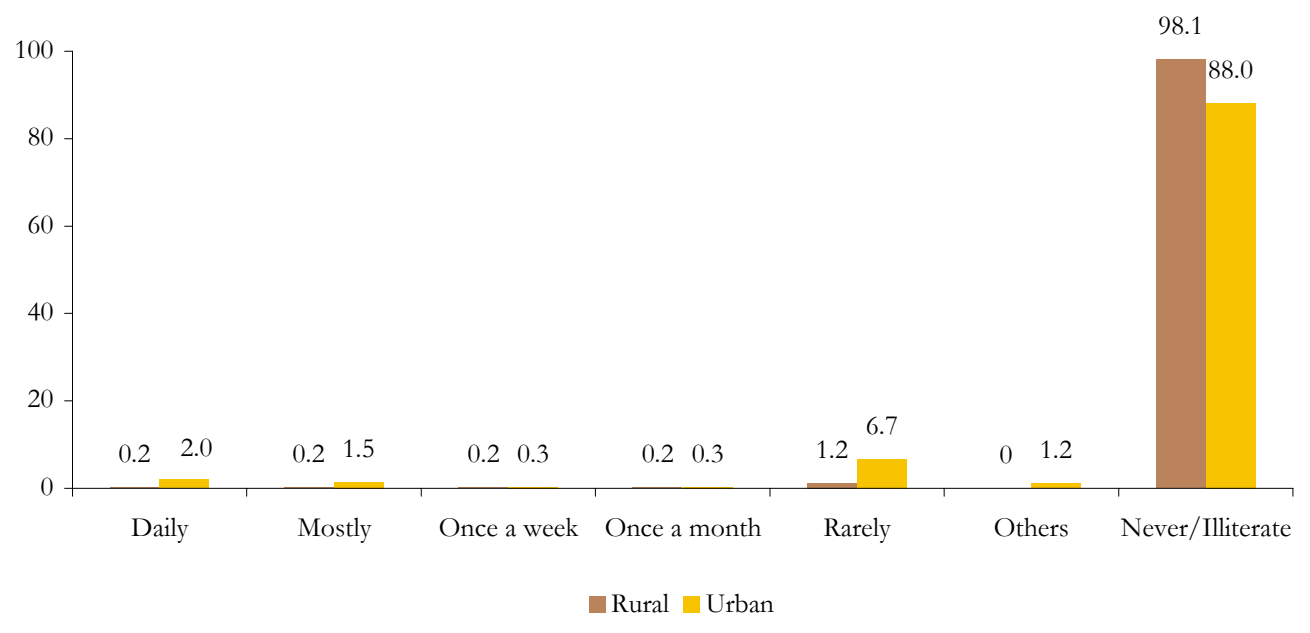

Figure 3.6: $\quad$ Exposure to mass media (radio, television or newspaper)

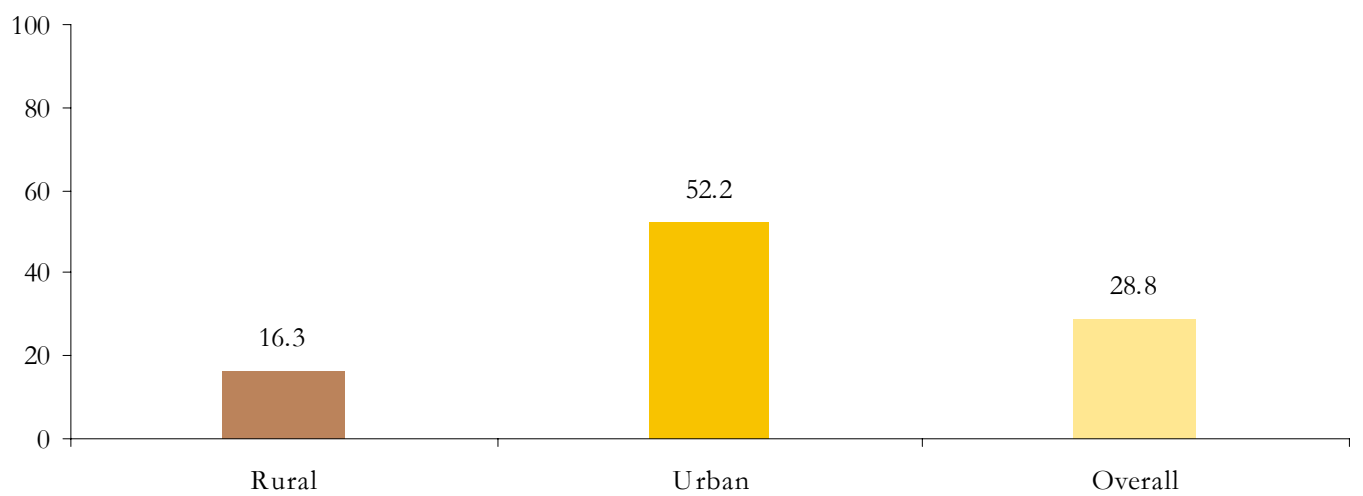

Figure 3.6 shows that less than 29 percent of the respondents overall in Lasbela have access to some sort of media, whether it is television, radio or newspapers. While it may seem relatively easy to reach this small population through one of the three main media channels, there are some obstacles that stand in the way including the lack of decision-making power for women and the infrequency of access to the media. As well, it is important to keep in mind that a large portion of the population of Lasbela has no access to any one of the three media channels mentioned above. In order to educate and inform this segment of the population regarding maternal and infant mortality and birth preparedness, more grassroot methods must be adopted. These grassroot efforts may include interpersonal communication through community workers, community gatherings, speeches and health education sessions. 
According to figure 3.7, television is the most trustworthy media source, as reported by 14.9 percent and 7.6 percent of the urban and rural respondents respectively. Radio is the next most trustworthy media source as cited by 4.7 percent and 8.6 percent of the rural and urban respondents respectively.

Figure 3.7: $\quad$ Most trustworthy form of media

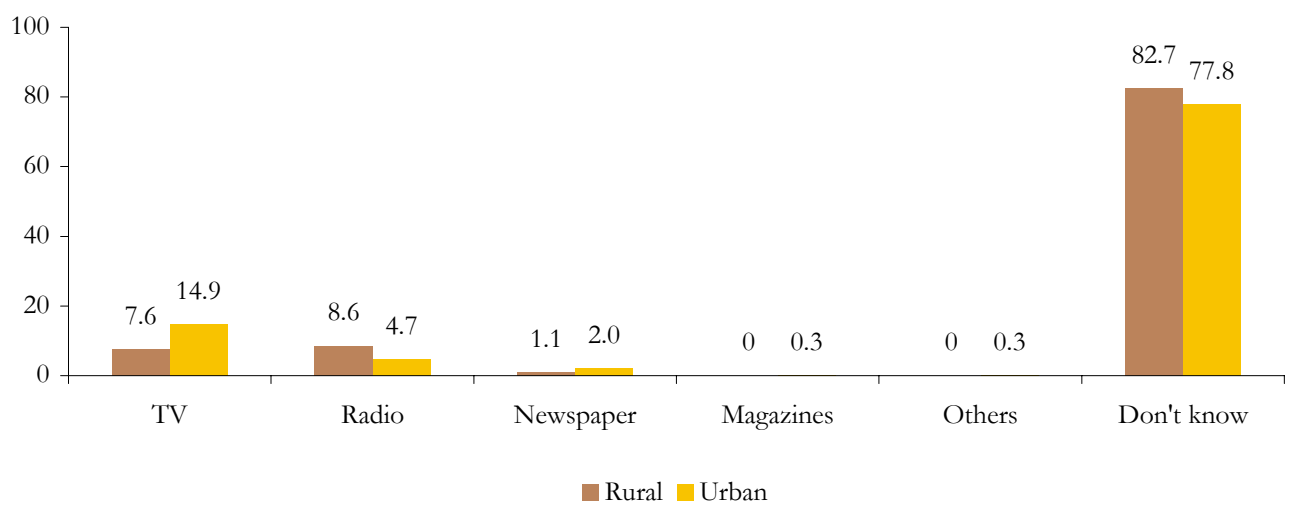

\section{Information/Education through Media}

Before moving on to questions regarding attitudes towards pregnancy, delivery and postpartum, respondents were asked to comment on whether or not they had heard/read anything about maternal and newborn health within the past three months.

According to figure 3.8, only 12 percent of the married women in sampled households had heard/read something about maternal health in the past three months. About 10 percent said the same thing in rural areas. Overall, 89.4 percent of the married women in sampled households had never heard or read anything about maternal health in the past three months in Lasbela. A question regarding newborn health was asked of the same respondents. Overall more than 92 percent women said that they had heard or read nothing about it in the past three months.

Moreover respondents were asked whether they had heard anything about maternal or newborn health from religious leaders or community/NGO workers in the past three months. A very low percentage of respondents reported having heard either religious leaders or community/NGO workers speak about maternal and newborn health. 
Figure 3.8: $\quad$ Percentage of married women who had heard/ read about maternal and newborn messages during the last 3 months

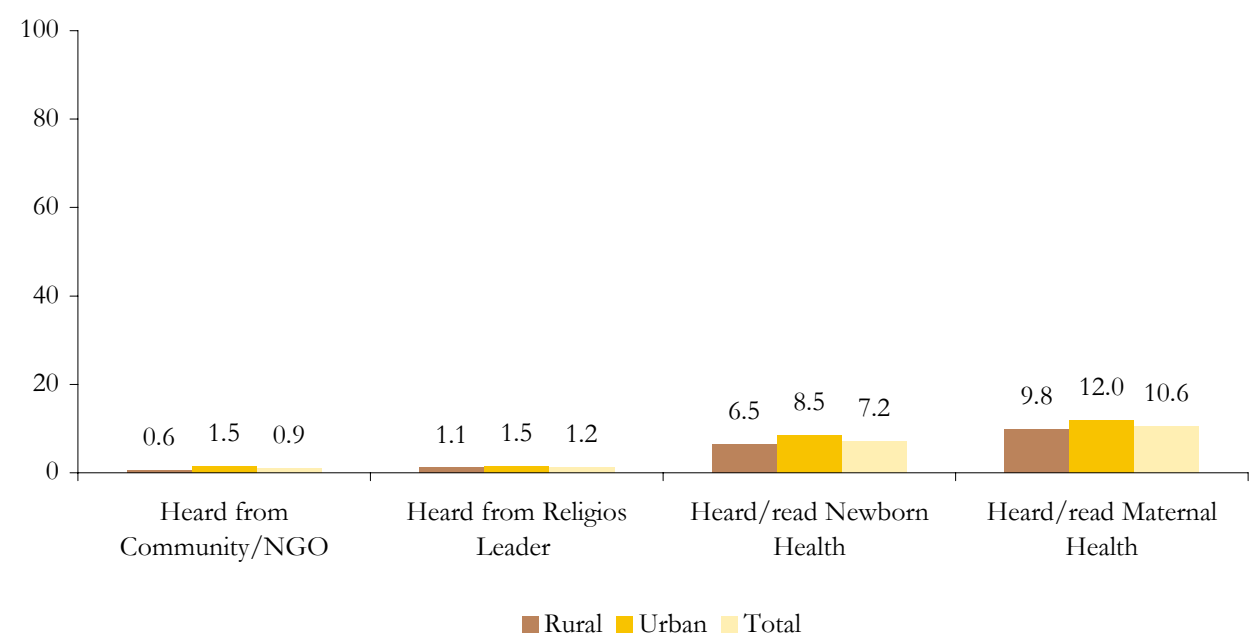

It becomes evident from the data that the percentage of married women who had heard anything about maternal or newborn health are very low for both urban and rural areas, indicating the absence of proactive education and awareness in many areas of Lasbela. Hence, it would be a challenge for the PAIMAN team to reach these women in both urban and rural areas, and convey messages regarding maternal and newborn health. 



\section{Chapter 4}

\section{Knowledge of Safe Motherhood, Birth Preparedness and Community Resources}

This chapter explores the level of understanding women have of safe motherhood practices, birth preparedness and the use of community resources. It examines the health awareness levels of women in the district, and thus provides an explanation for the maternal and newborn mortality rates.

Respondents were asked questions regarding knowledge of complications during pregnancy, delivery, the postpartum period and newborn health. The findings of those responses are presented in this chapter.

\section{Knowledge of Danger Signs}

\section{Knowledge of Danger Signs during Pregnancy}

Figure 4.1 shows the knowledge of respondents regarding danger signs during pregnancy. More than half of the respondents in both urban and rural areas said that "severe abdominal pain" required a doctor's care.

Less than half (47 percent) in rural and more than a third (36 percent) of respondents in urban areas said "high fever" was a sign of danger. More than one third (36 percent and 37 percent in urban and rural areas respectively) believed that "severe vomiting" was a sign of danger during pregnancy. Approximately one-quarter of the women surveyed in both rural and urban areas knew "heavy bleeding, swelling in face and high blood pressure" were signs of danger during pregnancy.

Figure 4.2 shows that 53 percent of the respondents in urban areas knew of three or more danger signs during pregnancy, compared to 46 percent in rural areas. About 14.3 percent and 17.5 percent in urban and rural areas of Lasbela were unable to name a single danger sign during pregnancy.

Upon analysis of these responses, it becomes evident that many women do not have a basic understanding of the complications that may arise during pregnancy, and may therefore fail to take action. Moreover, many may assume that the above-mentioned complications are part of the pregnancy process. 
Figure 4.1: $\quad$ Knowledge of danger signs during pregnancy which require medical attention

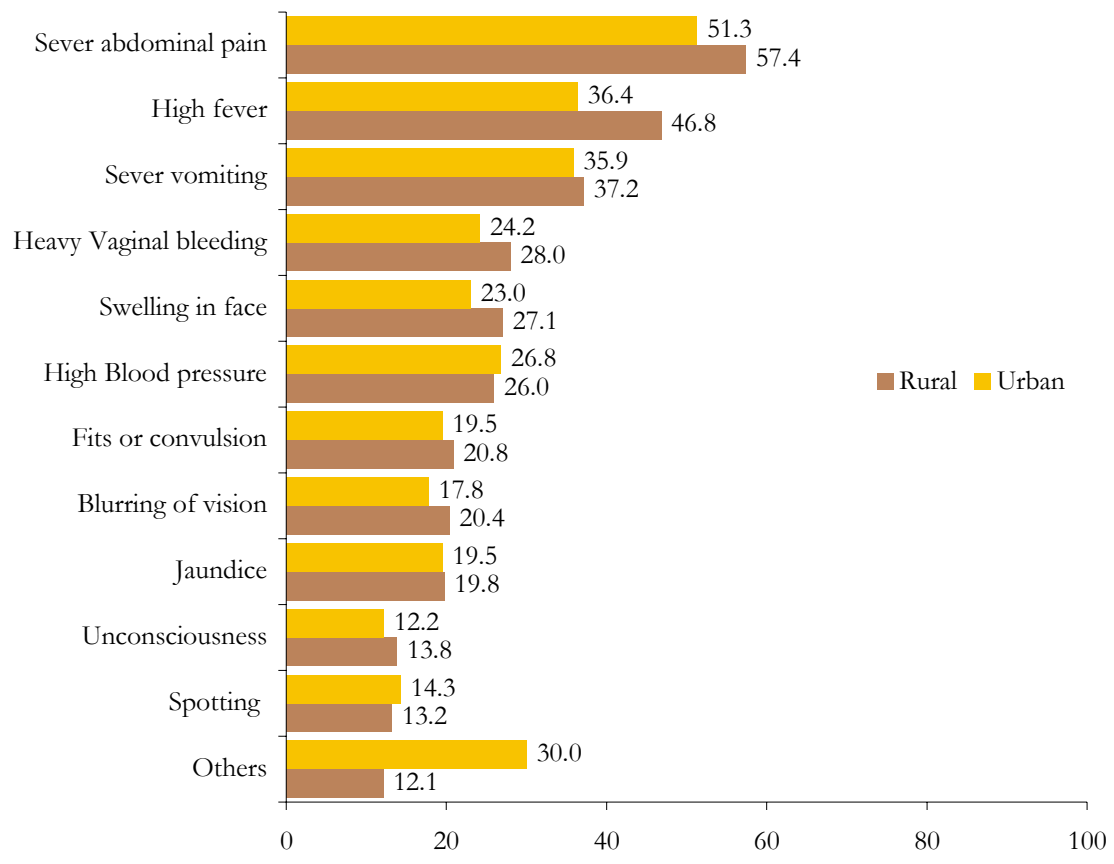

Figure 4.2: $\quad$ Percentage distribution of women by number of known danger signs of pregnancy

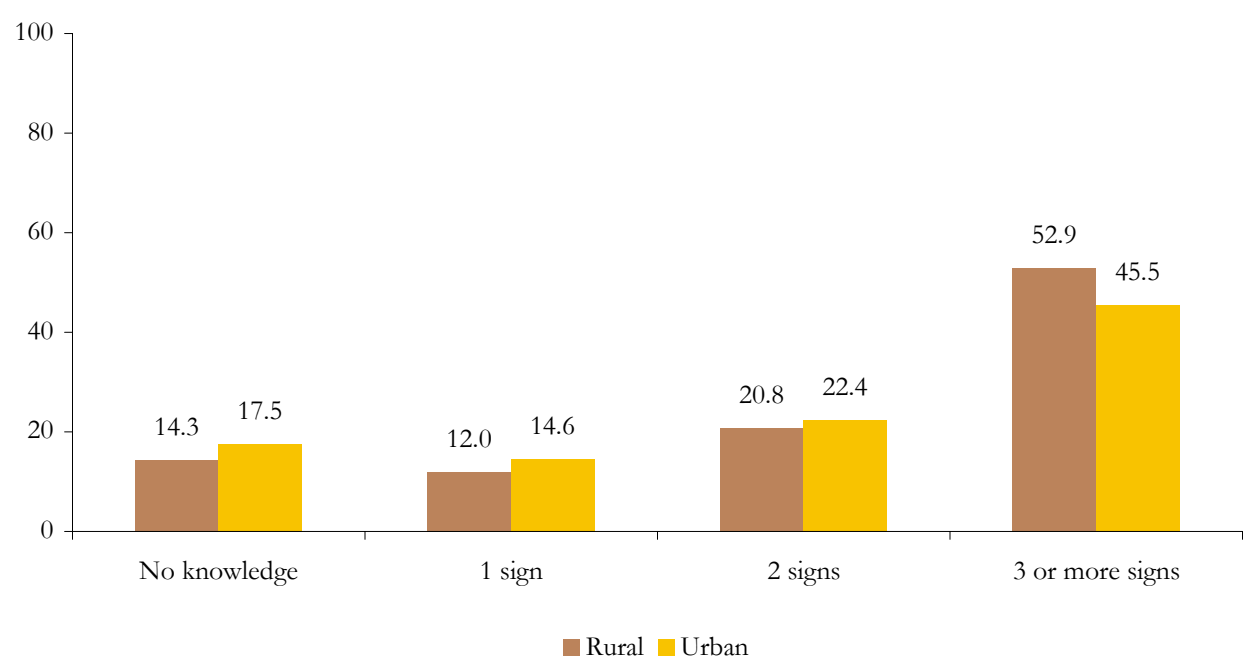




\section{Knowledge of Danger Signs during Childbirth/Delivery}

Respondents were also asked to indicate their knowledge of danger signs during delivery. Upon analysis of these answers, it becomes evident that many women do not have a basic understanding of the complications that may arise during delivery. Figure 4.3 shows that more than a third of the respondents in urban areas, along with 42 percent in rural areas indicated that "bleeding before labor began" was a dander sign during delivery. In rural areas, one-third of the respondents believed that "excessive vaginal bleeding" and "delay in delivery of placenta" were signs of danger during delivery. In urban areas, about a quarter of the respondents were of the opinion that "excessive vaginal bleeding" during delivery was a sign of danger. About one-third of the women in rural areas and onequarter in urban areas believed "prolonged labor" was a sign of danger during childbirth.

Figure 4.3: $\quad$ Distribution of respondents, who had knowledge about complications during delivery

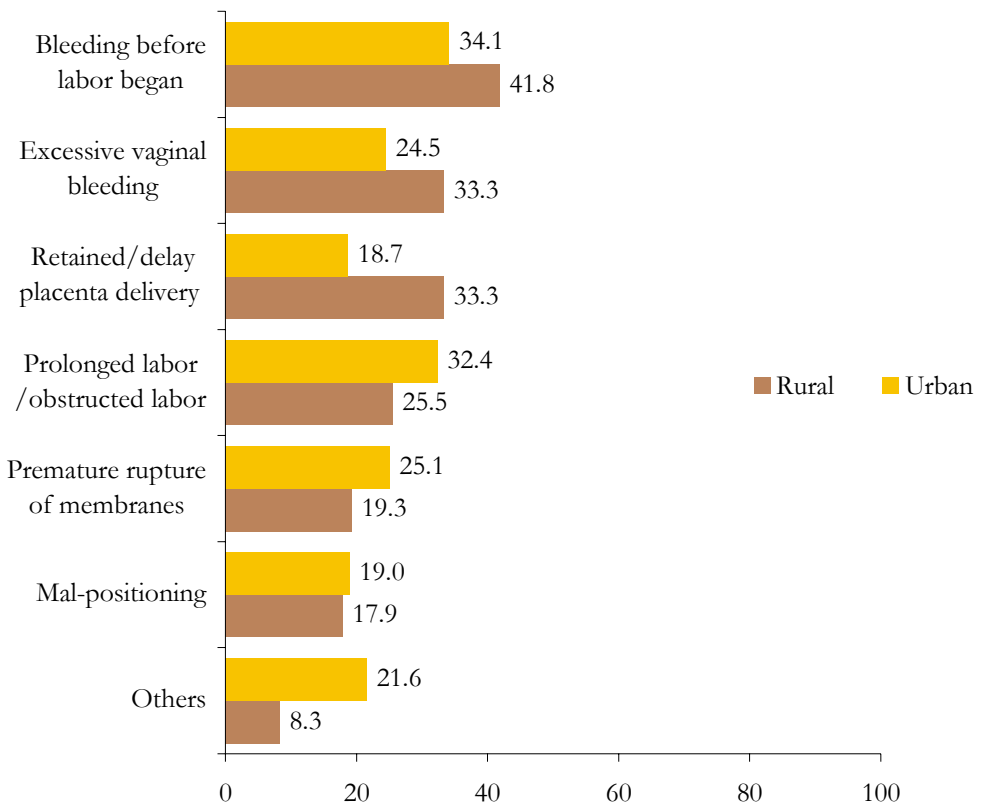

A large proportion of maternal mortalities occur during delivery in developing countries. More than three quarters of the women surveyed do not recognize the danger signs that lead to severe consequences. Deliveries can only be made safe if married women are educated regarding danger signs that may appear during delivery, so that they can decide when to seek treatment. Even under normal circumstances, approximately 15 percent of all pregnant women require emergency obstetric care to avoid maternal and newborn deaths.

Figure 4.4 shows that 23.5 percent of the respondents in rural areas and more than 18 percent in urban areas were able to name three or more danger signs during delivery. The number of women having no knowledge of danger signs during delivery was about 25 percent in rural areas and more than 35 percent in urban areas. 
Figure 4.4: $\quad$ Percentage distribution of women by number of known danger signs of delivery

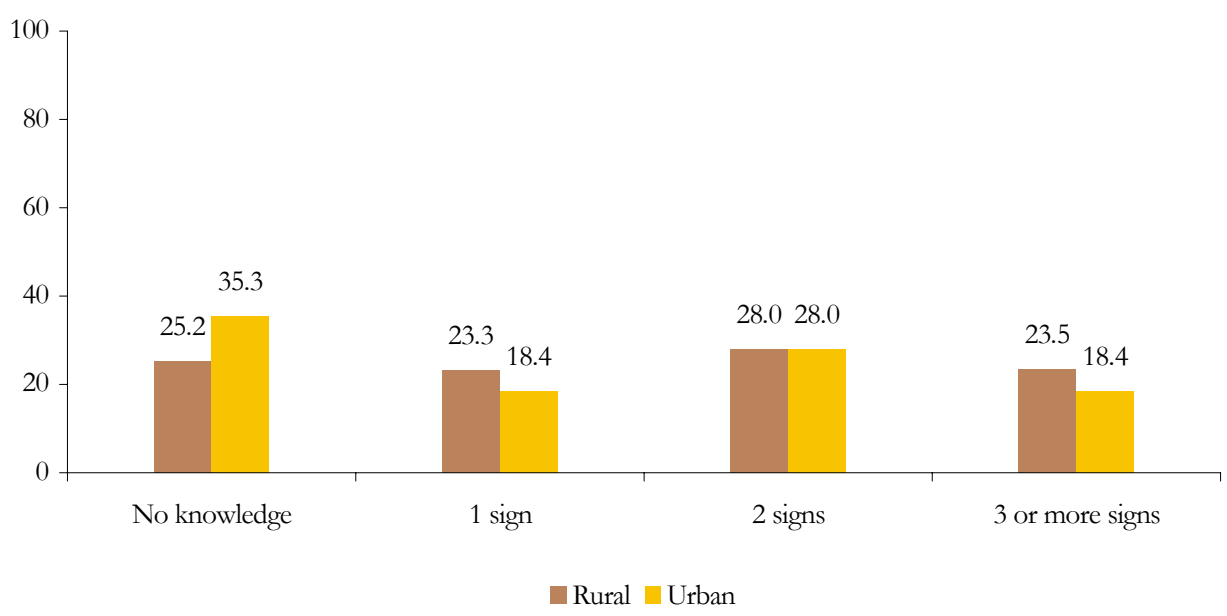

\section{Knowledge of Danger Signs during the Postpartum Period}

In the baseline survey, the postpartum period is defined as the 40 days after childbirth. Postpartum hemorrhage is the most significant cause of maternal morality in developing countries. Although baseline survey findings indicate that excessive vaginal bleeding is the most known danger sign during the postpartum period, not all women are aware of this fact. This calls for some innovative approaches to make communities knowledgeable regarding the danger signs during the postpartum period. If mothers are not medically fit and completely healthy during the postpartum period, they are unlikely to take adequate care of their newborns.

According to figure 4.5 respondents in both urban and rural areas indicated that "excessive vaginal bleeding", "high fever (with or without rigors)" and "fits or convulsions" were the three major danger signs in the postpartum period.

Figure 4.5: $\quad$ Percent of married women who had knowledge about complications during postpartum period by place of residence

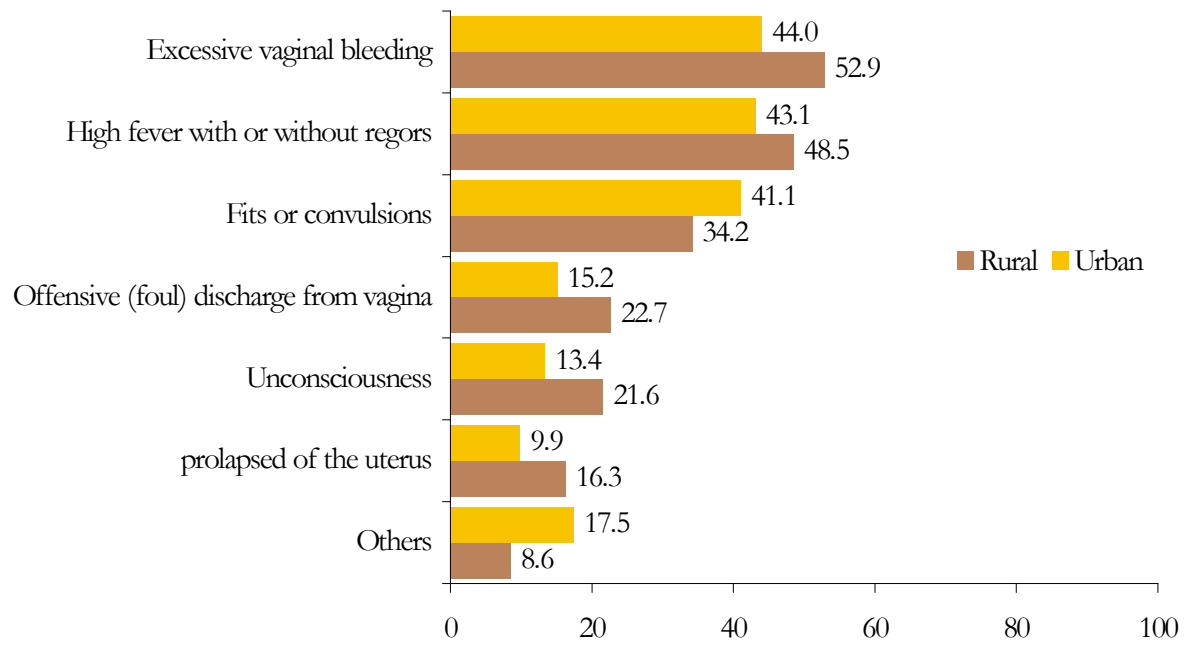


Figure 4.6 indicates that a very low percentage of respondents were able to name three or more danger signs that may arise during the postpartum period. About a quarter of the respondents in urban areas and one third in rural areas had knowledge of three or more danger signs. More than onequarter of the respondents (28 percent) in urban areas and about one-fifth (19 percent) in rural areas had no knowledge of danger signs during childbirth.

Figure 4.6: $\quad$ Percentage distribution of women by number of known danger signs during postpartum period

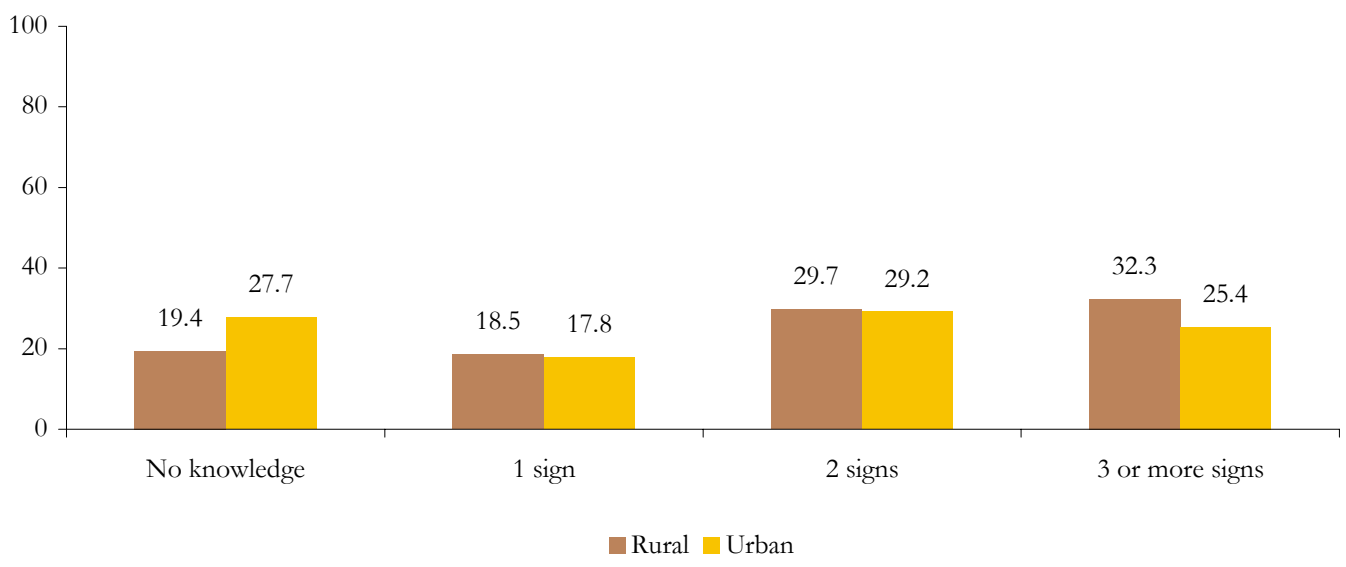

\section{Knowledge of Danger Signs in the Newborn}

Figure 4.7 indicates the percentage of respondents who believed that each complication listed required medical attention. About 32.4 percent of the respondents in urban areas and 40 percent in rural areas believed that "difficulty breathing" was a danger sign in newborns. "Fever/high fever (with or without rigors)" and "yellow skin color (jaundice)" were also stated by a large number of respondents as danger signs in newborns. 
Figure 4.7: $\quad$ Distribution of respondents who had knowledge about danger signs in newborns

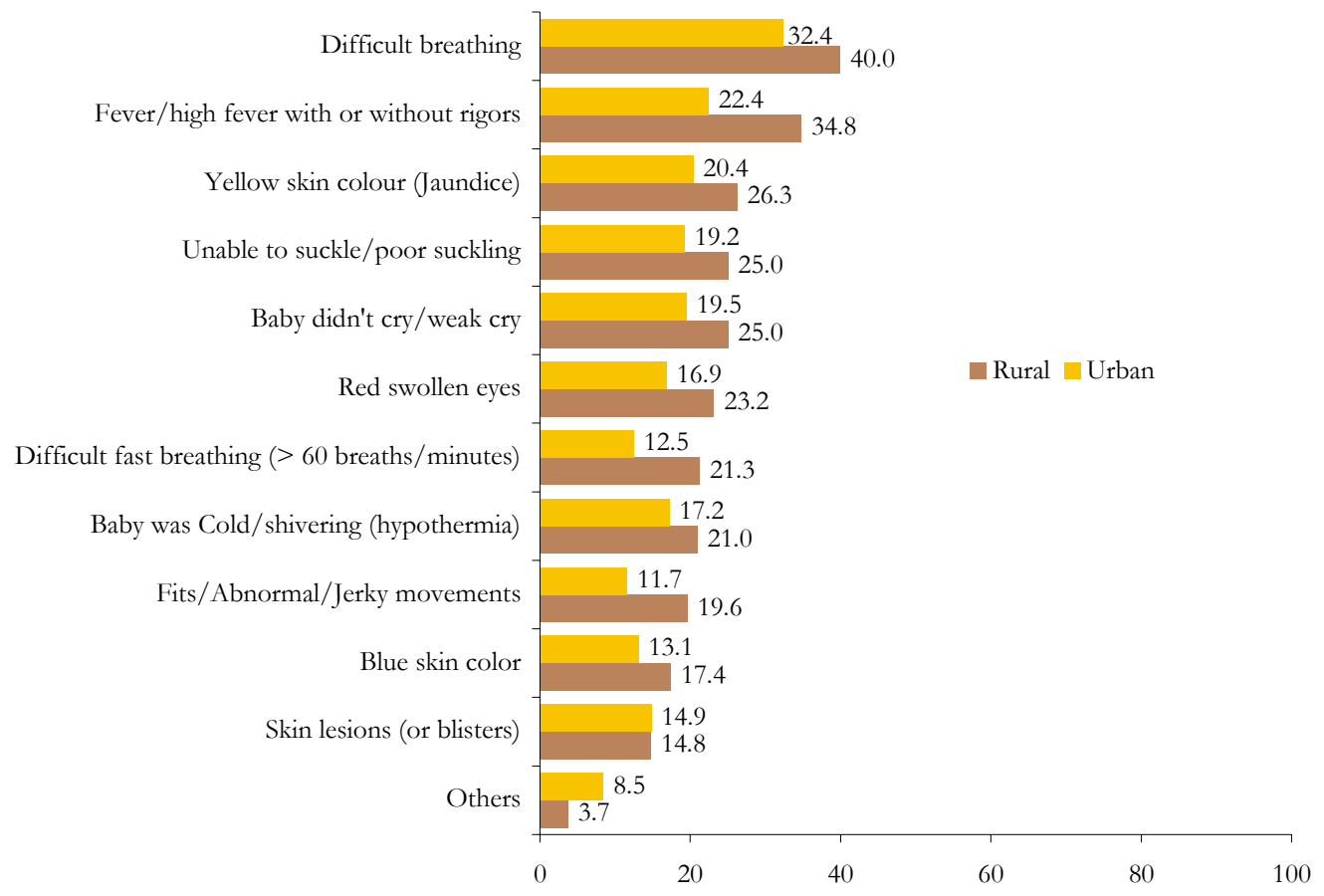

Figure 4.8: $\quad$ Percentage distribution of women by number of known danger signs in newborns

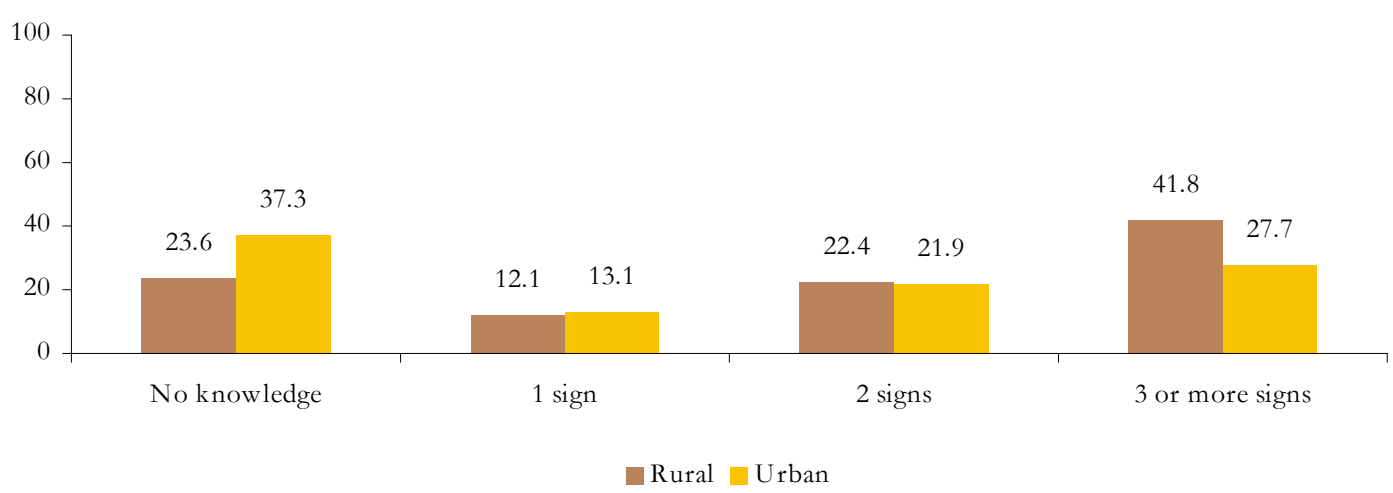

About 42 percent of the respondents in rural areas and 28 percent in urban areas were able to name three or more danger sings in newborns. On the other hand, more than 23 percent in rural areas and more than 37 percent in urban areas had no knowledge of any danger signs in newborns. 


\section{Source of Information Regarding Danger Signs}

Finally, respondents were asked about the source from which they received information regarding complications during pregnancy, delivery and the postpartum period. A very large percentage in both urban and rural areas indicated that they received their pregnancy-related information from their inlaws, family members and friends. About 46 percent of the respondents in urban areas and more than 30 percent in rural areas reportedly got information from private hospitals/clinics. A very small percentage of respondents indicated that they got information regarding complications during pregnancy from other sources such as an LHW and DHQ/THQs. This suggests that the majority of women obtain their pregnancy related information from non-medical persons, which may not be reliable.

Figure 4.9: $\quad$ Source of information about pregnancy by place of residence

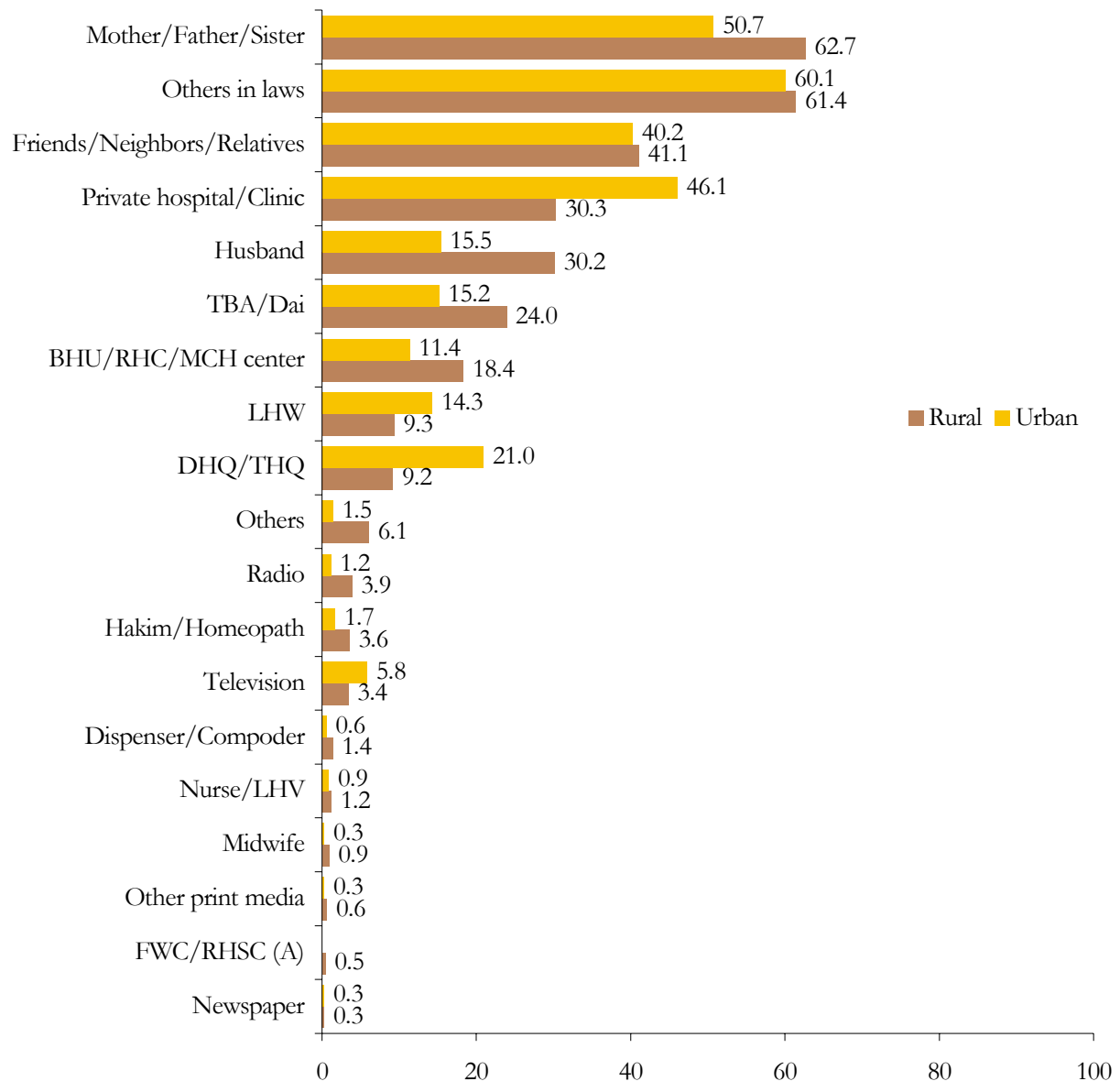




\section{Knowledge of Community Schemes for the Welfare of Women and Newborns}

The baseline focused on schemes pertaining to transportation, blood arrangements and funding; all of which help ensure that there are no delays at the time of delivery. Arrangement of transport to a health facility is a major cause of delay which can lead to maternal and newborn mortality, and therefore the arrangement of transport ahead of time is necessary to eliminate that delay. Unfortunately, many communities lack such facilities.

Table 4.1: $\quad$ Knowledge of existence and importance of transport, blood and finances by the community at the time of delivery by place of residence

\begin{tabular}{|c|c|c|c|c|c|c|}
\hline \multirow{2}{*}{ Transport } & \multicolumn{2}{|c|}{ Rural } & \multicolumn{2}{|c|}{ Urban } & \multicolumn{2}{|c|}{ Total } \\
\hline & Percent & Number & Percent & Number & Percent & Number \\
\hline $\begin{array}{l}\text { Existence of transport by the } \\
\text { community at delivery }\end{array}$ & 0.8 & 5 & 0.3 & 1 & 0.6 & 6 \\
\hline $\begin{array}{l}\text { Important to have community } \\
\text { provided transport facility }\end{array}$ & 98.1 & 631 & 99.4 & 341 & 98.6 & 972 \\
\hline $\begin{array}{l}\text { Existence of blood by the community } \\
\text { at time of delivery }\end{array}$ & 0.2 & 1 & 0.6 & 2 & 0.3 & 3 \\
\hline $\begin{array}{l}\text { Important to have community } \\
\text { provided blood facility }\end{array}$ & 98.3 & 632 & 100.0 & 343 & 98.9 & 975 \\
\hline $\begin{array}{l}\text { Existence of money by community at } \\
\text { the time of delivery }\end{array}$ & 0.2 & 1 & 0.3 & 1 & 0.2 & 2 \\
\hline $\begin{array}{l}\text { Important to have community } \\
\text { provided money facility }\end{array}$ & 98.4 & 633 & 100.0 & 343 & 99.0 & 976 \\
\hline Total & 100.0 & 643 & 100.0 & 343 & 100.0 & 986 \\
\hline
\end{tabular}

In the three delays model theory, delay due to transportation is very prevalent. Table 4.1 shows that about 99 percent of respondents were in favor of a community-based transport scheme, whereas only 0.6 percent actually knew of the existence of such a facility. A similar response was obtained regarding blood arrangements and the provision of emergency funds at the community level. Most communities do not have any arrangement of transport, provision of blood and existence of finances for helping pregnant women at the time of delivery. This is a major obstacle to safe birth practices. 


\section{Chapter}

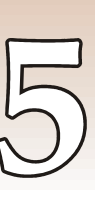

\section{Attitudes Towards Pregnancy, Delivery and Postpartum Period}

This chapter explores the attitudes of married women towards pregnancy, delivery and the postpartum period. Determining these attitudes and beliefs of women regarding pregnancy, delivery and the postpartum period can lead to the development of new strategies and methods that bring about a change in the traditional ways of thinking.

\section{Attitudes Towards Age at Marriage}

In response to the question of whether or not women should get married soon after puberty, 74 percent of the women surveyed in rural Lasbela believed girls should be married soon after puberty, whereas only 13 percent disagreed with that statement. In urban Lasbela, about 66 percent believed that women should be married soon after puberty. These responses might be attributed to the belief that the younger the age at marriage, the higher the fertility rate tends to be. Therefore, in order to lower the fertility rate, it is important to delay the age of marriage for women. Similarly, younger women are more likely to suffer from pregnancy-related complications as compared to those who do not get married at an early age.

Table 5.1: $\quad$ Percentage of respondents who believe girls should be married soon after puberty by place of residence

\begin{tabular}{lrrrrrr} 
Get married soon & \multicolumn{2}{c}{ Rural } & \multicolumn{2}{c}{ Urban } & \multicolumn{2}{c}{ Total } \\
\cline { 2 - 8 } $\begin{array}{l}\text { after puberty } \\
\text { Yes }\end{array}$ & \multicolumn{1}{c}{ Percent } & Number & Percent & Number & Percent & Number \\
\hline No & 74.2 & 477 & 65.6 & 225 & 71.2 & 702 \\
\hline No opinion & 12.9 & 83 & 29.2 & 100 & 18.6 & 183 \\
\hline Don't know & 12.3 & 79 & 4.7 & 16 & 9.6 & 95 \\
Total & 0.6 & 4 & 0.6 & 2 & 0.6 & 6 \\
\hline
\end{tabular}




\section{Attitudes Towards Antenatal Care}

Women in both urban and rural areas of Lasbela were then asked if they believed women required antenatal check-ups. A majority of the women (80 percent in rural areas and 91 percent in urban areas) believed it necessary for women to receive these check-ups, whereas approximately 10 percent and 7 percent of the married women in rural and urban Lasbela respectively felt it was not necessary. Therefore, it becomes quite clear that while many women do want to receive antenatal check-ups, and feel that it is a necessary part of neonatal care, many are not accessing this service. Table 5.2 outlines the percentage of respondents who feel that antenatal check-ups are either necessary or not necessary by place of residence.

Table 5.2: $\quad$ Antenatal check-up by place of residence

\begin{tabular}{lrrrrrrr}
\multirow{2}{*}{$\begin{array}{c}\text { Should have antenatal } \\
\text { check-up }\end{array}$} & \multicolumn{2}{c}{ Rural } & \multicolumn{2}{c}{ Urban } & \multicolumn{2}{c}{ Total } \\
\cline { 2 - 8 } & Percent & Number & Percent & Number & Percent & Number \\
\hline Yes & 80.4 & 517 & 91.3 & 313 & 84.2 & 830 \\
\hline No & 9.5 & 61 & 7.0 & 24 & 8.6 & 85 \\
\hline Don't know & 10.1 & 65 & 1.7 & 6 & 7.2 & 71 \\
Total & 100.0 & 643 & 100.0 & 343 & 100.0 & 986 \\
\hline
\end{tabular}

Antenatal care also encourages mothers to be more aware of their own health as well as the health of their newborn babies. When asked to state in which month of pregnancy a woman should receive antenatal check-ups, the responses received varied. Table 5.3 below outlines the different responses and opinions.

Table 5.3:

Month of the pregnancy when women should go for antenatal care by place of residence

\begin{tabular}{lrrrrrr} 
& \multicolumn{2}{c}{ Rural } & \multicolumn{2}{c}{ Urban } & \multicolumn{2}{c}{ Total } \\
\cline { 2 - 7 } 1 & Percent & Number & Percent & Number & Percent & Number \\
\hline 2 & 0.6 & 3 & 2.6 & 8 & 1.3 & 11 \\
\hline 3 & 2.1 & 11 & 6.7 & 21 & 3.9 & 32 \\
\hline 4 & 13.5 & 70 & 19.2 & 60 & 15.7 & 130 \\
\hline 5 & 11.8 & 61 & 8.0 & 25 & 10.4 & 86 \\
\hline 6 & 7.9 & 41 & 9.9 & 31 & 8.7 & 72 \\
\hline 7 & 6.4 & 33 & 9.9 & 31 & 7.7 & 64 \\
\hline 8 & 10.4 & 54 & 15.7 & 49 & 12.4 & 103 \\
\hline 9 & 6.0 & 31 & 2.9 & 9 & 4.8 & 40 \\
\hline $\begin{array}{l}\text { As soon as possible after } \\
\text { pregnancy }\end{array}$ & 1.5 & 8 & 1.0 & 3 & 1.3 & 11 \\
\hline When check-up is needed & 18.4 & 95 & 8.3 & 26 & 14.6 & 121 \\
\hline Don't know & 17.0 & 88 & 14.1 & 44 & 15.9 & 132 \\
\hline Total & 4.3 & 22 & 1.9 & 6 & 3.4 & 28 \\
\hline
\end{tabular}


The largest proportion of the women believed that antenatal check-ups should occur in the third or fourth months of the pregnancy, along with a considerable percentage of respondents falling into the seven month category. About 15 percent stated that the check-up should take place as soon as possible after pregnancy. However, 16 percent of the married women surveyed indicated that an antenatal check-up was only necessary in the event of some complication.

Moreover, the number of antenatal visits which the respondents thought were necessary was a good indicator of education, awareness and decision-making abilities. As mentioned earlier, a majority of the people interviewed indicated that they were in favor of antenatal care.

Table 5.4:

Number of antenatal visits believed necessary by place of residence

\begin{tabular}{lrrrrrr} 
& \multicolumn{2}{c}{ Rural } & \multicolumn{2}{c}{ Urban } & \multicolumn{2}{c}{ Total } \\
\cline { 2 - 8 } 1 & Percent & Number & Percent & Number & Percent & Number \\
\hline 2 & 6.4 & 33 & 1.9 & 6 & 4.7 & 39 \\
\hline 3 & 11.2 & 58 & 16.9 & 53 & 13.4 & 111 \\
\hline 4 & 14.1 & 73 & 16.9 & 53 & 15.2 & 126 \\
\hline 5 & 7.8 & 40 & 13.4 & 42 & 9.9 & 82 \\
\hline 6 & 0.8 & 4 & 1.9 & 6 & 1.2 & 10 \\
\hline 7 & 1.2 & 6 & 2.2 & 7 & 1.6 & 13 \\
\hline 8 & 0.4 & 2 & 1.6 & 5 & 0.8 & 7 \\
\hline $9+$ & 0.6 & 3 & 1.6 & 5 & 1.0 & 8 \\
\hline When check-up is & 0.2 & 1 & 1.3 & 4 & 0.6 & 5 \\
needed & 52.1 & 269 & 41.2 & 129 & 48.0 & 398 \\
\hline Don't know & 5.2 & 27 & 1.0 & 3 & 3.6 & 30 \\
Total & 100.0 & 516 & 100.0 & 313 & 100.0 & 829
\end{tabular}

According to table 5.4, a large proportion of the respondents believe that two or three antenatal visits are needed during pregnancy. However, nearly half of the women indicated that they would have antenatal check-ups only when necessary. This gives rise to the question of access. What obstacles stand in the way of women receiving adequate antenatal care? Age, once again, is an important factor. The younger the expectant mother, the less decision-making power she is likely to have. Information on the issue as well is an important factor. The younger the mother, the less information on maternal issues she is likely to have, and therefore the less decision-making power is available to her. Issues regarding transportation, financial constraint and tradition may also stand in the way.

Health education can help women become better aware of pregnancy-related care. For example, according to figure 5.1, 40 percent of the women in rural Lasbela and 16.6 percent of the women in urban Lasbela believed that TT shots were not necessary during pregnancy. 
Figure 5.1: $\quad$ Percentage of married women who thought they should have TT shots and take iron/folate during pregnancy

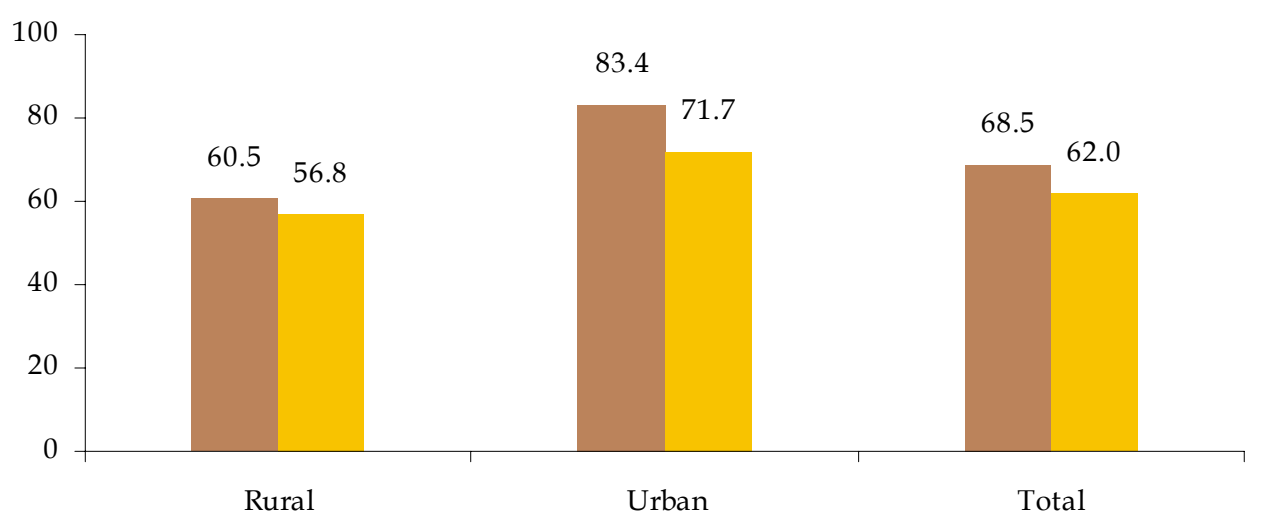

TT Injections $\square$ Iron/Folate

The proportion of women who failed to realize the importance of iron/folate supplements during pregnancy was also quite high. About 43 percent of the women in rural Lasbela thought it unnecessary to take iron/folate supplements, whereas 28 percent in urban Lasbela believed the same thing, as depicted in figure 5.1 .

\section{Attitudes Towards Delivery}

Many families prefer the traditional practice of employing Traditional Birth Attendants (TBAs) or Dais to assist with deliveries. These TBAs/Dais have vast experience but no formal training, and therefore do not qualify as skilled birth attendants. However, many families do not realize the impact which lack of training can potentially have on childbirth, and chose to opt for TBAs over skilled birth attendants (SBA). In fact, when asked if women should receive delivery services from SBA, more than 6 percent of the respondents in rural areas and 5 percent in urban areas disagreed with the idea of a SBA assisting a delivery. About 13 percent of the respondents in rural areas, along with 1.7 percent in urban areas were unsure as to whether or not they should take assistance from a SBA. This shows that traditional deliveries are still preferred in most areas of Lasbela. However, this trend is more common in rural areas than the urban areas.

Table 5.5: Believe that women should receive delivery services from bealth professional by place of residence

\begin{tabular}{|c|c|c|c|c|c|c|}
\hline \multirow{2}{*}{ Number } & \multicolumn{2}{|c|}{ Rural } & \multicolumn{2}{|c|}{ Urban } & \multicolumn{2}{|c|}{ Total } \\
\hline & Percent & Number & Percent & Number & Percent & Number \\
\hline Yes & 80.6 & 518 & 93.3 & 320 & 85.0 & 838 \\
\hline No & 6.4 & 41 & 5.0 & 17 & 5.9 & 58 \\
\hline Don't know & 13.1 & 84 & 1.7 & 6 & 9.1 & 90 \\
\hline Total & 100.0 & 643 & 100.0 & 343 & 100.0 & 986 \\
\hline
\end{tabular}

A majority of the respondents in urban (81 percent) and rural areas (60 percent) reported that only some pregnant women obtain delivery services from SBAs. Only 7.6 percent in urban areas and 4.7 percent in rural areas reported that most pregnant women in their communities obtain delivery services from SBA's (Figure 5.2). 
Figure 5.2: $\quad$ Percentage of women who thought women in their community went for skilled birth attendant for their delivery

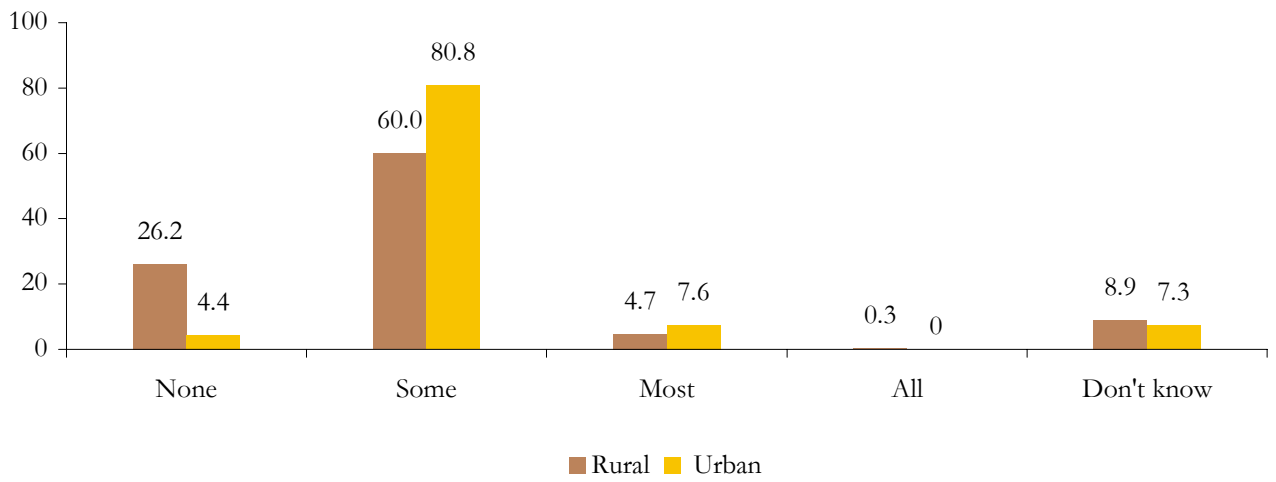

As seen in Figure 5.3, 62 percent of the women surveyed in urban Lasbela would prefer to deliver at a hospital, whereas 43 percent of the rural respondents feel the same way. Over half ( 56.3 percent) of the respondents in rural Lasbela indicated that they would prefer to deliver at home.

Figure 5.3: $\quad$ Percentage of women by their perception where should delivery take place

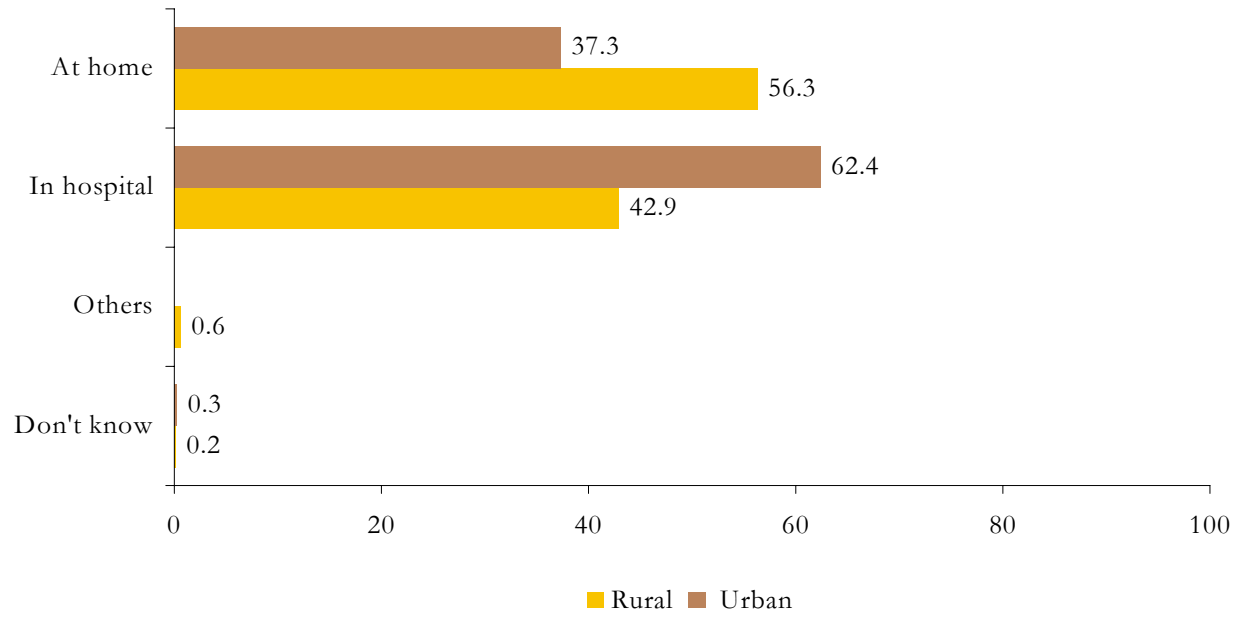

A possible reason why some women still deliver at home may be that they are unable to make major decisions independently, and must rely on their husbands or in-laws. Respondents were asked to indicate the person in their communities who should take charge of a pregnant woman and should be responsible for making important decisions regarding her health. 
According to table 5.6, only 13 percent of the respondents in rural areas and 9 percent in urban areas indicated that a pregnant woman should take care of herself. A majority of the respondents believed that a women's husband must make important decisions regarding pregnancy. Interestingly, a higher percentage of urban respondents believed that a woman's husband must take charge when compared to their rural counterparts. About 17 percent of the respondents in rural areas, and 8 percent in urban areas of Lasbela believed that it should be the family members who make decisions regarding the health of the pregnant woman.

Table 5.6:

Person who should make decisions regarding health of a pregnant woman

\begin{tabular}{lrrrrrr}
\multirow{2}{*}{ Person } & \multicolumn{2}{c}{ Rural } & \multicolumn{2}{c}{ Urban } & \multicolumn{2}{c}{ Total } \\
\cline { 2 - 7 } Pregnant woman & Percent & Number & Percent & Number & Percent & Number \\
\hline Husband & 12.6 & 81 & 9.0 & 31 & 11.4 & 112 \\
\hline Other family members & 68.1 & 438 & 82.2 & 282 & 73.0 & 720 \\
\hline Friend/Neighbor/Relative & 16.6 & 107 & 7.9 & 27 & 13.6 & 134 \\
\hline TBA/Dai & 0.3 & 2 & & & 0.2 & 2 \\
\hline Don't know & 0.9 & 6 & 0.6 & 2 & 0.8 & 8 \\
Total & 1.4 & 9 & 0.3 & 1 & 1.0 & 10 \\
\hline
\end{tabular}

Due to these sentiments, many women may not be allowed access to health care facilities and health professionals even if they want to. Table 5.6 also indicates how family members often have a major impact on the decisions made regarding the health of an expectant mother. Since women are largely not allowed to make their own decisions, they are unable to seek medical care when they deem necessary, and often do not make decisions such as those regarding the location of delivery.

Finally, respondents were asked to indicate the mode of transportation they planned to use in order to reach a health facility at the time of delivery. According to figure 5.4, only 6 percent had their own transportation, whereas almost the same percentage indicated that no mode of transport was available to them, and that they would walk to the health facility in time of need. About 83 percent in urban areas and 73 percent in rural areas indicated that they would hire private transport. Approximately 6 percent of the respondents in rural areas and 3 percent in urban areas cited community transport as their main source of transportation despite their unreliability. Lack of transportation to a health facility can be a critical and fatal delay in the delivery process. 
Figure 5.4: $\quad$ Percentage of married women by mode of transport they would use to reach a health facility

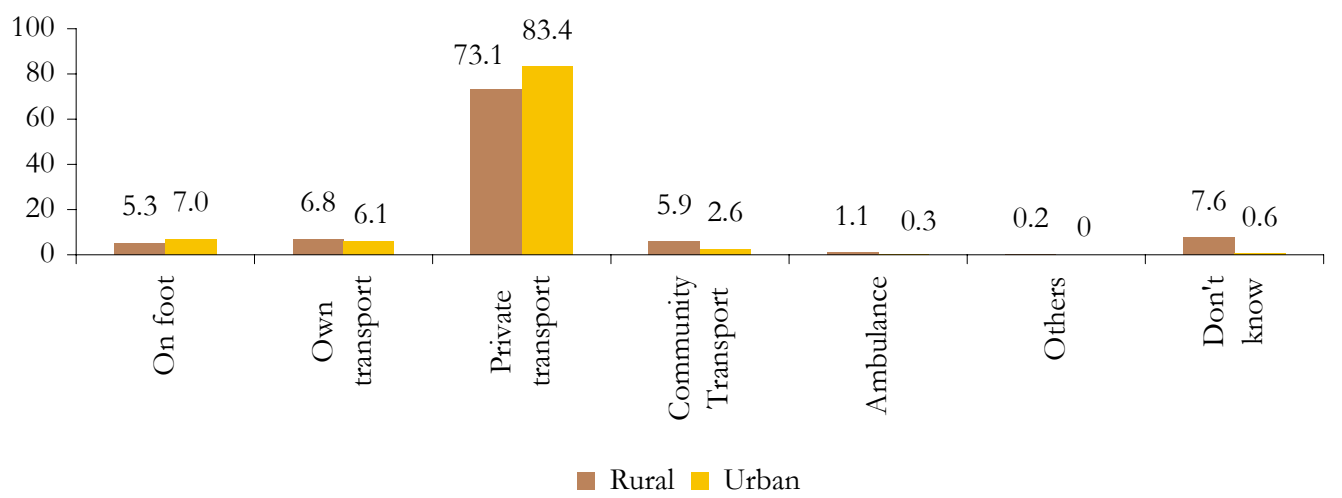

\section{Attitudes Towards Postpartum and Neonatal Care}

The importance of postnatal care is often undervalued. Postnatal care ensures that both mother and newborn are in good health, and monitors the recovery process of new mothers. However, when asked if women require postnatal care, almost a quarter (23 percent) of the population indicated that postnatal care was not necessary. Surprisingly, the proportion of those women who did not feel postnatal care was necessary was higher in urban centers than in rural areas.

Table 5.7: $\quad$ Belief in necessity of postnatal care by place of residence

\begin{tabular}{lrrrrrrr}
\multicolumn{2}{c}{ Need postnatal } & \multicolumn{2}{c}{ Rural } & \multicolumn{2}{c}{ Urban } & \multicolumn{2}{c}{ Total } \\
\cline { 2 - 8 } Yes & Percent & Number & Percent & Number & Percent & Number \\
\hline No & 59.3 & 381 & 62.7 & 215 & 60.4 & 596 \\
\hline Don't know & 21.3 & 137 & 26.5 & 91 & 23.1 & 228 \\
Total & 19.4 & 125 & 10.8 & 37 & 16.4 & 162 \\
\hline
\end{tabular}

Only three fifths of the respondents felt that postnatal care was necessary. This would suggest that about two fifths of the population is not aware of the complications that can arise following birth, and may therefore ignore or overlook the symptoms. A large number of maternal deaths occur during the 48 hours after birth (JHPIEGO, 2004). However, "in spite of the high risk associated with the postpartum period, people seem to know very little about health practices during this period" (JHPIEGO, 2004, pp 142).

Furthermore, most respondents in both urban and rural areas of Lasbela believed that only some women in their area received postnatal care. According to table 5.8, one-third of the respondents in rural Lasbela believed that none of the women in their area received postnatal care, thus putting their health at serious risk. 
In urban areas, the proportion of respondents who believed that none of the women in the area received postnatal care was 12 percent. Under normal circumstances, about 15 percent of pregnant women require emergency obstetric care to prevent mortality, which makes it necessary to have regular postnatal check-ups. A lack of knowledge during the postpartum period may influence inappropriate or delayed care seeking, which may result in maternal morbidity or mortality.

Table 5.8:

Number of postnatal care visits women should have in the community by place of residence

\begin{tabular}{l|rrrrrrr}
\multirow{2}{*}{ Number of visits } & \multicolumn{2}{c}{ Rural } & \multicolumn{2}{c}{ Urban } & \multicolumn{2}{c}{ Total } \\
\cline { 2 - 7 } & Percent & Number & Percent & Number & Percent & Number \\
\hline None & 33.4 & 215 & 12.0 & 41 & 26.0 & 256 \\
\hline Some & 53.8 & 346 & 73.2 & 251 & 60.5 & 597 \\
\hline Most & 3.9 & 25 & 4.4 & 15 & 4.1 & 40 \\
\hline All & 0.2 & 1 & & & 0.1 & 1 \\
\hline Don't know & 8.7 & 56 & 10.5 & 36 & 9.3 & 92 \\
\hline Total & 100.0 & 643 & 100.0 & 343 & 100.0 & 986
\end{tabular}

\section{Coverage of Lady Health Workers}

Women were asked if a Lady Health Worker (LHW) had been to their community. According to the table 5.9 below, 79 percent of the respondents from rural areas and 53 percent of the respondents from urban areas indicated that no LHW had been to their community.

Table 5.9: $\quad$ Presence of lady health worker in the community by place of residence

\begin{tabular}{lrrrrrrr}
\multirow{2}{*}{ Has LHW in the area } & \multicolumn{2}{c}{ Rural } & \multicolumn{2}{c}{ Urban } & \multicolumn{2}{c}{ Total } \\
\cline { 2 - 7 } Yes & Percent & Number & Percent & Number & Percent & Number \\
\hline No & 20.1 & 129 & 45.2 & 155 & 28.8 & 284 \\
\hline Respondent herself is LHW & 79.0 & 508 & 52.5 & 180 & 69.8 & 688 \\
\hline Don't know & 0.3 & 2 & 0.6 & 2 & 0.4 & 4 \\
Total & 0.6 & 4 & 1.7 & 6 & 1.0 & 10 \\
\hline
\end{tabular}

Among the respondents who indicated having an LHW in their community, a majority (88.7 percent) indicated that the LHW had visited their home during the three months prior to the survey. The figure is 87 percent for the rural areas and 90 percent for the urban areas.

Table 5.10: $\quad$ LHW ever visited home during last three months by place of residence

\begin{tabular}{lrrrrrr}
\multicolumn{1}{c}{ Ever visited } & \multicolumn{2}{c}{ Rural } & \multicolumn{2}{c}{ Urban } & \multicolumn{2}{c}{ Total } \\
\cline { 2 - 7 } Yes & Percent & Number & Percent & Number & Percent & Number \\
\hline No & 86.8 & 112 & 90.3 & 140 & 88.7 & 252 \\
\hline Total & 13.2 & 17 & 9.7 & 15 & 11.3 & 32 \\
\hline
\end{tabular}




\section{Chapter}

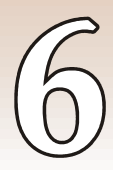

\section{Contraceptive Knowledge and Use}

Respondents were asked to name the ways in which a couple could delay or avoid pregnancy. If the respondent did not spontaneously mention a particular method, the interviewer described different methods and asked the respondent to indicate if she recognized them. In the questionnaire, descriptions were included for six modern contraceptive methods and two traditional methods.

\section{Knowledge of Contraceptive Methods}

Many women are unaware of the different types of contraceptives that may be used to either delay or prevent pregnancy. Knowledge of contraception is an important step towards reproductive choice.

Figure 6.1: $\quad$ Percentage of married women by knowledge of specific contraceptive method- rural Lasbela

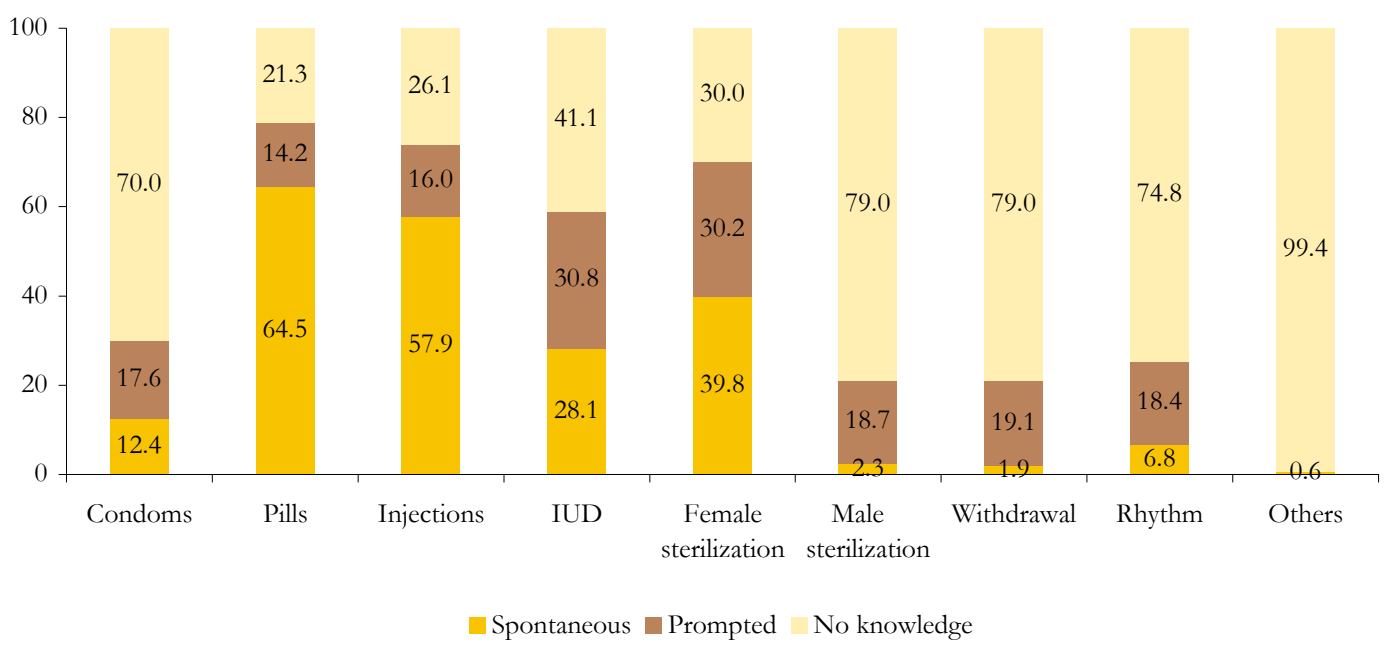

According to Figure 6.1, the most widely known methods in rural areas are the pill (64 percent) injection (58 percent), and female sterilization (40 percent). However, fewer women have heard about male sterilization ( 2 percent), and condoms (12 percent). In urban areas, the most widely known methods are the pill ( 83 percent), injection (80 percent), IUD (59 percent) and female sterilization (63 percent). Figure 6.2 shows that in urban areas the highest proportion of women know pills (83 percent) followed by injectables ( 80 percent), female strelization (63 percent) and condom (30 percent). 
Figure 6.2: $\quad$ Percentage of married women by knowledge of specific contraceptive method-urban Lasbela

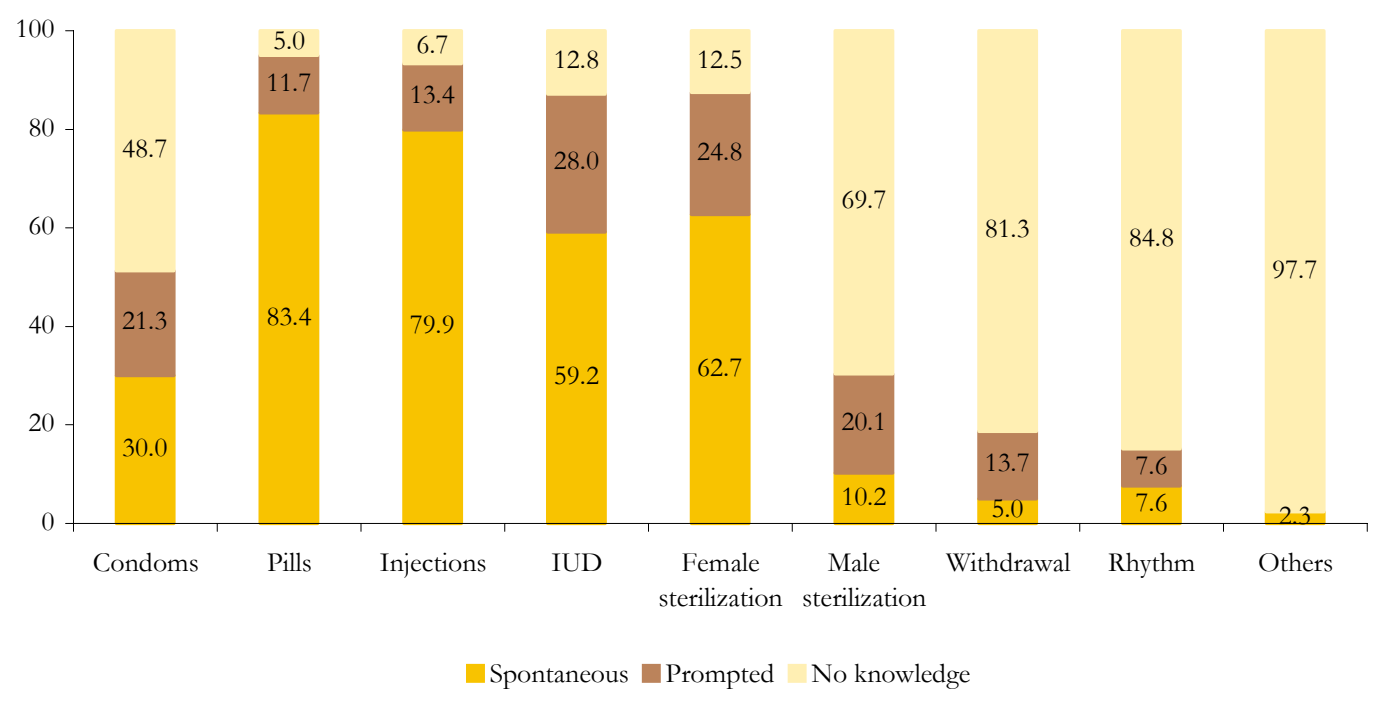

\section{Ever Use of Contraception}

When asked if they had ever used any form of contraception, the highest percentage of respondents confirmed the use of pills ( 8 percent) and injections ( 5.7 percent). The next most popular form of birth control was female sterilization ( 3.1 percent), while male sterilization ( 0.2 percent) was almost non-existent in the district of Lasbela. Condoms were used by nearly 2 percent of the sample population. The traditional methods such as withdrawal ( 0.3 percent $)$ and rhythm ( 0.7 percent $)$ did not appear to be popular methods of contraception in this particular district. Overall, 16 percent of the married women reported ever use of any contraceptive method.

Table 6.1: $\quad$ Ever used FP method by contraceptive and place of residence

\begin{tabular}{lrrrr}
\multirow{2}{*}{ Contraceptive method } & \multicolumn{2}{c}{ Place of residence } & \multicolumn{2}{c}{ Total } \\
\cline { 2 - 5 } Any method & Rural & Urban & Percentage & Number \\
\hline Condoms & 11.2 & 26.2 & 16.4 & 162 \\
\hline Pills & 0.5 & 3.8 & 1.6 & 16 \\
\hline Injections & 6.4 & 11.1 & 8.0 & 79 \\
\hline IUD & 4.0 & 8.7 & 5.7 & 56 \\
\hline Female sterilization & 0.6 & 2.3 & 1.2 & 12 \\
\hline Male sterilization & 1.9 & 5.2 & 3.0 & 31 \\
\hline Withdrawal & & 0.6 & 0.2 & 2 \\
\hline Rhythm & & 0.9 & 0.3 & 3 \\
\hline
\end{tabular}




\section{Current use of Contraceptive methods}

Contraceptive prevalence is defined as the proportion of currently married women aged 15-49 years who were using some method of family planning at the time of the survey. Table 6.2 shows the percentage distribution of married women who are currently using specific family planning methods. Results indicate that only 10 percent of the married women interviewed use some form of contraception, amongst which a majority use modern methods with only 0.3 percent using traditional methods. Furthermore, among modern methods, pills ( 3.1 percent), female sterilization ( 3 percent) and injectables ( 2.3 percent) are the most commonly used methods. On the other hand, 94 percent of the population in rural Lasbela, along with 83 percent in urban Lasbela is not using any form of birth control.

Table 6.2: $\quad$ Current use of specific contraceptive method

\begin{tabular}{lcrr}
\multicolumn{1}{c}{ Contraceptive Method } & Rural & Urban & All \\
Any method & 6.5 & 16.6 & 10.0 \\
\hline Any modern method & 6.5 & 15.7 & 9.7 \\
\hline Any traditional method & 0.0 & 0.9 & 0.3 \\
\hline Condom & & 2.9 & 1.0 \\
\hline Pill & 2.8 & 3.8 & 3.1 \\
\hline Injectables & 1.9 & 3.2 & 2.3 \\
\hline IUD & & 0.6 & 0.2 \\
\hline Female sterilization & 1.9 & 5.2 & 3.0 \\
\hline Withdrawal & & 0.6 & 0.2 \\
\hline Rhythm & & 0.3 & 0.1 \\
\hline Not currently using & 93.5 & 83.4 & 89.9 \\
\hline Number & 643 & 343 & 986 \\
\hline
\end{tabular}

\section{Source of Contraceptive Supplies}

Respondents were then asked where they obtained their method of contraception. Table 6.3 shows the distribution of current users by most recent source of contraception. Findings show that contraceptive users in rural areas are more likely to rely on the private clinics or hospitals; however, at the same time DHQ and THQs are also important sources for the respondents in urban areas of Lasbela. Medical stores and LHWs are the main source of contraceptive supplies for about one-tenth of the population in the district of Lasbela. 
Table 6.3: $\quad$ Source of contraception by place of residence

\begin{tabular}{lrrrrrr}
\multirow{2}{*}{ Source/Place } & \multicolumn{2}{c}{ Rural } & \multicolumn{2}{c}{ Urban } & \multicolumn{2}{c}{ Total } \\
\cline { 2 - 7 } LHW & Percent & Number & Percent & Number & Percent & Number \\
\hline DHQ/THQ & 9.5 & 4 & 9.3 & 5 & 9.4 & 9 \\
\hline Private clinic/hospital & 26.2 & 11 & 40.7 & 22 & 34.4 & 33 \\
\hline FWC/RHSA & 52.4 & 22 & 27.8 & 15 & 38.5 & 37 \\
\hline Medical Store & & & 1.9 & 1 & 1.0 & 1 \\
\hline General Store/shop & 7.1 & 3 & 13.0 & 7 & 10.4 & 10 \\
\hline Others & 2.4 & 1 & & & 1.0 & 1 \\
\hline Don't know & 2.4 & 1 & 3.7 & 2 & 3.1 & 3 \\
\hline Total & & & 3.7 & 2 & 2.1 & 2 \\
\hline
\end{tabular}

\section{Intentions of Future Use}

Respondents who indicated that they did not use family planning methods were asked if they planned on using contraception in the future. Only about 12 percent of the respondents in rural areas, along with 8.8 percent in urban Lasbela intended to use family planning methods in future. It is interesting to note that more women in rural area are planning to use contraception when compared to their urban counterparts. More than half of the respondents interviewed indicated that they did not want to use any contraception or family planning methods. This may be due to the fact that contraception is sometimes considered dangerous, harmful, wrong or even un-Islamic.

Figure 6.3: $\quad$ Percentage of married women by future intention to use contraceptives

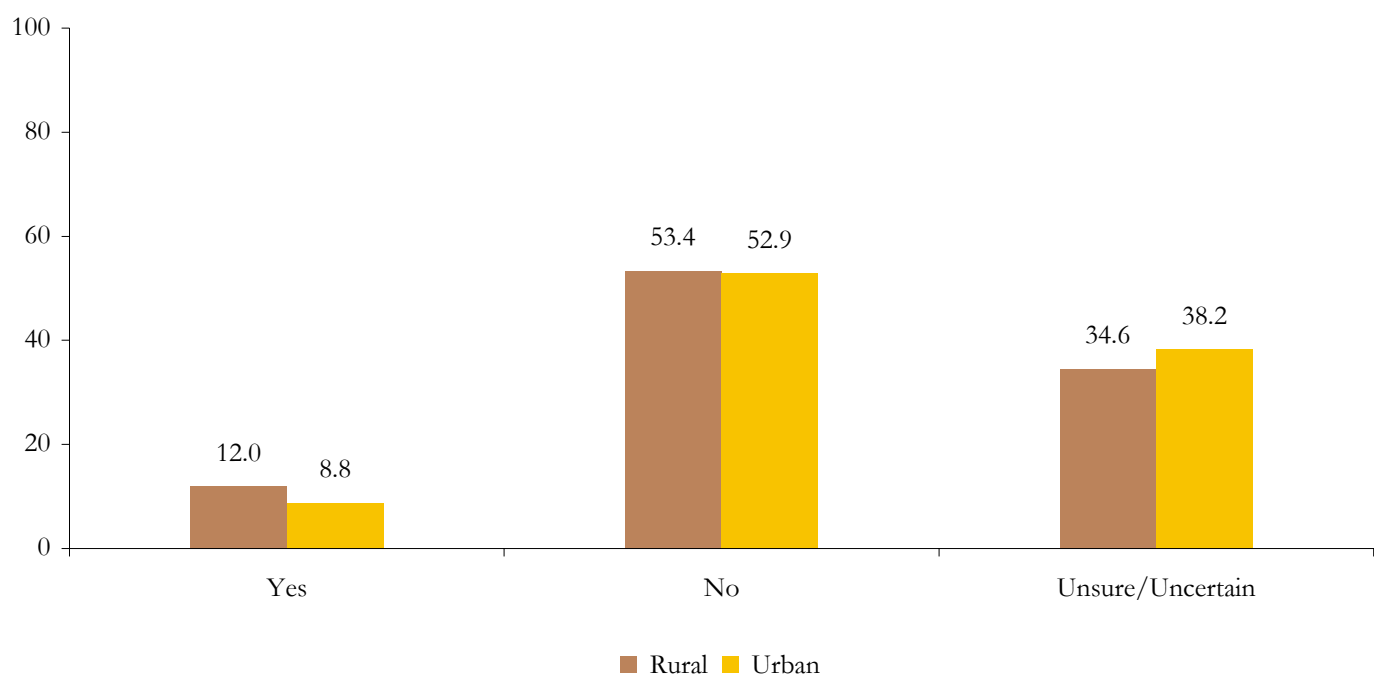




\section{Chapter

\section{Behavior Regarding Maternal and Newborn Health}

Many of the women who were interviewed were currently pregnant. However, some women, especially those in the early stages of pregnancy, had not yet experienced the full range of events that take place over the nine-month gestational period. Women who had recently given birth were able to provide a full range of information on these events and thus constitute an important part of the sample population in terms of understanding attitudes and behaviors concerning maternal and newborn health. This chapter pertains to the respondents' last pregnancy, given that it was within the past three years. Respondents were asked several questions regarding their experience during their last pregnancy including antenatal and delivery care, complications during pregnancy and delivery, postnatal care, and problems in accessing health care.

Information on antenatal care, delivery services and postnatal care is of great value in identifying segments of married women who do not utilize such services, and it is useful in planning for future improvements in these services. Delivery services are described according to the person assisting and the rate of caesarean section. Information on postnatal care was collected for women who did not give birth in a health facility, and it describes the time since delivery when care was received, as well as the caregiver.

\section{Gestational Age}

The respondents were asked to indicate gestational age at the time at which their last pregnancy ended. Table 7.1 shows that from those pregnancies that ended in live births, almost 91 percent were completed after a nine month gestational period, whereas about 9 percent of the pregnancies ended before the nine month gestational period. According to the table, the majority of the reported spontaneous abortions occurred in the second trimester of pregnancy, therefore highlighting the importance of antenatal care for expectant women during this period. Stillbirths also occurred mostly in the third trimester of pregnancy. 
Table 7.1: $\quad$ Pregnancy outcome by gestational age

\begin{tabular}{|c|c|c|c|c|}
\hline \multirow{2}{*}{$\begin{array}{l}\text { Gestational age when pregnancy } \\
\text { ended }\end{array}$} & \multirow[b]{2}{*}{ Live Birth } & \multirow[b]{2}{*}{ Still birth } & Spontaneous & \multirow{2}{*}{$\begin{array}{l}\text { Induced } \\
\text { Abortion }\end{array}$} \\
\hline & & & Abortion & \\
\hline First trimester of pregnancy & & & 8.7 & 100 \\
\hline Second trimester of pregnancy & & & 91.3 & \\
\hline 7 & 0.9 & 9.5 & & \\
\hline 8 & 8.5 & 19.0 & & \\
\hline 9 & 87.3 & 71.4 & & \\
\hline 10 & 3.3 & & & \\
\hline Total & 100 & 100 & 100 & 100 \\
\hline Number of pregnancies & 543 & 21 & 23 & 3 \\
\hline
\end{tabular}

\section{Antenatal Care}

In this survey, antenatal care was defined according to the type of provider, the number of visits made, and the stage of pregnancy at the time of the first visit, including whether or not tetanus toxoid injections and iron/folate tablets were received. The survey also included questions regarding the antenatal care received by the respondent during her last pregnancy. Interestingly, the responses obtained were overall very positive. The percentage of women who received antenatal care for past pregnancies was higher for both rural and urban areas compared to the percentage of women who obtained antenatal care for current pregnancies.

According to figure 7.1, more than 46 percent of all pregnant women in rural Lasbela went for antenatal check-ups. Even better, over 68 percent of the women in urban Lasbela had at least one check-up during their last pregnancy. It also shows that 23 percent of the rural and 36 percent of the urban pregnant women went for at least 3 antenatal visits during their last pregnancy.

According to table 7.2, of those who went for antenatal care services, a quarter did so during the third month of pregnancy. Furthermore, 36 percent went during their first trimester, 38 percent went during their second trimester and the rest had their antenatal check-ups in their third trimester. 
Figure 7.1: $\quad$ Percentage of pregnant women by their antenatal care status for the pregnancy three years preceding the baseline survey

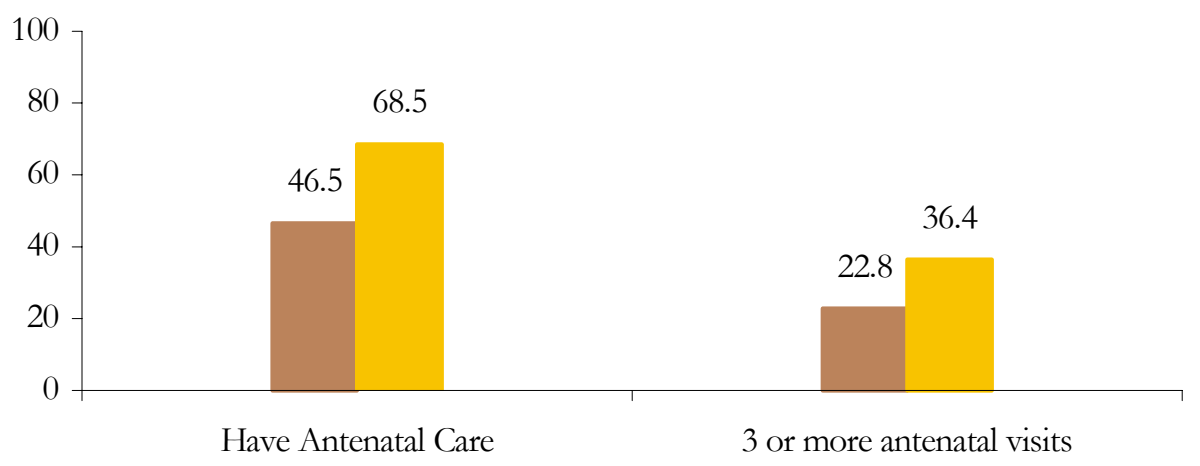

Rural Urban

Table 7.2: $\quad$ Status of the antenatal check-ups who went for the services by place of residence

\begin{tabular}{|c|c|c|c|c|c|c|c|}
\hline \multirow{2}{*}{\multicolumn{2}{|c|}{ Check-ups }} & \multicolumn{2}{|c|}{ Rural } & \multicolumn{2}{|c|}{ Urban } & \multicolumn{2}{|c|}{ Total } \\
\hline & & Percent & Number & Percent & Number & Percent & Number \\
\hline \multirow{11}{*}{$\begin{array}{l}\text { Gestational age } \\
\text { of pregnancy at } \\
\text { first antenatal } \\
\text { care }\end{array}$} & 0 & 0.5 & 1 & & & 0.3 & 1 \\
\hline & 1 & 2.1 & 4 & 4.0 & 5 & 2.9 & 9 \\
\hline & 2 & 5.8 & 11 & 12.1 & 15 & 8.3 & 26 \\
\hline & 3 & 23.2 & 44 & 26.6 & 33 & 24.5 & 77 \\
\hline & 4 & 20.5 & 39 & 7.3 & 9 & 15.3 & 48 \\
\hline & 5 & 9.5 & 18 & 13.7 & 17 & 11.1 & 35 \\
\hline & 6 & 11.6 & 22 & 11.3 & 14 & 11.5 & 36 \\
\hline & 7 & 9.5 & 18 & 15.3 & 19 & 11.8 & 37 \\
\hline & 8 & 7.4 & 14 & 5.6 & 7 & 6.7 & 21 \\
\hline & 9 & 2.6 & 5 & 1.6 & 2 & 2.2 & 7 \\
\hline & Don't know & 7.4 & 14 & 2.4 & 3 & 5.4 & 17 \\
\hline \multirow{10}{*}{$\begin{array}{l}\text { Number } \\
\text { antenatal check- } \\
\text { ups during } \\
\text { pregnancy }\end{array}$} & 1 & 20.0 & 38 & 7.3 & 9 & 15.0 & 47 \\
\hline & 2 & 27.4 & 52 & 37.1 & 46 & 31.2 & 98 \\
\hline & 3 & 21.6 & 41 & 21.0 & 26 & 21.3 & 67 \\
\hline & 4 & 15.3 & 29 & 18.5 & 23 & 16.6 & 52 \\
\hline & 5 & 6.3 & 12 & 4.0 & 5 & 5.4 & 17 \\
\hline & 6 & 3.7 & 7 & 3.2 & 4 & 3.5 & 11 \\
\hline & 7 & & & 0.8 & 1 & 0.3 & 1 \\
\hline & 8 & & & 1.6 & 2 & 0.6 & 2 \\
\hline & 10 & 1.0 & 2 & 2.4 & 3 & 1.5 & 5 \\
\hline & Don't know & 4.7 & 9 & 4.0 & 5 & 4.5 & 14 \\
\hline Total & & 100.0 & 190 & 100.0 & 124 & 100.0 & 314 \\
\hline
\end{tabular}


Figure 7.2 shows that most of the women (47 percent) who received antenatal care were accompanied by their husbands, followed by other family members (30 percent), and mothers in law (17 percent). About 2 percent reportedly went for ANC visits by themselves

Figure 7.2: $\quad$ Percentage distribution of married women by persons who accompanied them to their antenatal check-up

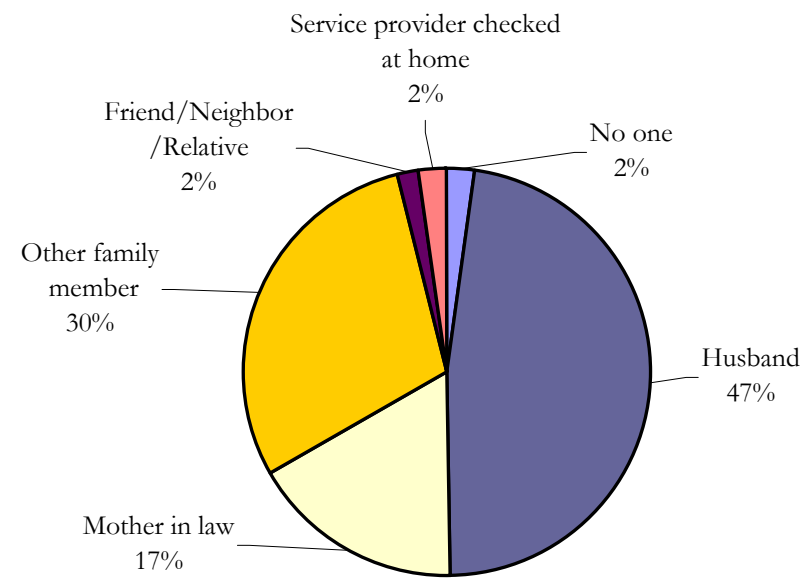

\section{Components of Antenatal care}

In Pakistan, it is recommended that every pregnant woman receive the following services: height and weight measurements, blood pressure measurement, iron tablets, tetanus toxoid immunization, and an abdominal examination. In any antenatal care visit, a woman should be informed of the danger signs of pregnancy, and provide blood and urine samples for testing. Antenatal care can improve certain outcomes through the detection and management of possible complications. Antenatal care may improve birth weight and can also prevent, identify and treat iron deficiency and anemia in pregnant mothers.

Respondents were asked to state the number of antenatal check-ups they received, as well as the questions their health providers asked them during the visits. This was to determine the level of care being provided by various district health care facilities in both urban and rural Lasbela. Figure 7.3 outlines the questions asked of, and the tests performed on, pregnant women during their antenatal check-ups in Lasbela. When comparing urban and rural areas of Lasbela, there were slight variations in the percentage of respondents on whom the various tests were conducted. Almost 19 percent of the respondents in rural areas, along with about 24 percent of the respondents in urban areas had their weight measured during their antenatal check-ups. Only 35 percent of the respondents in urban Lasbela were asked for their obstetric history, whereas 47 percent of their counterparts in rural Lasbela were asked the same question. Almost two in every five pregnant women in rural areas had a blood test while half of the women in urban areas had the same service performed on them.

Furthermore, approximately 46 percent of the respondents in urban areas were tested against anemia, compared to 57 percent of the rural respondents. Anemia is a condition that often occurs during pregnancy and has the potential to cause serious harm if left unchecked. For this reason, it is surprising that a large number of women in rural Lasbela were not tested for anemia during their antenatal visit. 
Figure 7.3: $\quad$ Services performed/asked during antenatal check-up

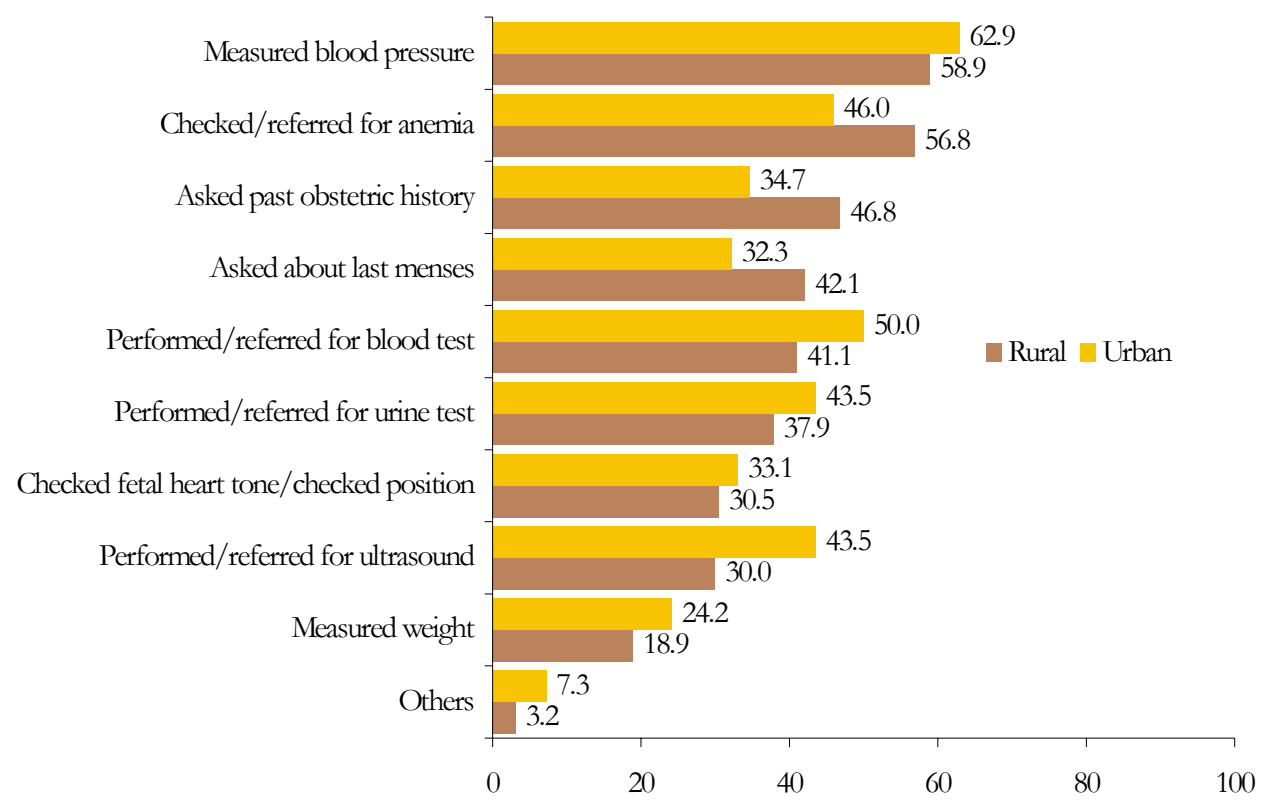

Figure 7.4: $\quad$ Percentage of pregnant women by issues discussed during antenatal check-up

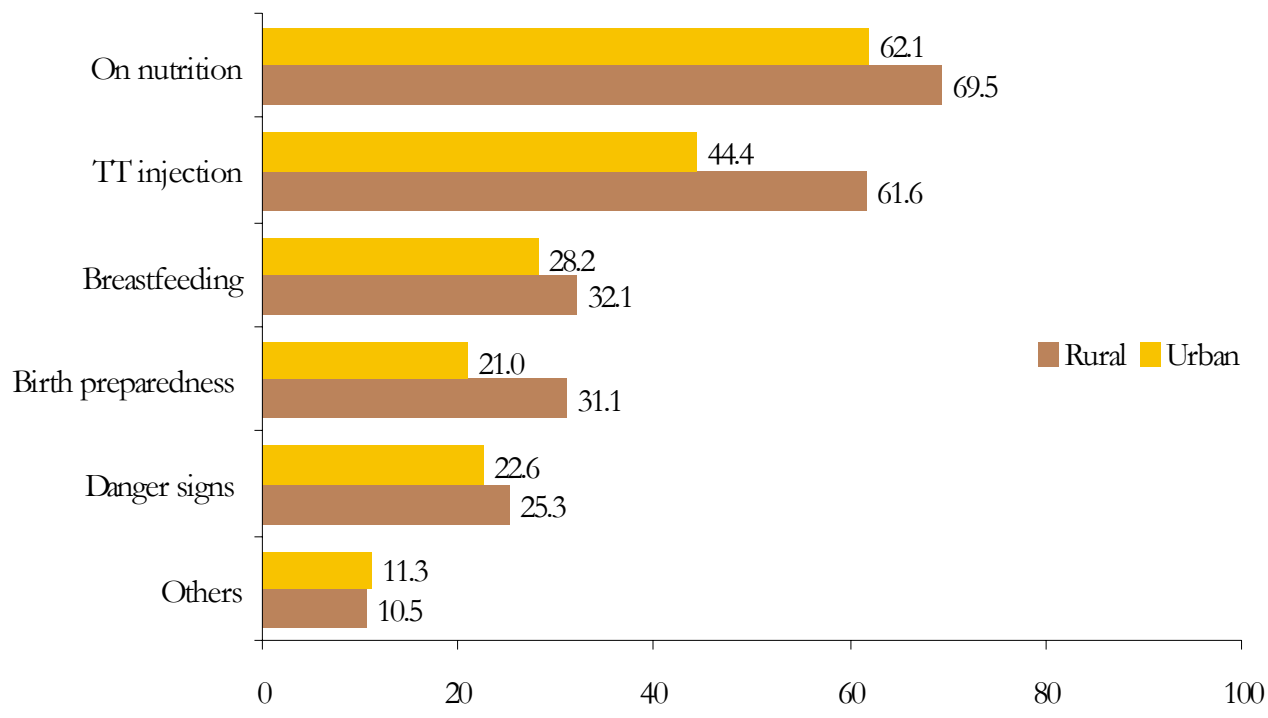

According to figure 7.4, most respondents in both urban and rural areas (62 percent and 70 percent respectively) were advised about nutrition during their antenatal check-up. About 62 percent in rural areas and 42 percent in urban Lasbela were advised to take TT injections, while less than a quarter of the women were briefed about the danger signs that may appear during pregnancy. 


\section{TT Injections and Iron/Folate Tablets}

Respondents were also asked to state whether they took iron and folate supplements and received TT shots during their last pregnancy. In Pakistan, the immunization of pregnant women is enforced by a program coordinated by the Expanded Program on Immunization (EPI) and the Maternal and Child Health Care $(\mathrm{MCH})$ departments at the district level. The program recommends that women receive two tetanus toxoid (TT) injections during their first pregnancy. Booster injections are given once during each subsequent pregnancy to maintain full protection. In recent years, TT immunization has also been given to women before marriage, so that any pregnancy occurring within three years of their marriage would be protected against tetanus.

Figure 7.5: $\quad$ Percentage of married women by status of TT injections during the last pregnancy

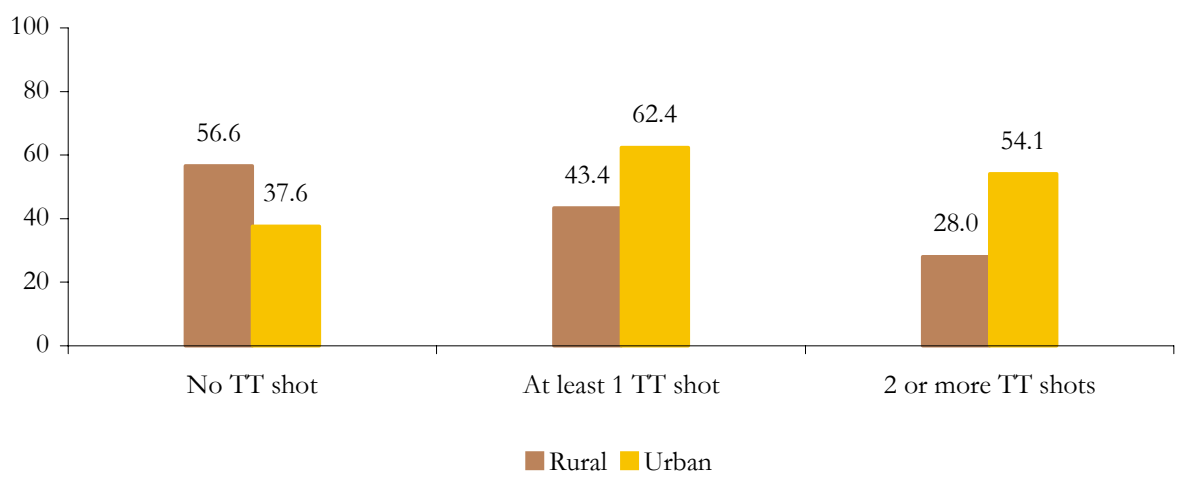

According to the baseline findings, 43 percent of the rural respondents reported having received at least one TT shot during their last pregnancy, while 62 percent of their counterparts in urban Lasbela made the same claim. Figure 7.5 also shows that 28 percent of the respondents in rural areas and 54 percent in urban areas were immunized with two or more TT shots.

Figure 7.6 shows that 45 percent of the rural and 53 percent of the urban pregnant women reported having iron/folate tablets during the course of their last pregnancy. However, a large portion of both rural (56 percent) and urban ( 47 percent) respondents indicated that they took no iron or folate supplements during their pregnancy.

Figure 7.6: $\quad$ Percentage of married women by status of iron/folate tablets during the last pregnancy

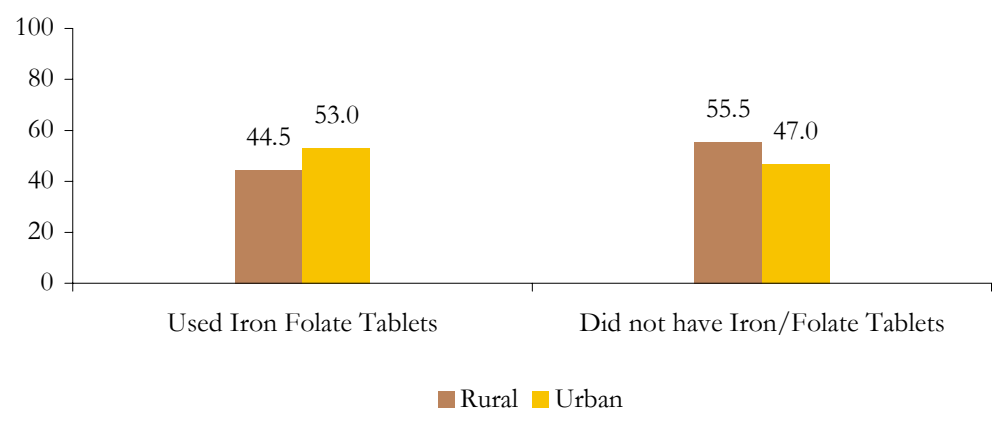




\section{Experience of Complications and Birth Preparedness}

\section{Complications During Pregnancy}

In order to identify complications associated with pregnancy, women were asked to indicate certain signs and symptoms that they had experienced during their last pregnancy within the past three years. Three quarters of both urban and rural respondents indicated that they experienced some type of complication.

The percentage of the respondents that experienced complications during their last pregnancy was higher in rural areas than in urban centers of Lasbela. Figure 7.7 shows that in rural areas, the percentage of women that suffered from "severe headache" and "high fever" was established at 39 percent and 36 percent respectively, while 34 percent reported having experienced "severe lower abdominal pain", and 32 percent ensured "prolonged vomiting”. In urban areas, 34 percent had "severe lower abdominal pain", 29 percent suffered from "high fever", and 28 percent experienced "prolonged vomiting".

It was determined that urban women were more likely to report "high blood pressure" during their pregnancy than rural women. Overall, more rural women reported complications during pregnancy than did their counterparts in urban areas.

Figure 7.7: $\quad$ Percentage of married women who experienced complications during their last pregnancy

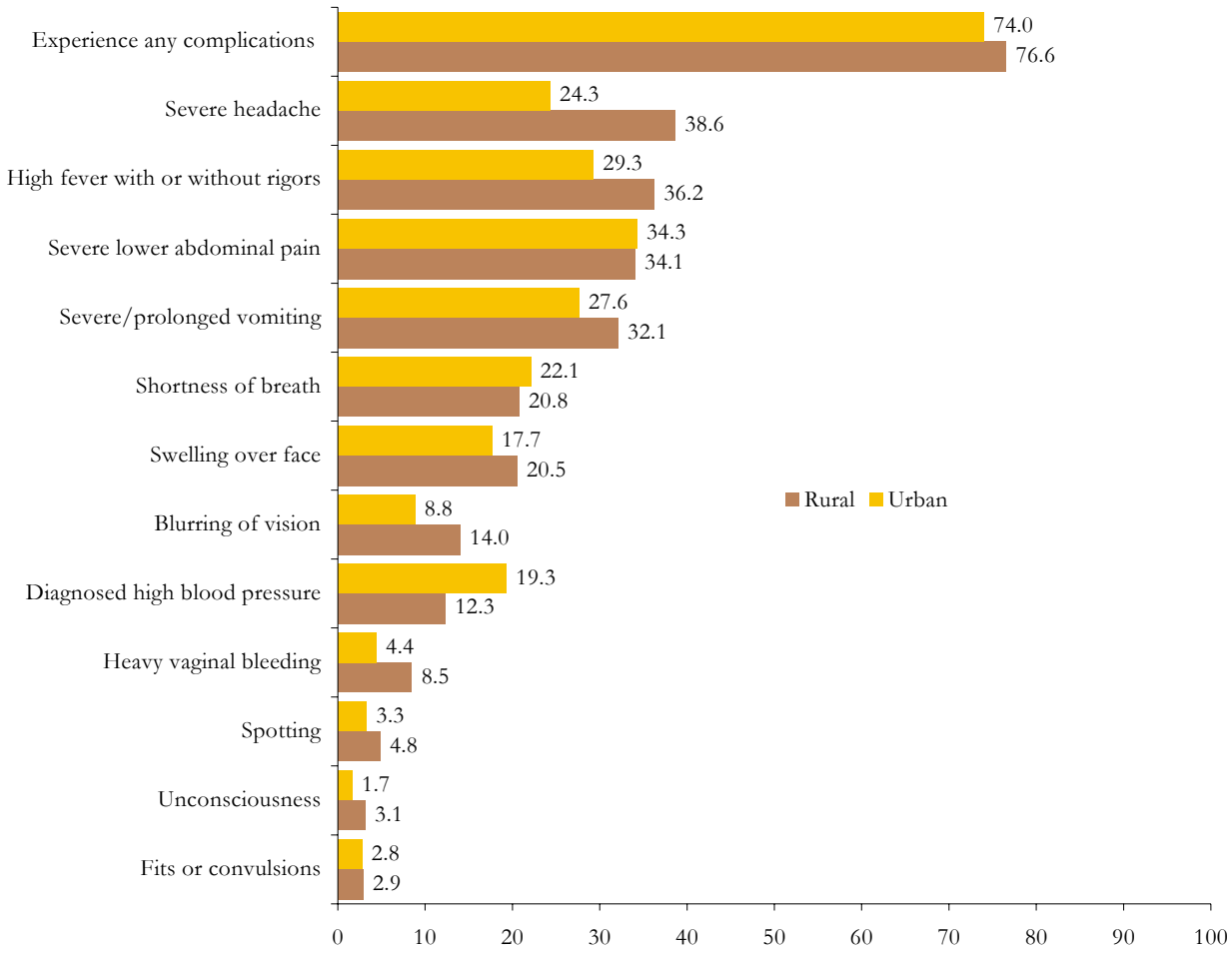




\section{Preparedness for Childbirth}

To ensure the safety of the mother and newborn at the time of delivery, certain preparations need to be made. These include deciding upon a person who will assist in the delivery, where the delivery is going to take place, how the woman is going to get to the place of delivery, and how much the delivery is going to cost. Delivery services, especially emergency obstetric care, are critical for pregnant women. Emergency care is important in the event that a pregnant mother experiences obstructed labor, pregnancy-induced hypertension, eclampsia or severe untreated anemia. Obstructed or prolonged labor is one of the more serious complications that can cause maternal death. Obstetric care can also prevent or treat complications that affect the neonate, such as birth asphyxia.

Figure 7.8: $\quad$ Percentage of married women who made arrangements for their last delivery

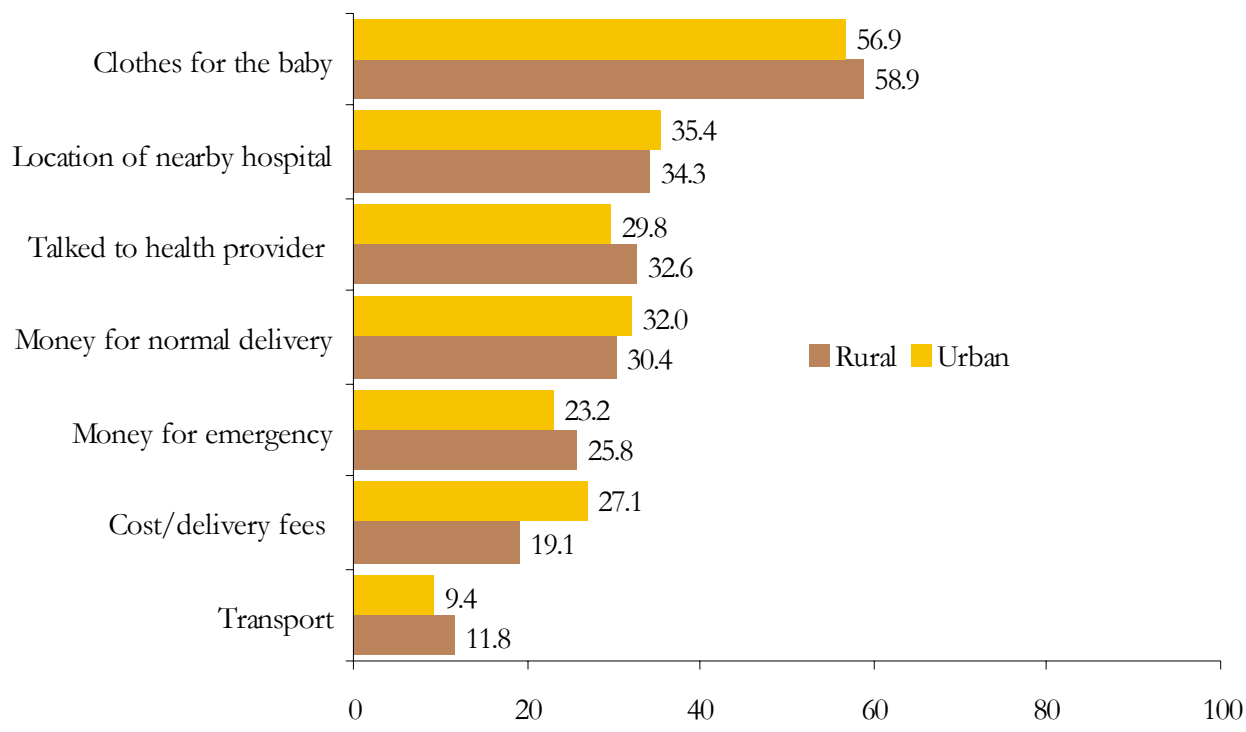

Respondents were asked if they had made necessary arrangements regarding transport, money, blood, location and hours of operation of the nearest hospital, as well as clothes for the newborn baby. The findings presented in figure 7.8 indicate that a large percentage of women appeared to have made no prior arrangements for the time of delivery. Less than a quarter of the married women had arranged for money in the event of an emergency, 34 percent and 35 percent in rural and urban areas respectively had located the nearby hospital, while only 12 percent in rural areas and more than 9 percent in urban areas had arranged for transport at the time of delivery. Only 27 percent in urban areas and 19 percent in rural areas knew what the delivery fees were, and were aware of the costs that would be incurred at the time of delivery. 


\section{Delivery Characteristics}

When asked about the status of the last delivery, 93 percent of the respondents in rural areas indicated that they had a normal vaginal delivery, while 89 percent in urban areas reported the same thing. The number of assisted vaginal deliveries were about 2 percent in rural areas and less than 1 percent in urban. The rates of spontaneous abortion were also higher in rural areas, sitting at about 4.6 percent compared to 2.2 percent in urban areas. However, induced abortions were higher in urban areas. As well, Caesarean section deliveries appeared to be much more common in urban areas compared to rural Lasbela (7 percent versus 1 percent respectively).

Table 7.3:

Status of the last delivery

\begin{tabular}{lrrrrrrr}
\multirow{2}{*}{ Status } & \multicolumn{2}{c}{ Rural } & \multicolumn{2}{c}{ Urban } & \multicolumn{2}{c}{ Total } \\
\cline { 2 - 8 } & Percent & Number & Percent & Number & Percent & Number \\
\hline Normal vaginal delivery & 92.5 & 382 & 89.0 & 161 & 91.4 & 543 \\
\hline Assisted vaginal delivery & 1.9 & 8 & 0.6 & 1 & 1.5 & 9 \\
\hline Caesarean section & 0.7 & 3 & 7.2 & 13 & 2.7 & 16 \\
\hline Spontaneous abortion & 4.6 & 19 & 2.2 & 4 & 3.9 & 23 \\
\hline Induced abortion & 0.2 & 1 & 1.1 & 2 & 0.5 & 3 \\
\hline Total & 100.0 & 413 & 100.0 & 181 & 100.0 & 594
\end{tabular}

The outcomes of all the pregnancies were recorded, with live births making up 91 percent of the total births in rural areas, as well as 95 percent in urban areas. Figure 7.9 shows that a higher proportion of live births were recorded in urban centers compared to rural areas. Approximately 4.2 percent and 2.2 percent of the pregnancies in rural and urban areas respectively resulted in stillbirths. It is noted that the percentage of induced abortions reported is lower than the percentage of spontaneous abortions reported in both rural and urban areas. This may be due to the fact that spontaneous abortions are more socially acceptable than induced abortions, and may therefore be misreported.

Figure 7.9: $\quad$ Outcome of last pregnancy

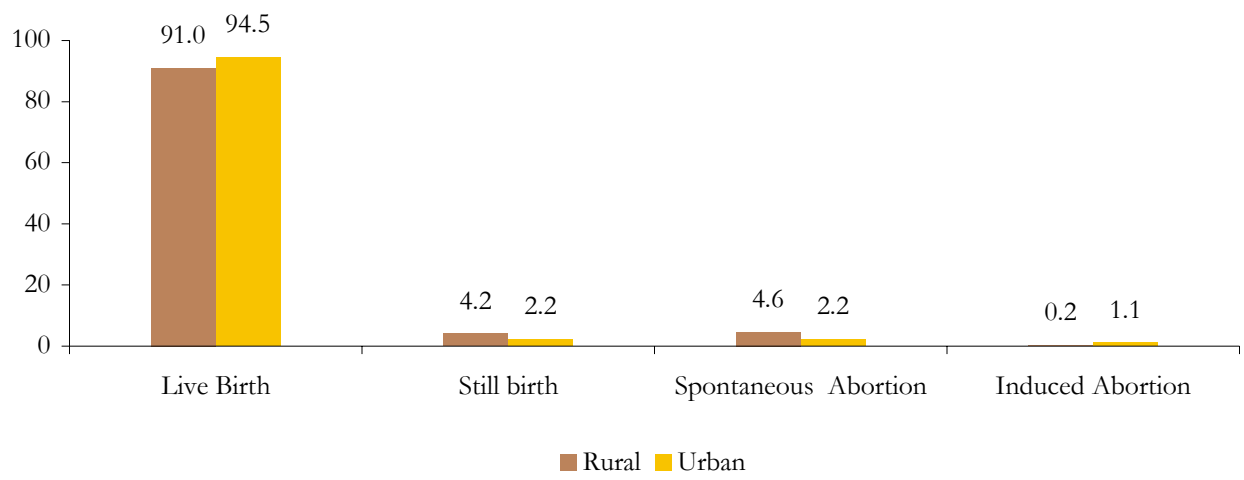




\section{Place of Delivery}

A vast majority of the women in both urban and rural Lasbela (52 and 89 percent respectively) delivered their babies at home. Figure 7.10 also shows that 35 percent of the rural respondents and 8 percent of the urban respondents delivered at private clinics and hospitals, whereas 13 percent of the respondents in urban areas, along with 2 percent in rural areas chose to deliver at DHQ/THQs.

Figure 7.10: $\quad$ Place of delivery

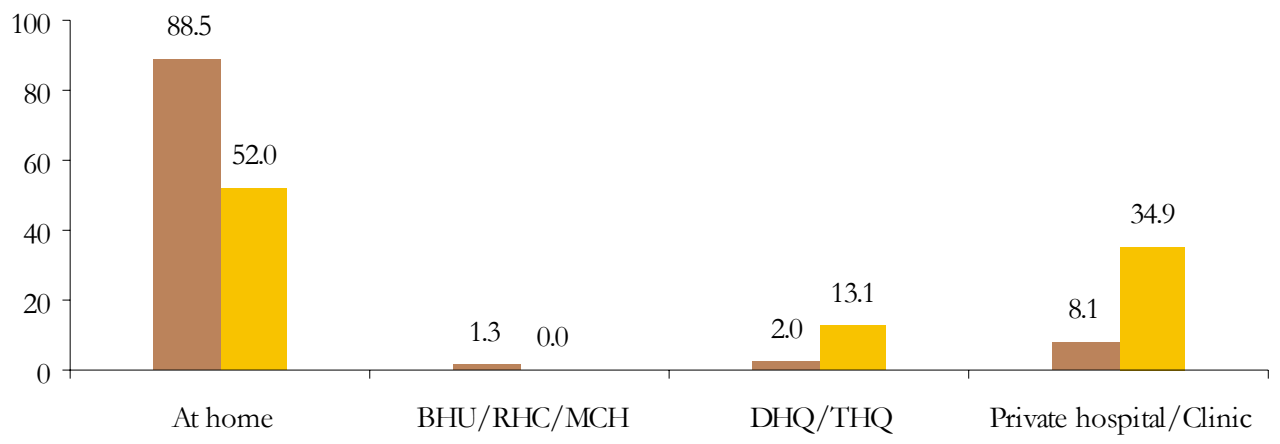

Rural $\square$ Urban

Financial constraints may be the leading cause which forces women to deliver at home. Also, women may not be allowed to deliver at a health facility by their husbands, in-laws or family members. Nonavailability of such services may also be a problem for pregnant women in these areas.

\section{Assistance during Delivery}

According to Figure 7.11, in both urban and rural Lasbela, TBAs assisted less than two-thirds (63 percent) of the deliveries that took place at home. Female relatives assisted approximately a quarter (26 percent) of all deliveries, whereas lady doctors conducted only 1.8 percent of the deliveries. Once again, while a large number of respondents preferred the idea of having a SBA deliver their baby, in reality many have access only to TBAs.

Figure 7.11: $\quad$ Percentage of married women who delivered their last cbild at home by delivery attendant

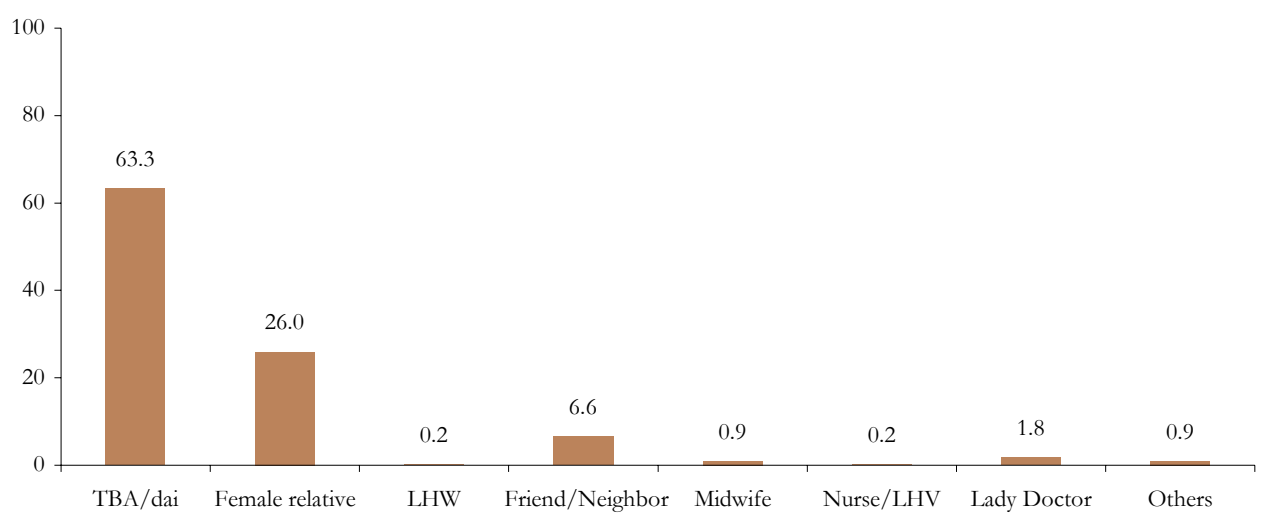


Figure 7.12 presents the main reasons provided by respondents for choosing a TBA to assist with deliveries. More than half of the respondents indicated that family choice was the leading factor, while 28 percent reported having already used the TBA for earlier deliveries. Nearly 16 percent of the women cited geographical proximity as their main reason for choosing a TBA to assist with their delivery.

Figure 7.12: $\quad$ Main reason for choosing a $\mathrm{TB} A$ / dai as delivery attendant

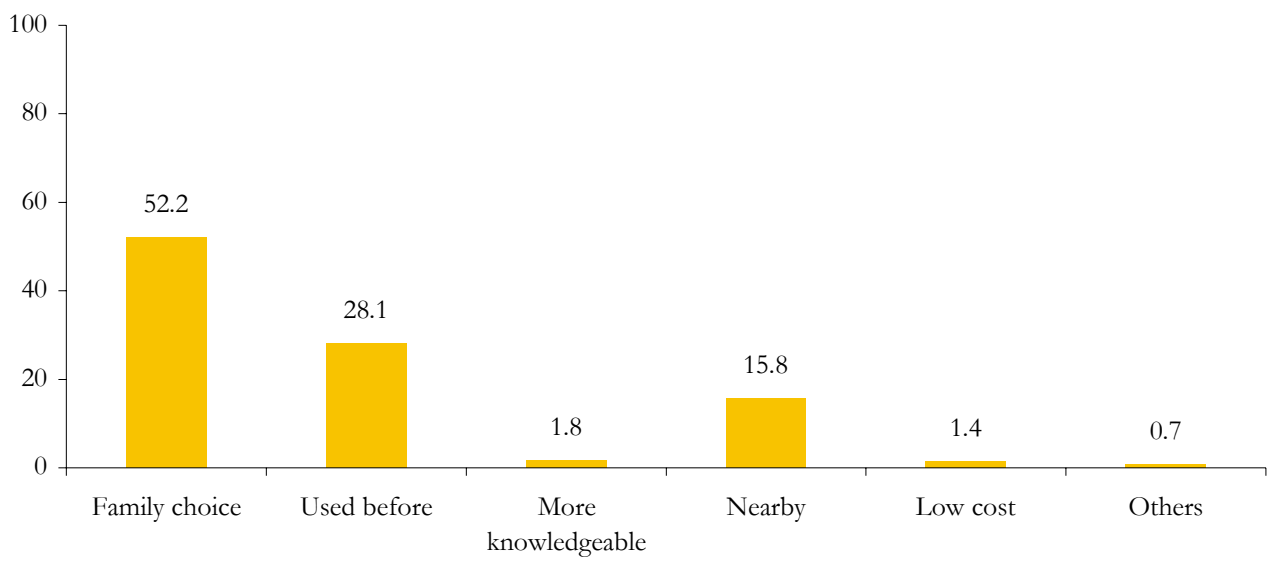

\section{Clean Delivery Practices}

Respondents were asked to state if their TBAs followed safe health practices such as washing their hands with soap prior to the delivery. Surprisingly, only 79 percent of the women in rural Lasbela, and 88 percent of the women in urban Lasbela indicated that the TBA who assisted with the delivery did wash her hands with soap.

Figure 7.13: $\quad$ Percentage of delivery attendants who reportedly washed hands before conducting the delivery and type of thread used to tie the cord

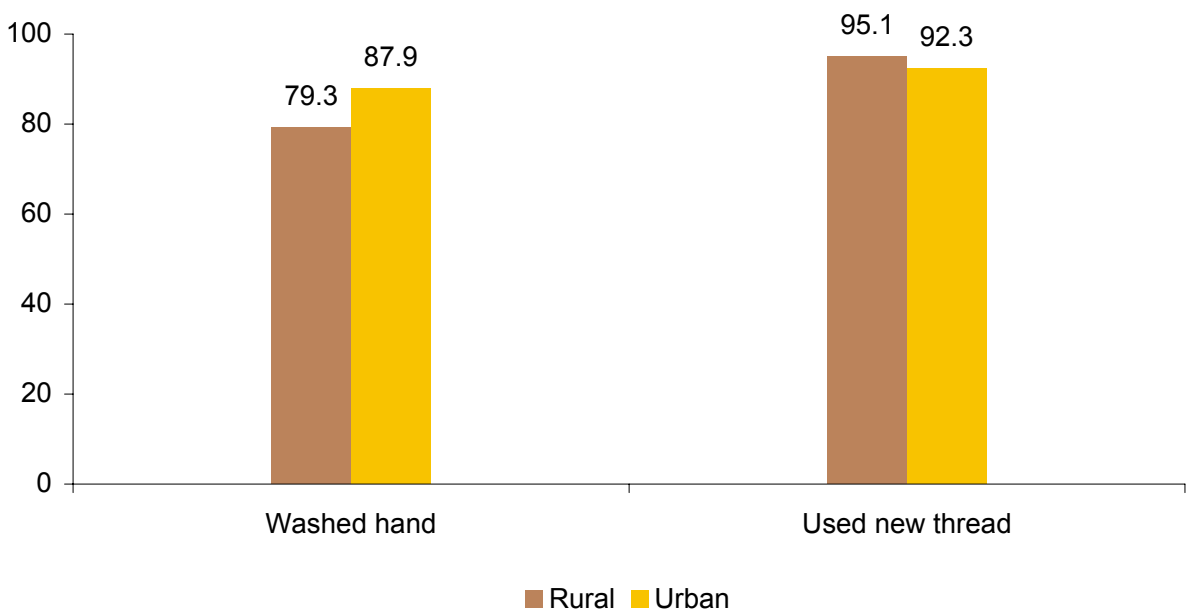


Cord cutting methods and instruments were also inquired about in order to determine how hygienic the place and methods of delivery were. Figure 7.13 also shows that in 91 percent of the cases in urban areas and 85 percent in rural areas, the TBA used new thread to tie the cord.

Figure 7.14: $\quad$ Percentage of delivery attendants who reported instruments for cutting the cord

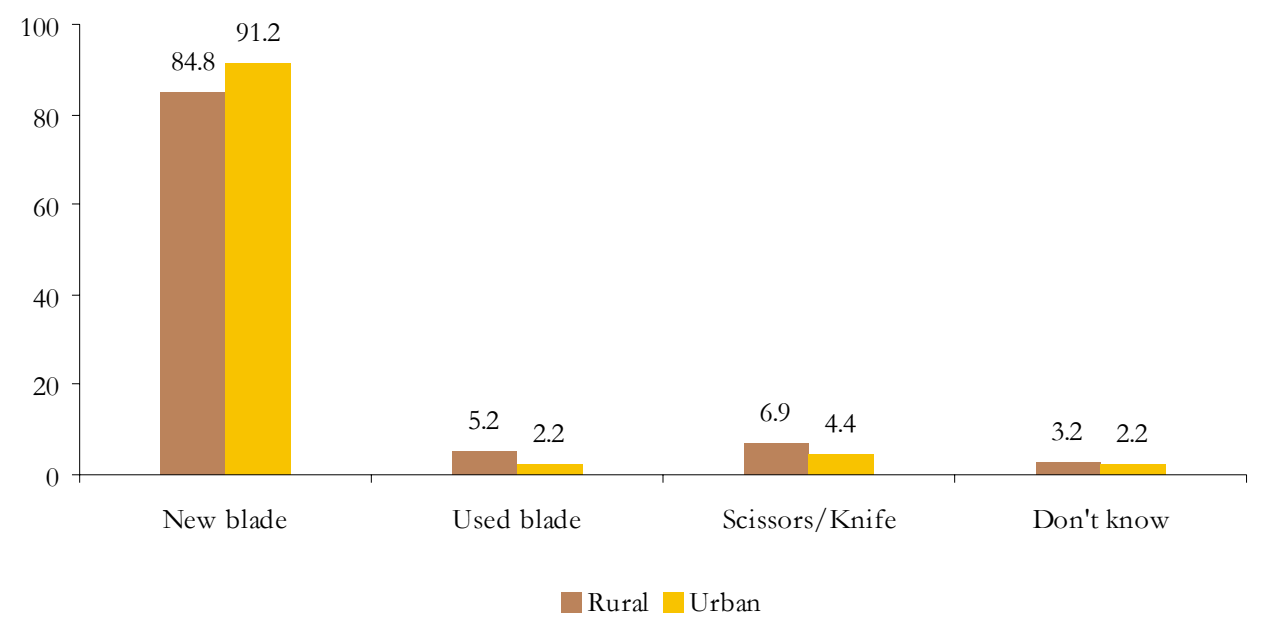

\section{Complications during Childbirth}

During the baseline survey, severe complications during childbirth were also discussed and respondents were asked to indicate the complications they may have experienced. About 40 percent of the respondents in rural areas indicated that they experienced "excruciatingly abnormal pain" during their last pregnancy, while 34 percent in urban centers reported the same thing. "Bleeding before labor began", "prolonged/obstructed labor" and "fever" were some of the other complications that were reported.

Table 7.4: $\quad$ Experienced complications during last delivery by place of residence

\begin{tabular}{lrrrr}
\multicolumn{1}{c}{ Complications } & Rural & Urban & \multicolumn{2}{c}{ Total } \\
& & & Percent & Number \\
Prolonged/obstructed labor & 12.3 & 21.0 & 15.0 & 89 \\
\hline Bleeding before labor began & 25.1 & 14.4 & 21.8 & 130 \\
\hline Excruciating abnormal pain & 40.1 & 33.7 & 38.2 & 227 \\
\hline Premature rupture of membranes & 3.1 & 3.3 & 3.2 & 19 \\
\hline $\begin{array}{l}\text { Delay in delivery of placenta/retained placenta } \\
\text { Excessively postpartum bleeding } \text { on day of }\end{array}$ & 9.4 & 4.4 & 7.9 & 47 \\
\hline delivery/abortion & 11.1 & 4.4 & 9.1 & 54 \\
\hline $\begin{array}{l}\text { Tear in vagina, cervix or uterus } \\
\text { Prolapsed of the uterus }\end{array}$ & 1.7 & 2.2 & 1.8 & 11 \\
\hline Fever & 3.6 & 1.1 & 2.9 & 17 \\
\hline Abnormal position fetus & 24.6 & 5.5 & 18.8 & 112 \\
\hline
\end{tabular}




\section{Decision-making within family}

Delays in seeking care, in reaching adequate health facilities, and in receiving appropriate care at health facilities are recognized barriers to care for pregnant women, and these factors may be especially pronounced for young and older pregnant mothers. Timely and appropriate care provides an opportunity to prevent or manage the direct causes of maternal mortality such as hemorrhage, obstructed labor, infection and hypertensive disorders. It also reduces fetal and neonatal deaths related to obstetric complications. According to table 7.5, 71 percent of the respondents in rural areas indicated that their husbands were the ones who made the decision to seek treatment for deliveryrelated complications. Approximately 81 percent in urban areas stated the same. In urban centers, only 10 percent of the respondents indicated that they themselves had the freedom to decide that they needed medical attention, compared to 13 percent of their rural counterparts.

\section{Availability of Transport}

The mode of transport to health facility was also an issue that was discussed during the survey. According to table 7.5 , most respondents (40 percent in rural areas and 68 percent in urban centers) reportedly used private/hired transport to reach a health facility. More than half of the respondents in rural areas, along with almost a quarter in urban areas stated that the health provider visited their homes. Finally, 5.6 percent in rural areas and 8.5 percent in urban areas stated that they had their own mode of transport with which they were able to reach a health facility.

Table 7.5: $\quad$ Person who made decision to seek bealth care/ mode of transport used to reach health facility

\begin{tabular}{|c|c|c|c|c|c|c|c|}
\hline \multirow{2}{*}{\multicolumn{2}{|c|}{ Measures taken }} & \multicolumn{2}{|c|}{ Rural } & \multicolumn{2}{|c|}{ Urban } & \multicolumn{2}{|c|}{ Total } \\
\hline & & Percent & Number & Percent & Number & Percent & Number \\
\hline \multirow{5}{*}{$\begin{array}{l}\text { Person who made } \\
\text { decision to seek } \\
\text { health care }\end{array}$} & Self & 13.3 & 19 & 10.2 & 6 & 12.4 & 25 \\
\hline & Husband & 70.6 & 101 & 81.4 & 48 & 73.8 & 149 \\
\hline & Mother in law & 4.9 & 7 & 1.7 & 1 & 4.0 & 8 \\
\hline & $\begin{array}{l}\text { Other family } \\
\text { member }\end{array}$ & 9.8 & 14 & 6.8 & 4 & 8.9 & 18 \\
\hline & TBA/Dai & 1.4 & 2 & & & 1.0 & 2 \\
\hline \multirow{6}{*}{$\begin{array}{l}\text { Mode of transport } \\
\text { to reach health } \\
\text { care service }\end{array}$} & $\begin{array}{l}\text { Service provider } \\
\text { visited at home }\end{array}$ & 52.1 & 75 & 23.7 & 14 & 43.8 & 89 \\
\hline & On foot & 1.4 & 2 & & & 1.0 & 2 \\
\hline & Own transport & 5.6 & 8 & 8.5 & 5 & 6.4 & 13 \\
\hline & Private transport & 39.6 & 57 & 67.8 & 40 & 47.8 & 97 \\
\hline & $\begin{array}{l}\text { Community } \\
\text { transport }\end{array}$ & 0.7 & 1 & & & 0.5 & 1 \\
\hline & Ambulance & 0.7 & 1 & & & 0.5 & 1 \\
\hline Total & & 100.0 & 144 & 100.0 & 59 & 100.0 & 203 \\
\hline
\end{tabular}

Figure 7.15 shows the distribution of respondents by the time they took to reach a health facility. About 7 percent reached the facility within fifteen minutes while less than one-fourth of the pregnant women were able to reach the facility within 15-30 minutes. Moreover, 15 percent took one to two hours to travel to reach the health facility to get delivery services. 
Figure 7.15:

Time taken to reach the bealth facility for childbirth

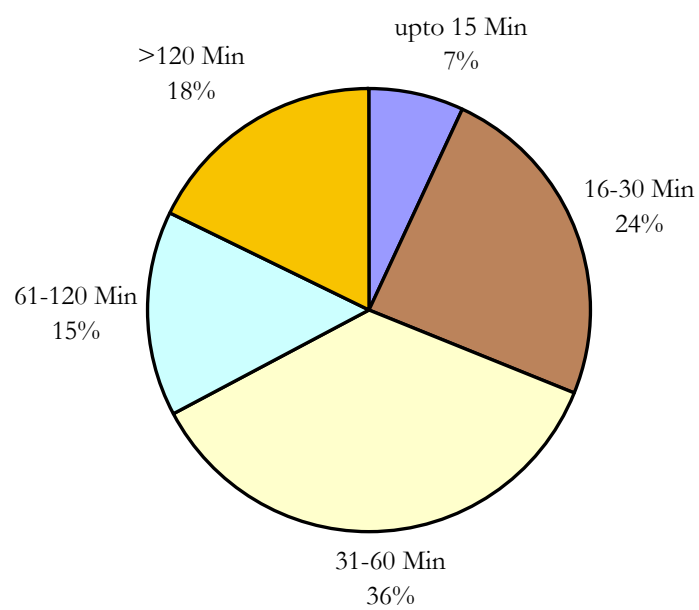

Figure 7.16 shows the median time taken to obtain transport, reach a health facility and obtain the treatment upon reaching the facility at the time of delivery. On average it reportedly took respondents 60 minutes to find a mode of transport to the health facility, and another 60 minutes of traveling to reach the health facility. The waiting time upon arrival at the facility was on average 20 minutes. Overall, it took more than two hours for a pregnant women to get to a health facility and obtain treatment at the time of delivery.

Figure 7.16: $\quad$ Median time to get the transport, reach the bealth facility, and to receive the treatment after reaching the facility

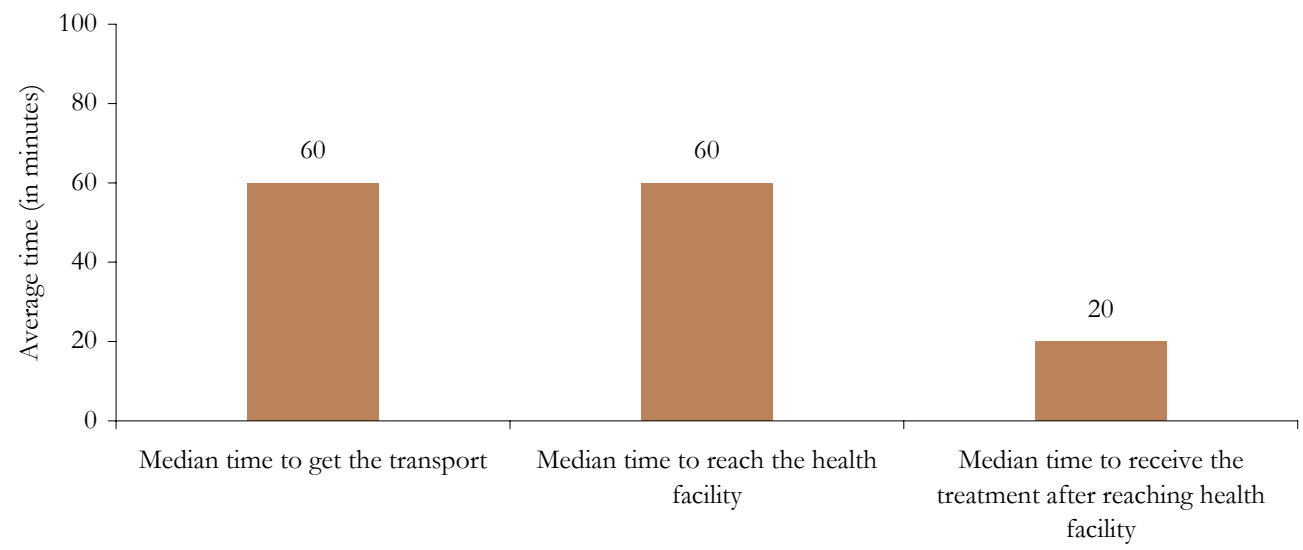




\section{Postpartum Care}

The postpartum period is a critical time for both the mother and the newborn. Respondents were asked about the quality and level of postpartum care they received after their last delivery. According to table 7.6, a large portion of the married women did not receive any postnatal check-ups after their last pregnancy. Almost three quarters of the respondents in both rural and urban Lasbela did not receive any postnatal check-ups after their last pregnancy. Among those who went for postnatal care, 17.6 percent went within 24 hours after the childbirth. Furthermore, according to table 7. 6, almost 41 percent of the respondents in rural areas and 48 percent in urban Lasbela reportedly experienced complications during the postpartum period.

Table 7.6: $\quad$ History of postpartum care

\begin{tabular}{|c|c|c|c|c|c|c|c|}
\hline \multirow{2}{*}{ History } & & \multicolumn{2}{|c|}{ Rural } & \multicolumn{2}{|c|}{ Urban } & \multicolumn{2}{|c|}{ Total } \\
\hline & & Percent & Number & Percent & Number & Percent & Number \\
\hline \multirow{3}{*}{$\begin{array}{l}\text { Have a postnatal } \\
\text { check-ups }\end{array}$} & Yes & 21.1 & 83 & 10.9 & 19 & 18.0 & 102 \\
\hline & No & 74.0 & 291 & 74.9 & 131 & 74.3 & 422 \\
\hline & $\begin{array}{l}\text { Delivered } \\
\text { in Hospital }\end{array}$ & 4.8 & 19 & 14.3 & 25 & 7.7 & 44 \\
\hline $\begin{array}{l}\text { No. of days after } \\
\text { delivery, have first } \\
\text { check-up }\end{array}$ & Same day & 19.3 & 16 & 10.5 & 2 & 17.6 & 18 \\
\hline \multirow{2}{*}{$\begin{array}{l}\text { Experienced } \\
\text { complications during } \\
\text { postpartum period }\end{array}$} & Yes & 40.6 & 168 & 48.1 & 87 & 42.9 & 255 \\
\hline & No & 59.4 & 246 & 51.9 & 94 & 57.1 & 340 \\
\hline Total & & 100.0 & 414 & 100.0 & 181 & 100.0 & 595 \\
\hline
\end{tabular}

\section{Newborn/Infant Care}

The care provided to a newborn upon birth is crucial to the baby's health. Survey questions regarding initial infant and childcare help determine the cause of newborn morbidity and mortality.

\section{Child Care during Birth}

Respondents were asked where their child was placed immediately after delivery. While a sizeable proportion of respondents indicated that their newborns were placed with the mother immediately following delivery, a large portion (42 percent) indicated that their newborns were placed on a piece of cloth. 
Table 7. 7:

History of newborn care

\begin{tabular}{|c|c|c|c|c|c|c|c|}
\hline \multirow{2}{*}{ History } & & \multicolumn{2}{|c|}{ Rural } & \multicolumn{2}{|c|}{ Urban } & \multicolumn{2}{|c|}{ Total } \\
\hline & & Percent & Number & Percent & Number & Percent & Number \\
\hline \multirow{6}{*}{$\begin{array}{l}\text { Placed child } \\
\text { immediately after } \\
\text { delivery }\end{array}$} & On floor & 18.9 & 70 & 4.7 & 8 & 14.4 & 78 \\
\hline & On mattress & 16.2 & 60 & 30.4 & 52 & 20.7 & 112 \\
\hline & $\begin{array}{l}\text { On a piece } \\
\text { of cloth }\end{array}$ & 39.6 & 147 & 46.2 & 79 & 41.7 & 226 \\
\hline & $\begin{array}{l}\text { Put with the } \\
\text { mother }\end{array}$ & 21.6 & 80 & 15.2 & 26 & 19.6 & 106 \\
\hline & Others & 1.9 & 7 & 0.6 & 1 & 1.5 & 8 \\
\hline & Don't know & 1.9 & 7 & 2.9 & 5 & 2.2 & 12 \\
\hline \multirow{3}{*}{$\begin{array}{l}\text { Child dried } \\
\text { up/cleaned before } \\
\text { giving bath }\end{array}$} & Yes & 89.5 & 331 & 98.2 & 168 & 92.2 & 499 \\
\hline & No & 3.0 & 11 & & & 2.0 & 11 \\
\hline & Don't know & 7.6 & 28 & 1.8 & 3 & 5.7 & 31 \\
\hline
\end{tabular}

It is not very common to weigh a newborn, especially in a district where most of the births take place at home. For those women who had not had their newborn weighed, a question was asked about the size of the baby at the time of the birth. Figure 7.16 depicts the percentage distribution of babies by their size at birth. Around 87 percent of the mothers reported that the size of their baby at the time of birth was normal. About 9 percent reported that there baby was smaller than average.

Figure 7.17: $\quad$ Percentage of live birth by their size (small, normal and big) at birth

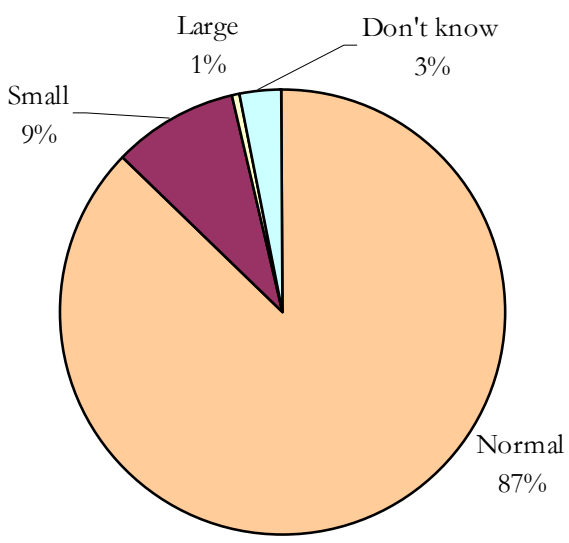

A question on the practice of bathing babies after the birth was also asked. Figure 7.17 shows that majority of the babies (84 percent) were given a bath within the first hour of birth. Only 3 percent of the babies were given a bath after the recommended time of 6 hours. 


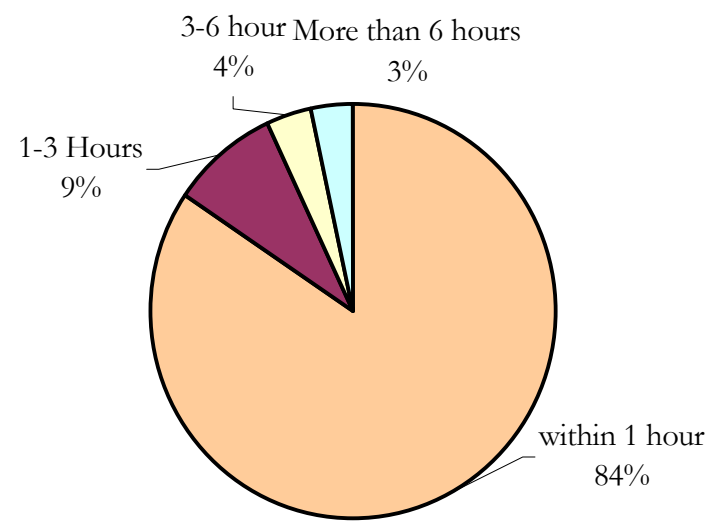

\section{Colostrum and Breastfeeding}

Respondents were also asked if they ever breastfed their infants. Over 94 percent in both urban and rural areas indicated that they did in fact breastfeed their child. However, the percentage of women who did not breastfeed was higher in rural areas than in urban centers. About 6 percent of the rural sample population in Lasbela indicated that they did not breastfeed, compared to 2 percent in urban Lasbela.

Colostrum is another very important aspect of newborn health, and respondents were asked if they gave colostrum to their newborn babies. In rural areas, 86 percent of the respondents stated that they did give colostrum to their babies, whereas in urban areas 93 percent of the mothers reported doing so with their newborns.

From those who gave colostrum to newborns, 6 percent of them gave it within the first hour following birth, while 87 percent did so within 24 hours. Furthermore, a sizeable portion of both urban and rural respondents provided their newborns with food supplements other than breast-milk within the first three days.

Figure 7.19: $\quad$ Newborn feeding and bealth indicators

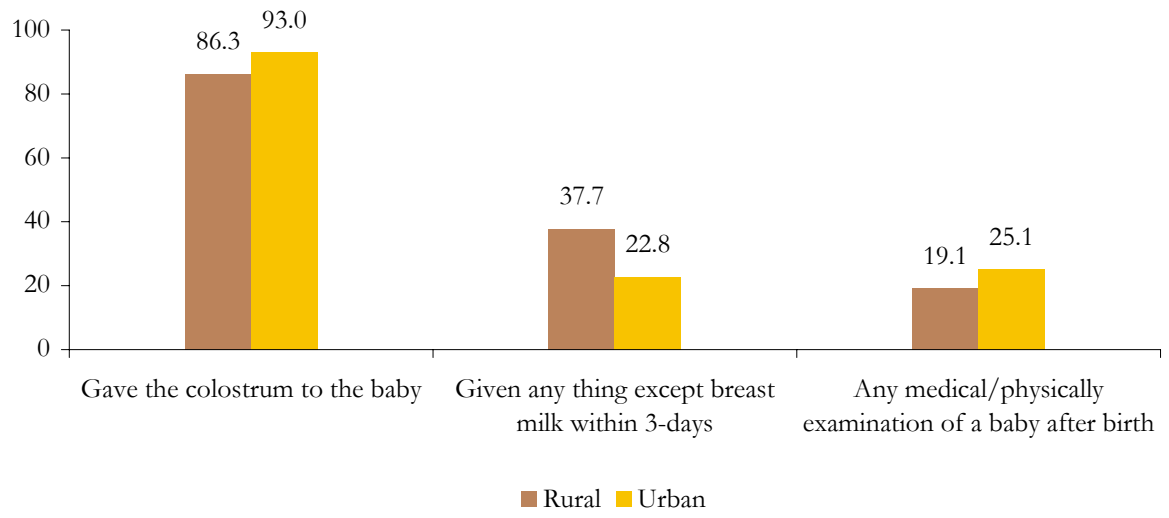




\section{Newborn Medical Check-ups}

Respondents were also asked if any physical/medical examinations were conducted on their newborn baby. About 19 percent of the rural respondents and 25 percent of the urban respondents indicated that their newborns had been medically/physically wxamined. A lack of physical and medical examinations after birth may potentially result in complications being left undetected and untreated, which in turn could be harmful to the health of a newborn. Respondents were asked to recall any complications or symptoms they noted in their newborn soon after delivery.

'Fever' and 'difficult breathing' were the most widely reported danger signs in newborns soon after delivery. Respondents were then asked if they noted any symptoms or complications within the first seven days after birth. Here the most widely reported danger signs were 'shivering' and 'frequent watery stools with blood or mucus'.

Figure 7.20: $\quad$ Percentage of newborns with danger signs/symptoms soon after delivery

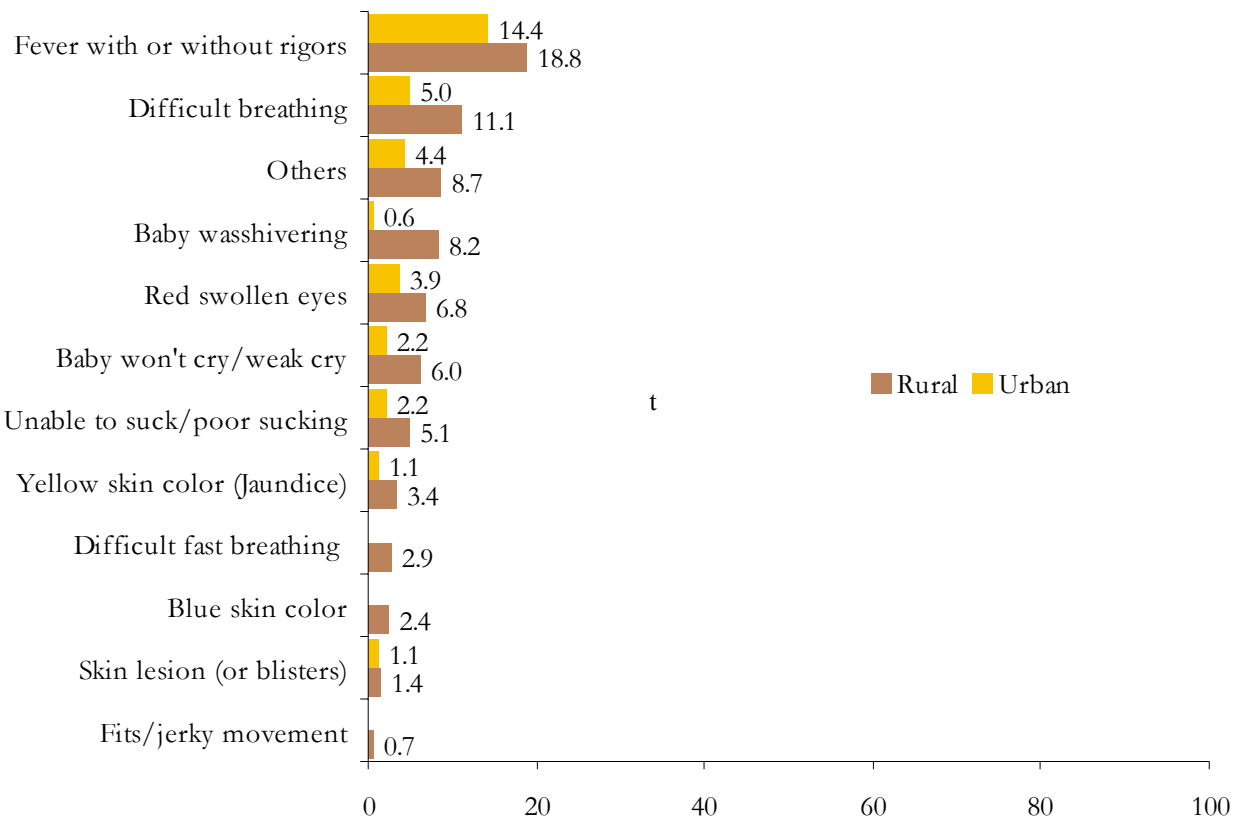


Figure 7.21: $\quad$ Percent of newborns with danger signs/symptoms within 7-days after last delivery

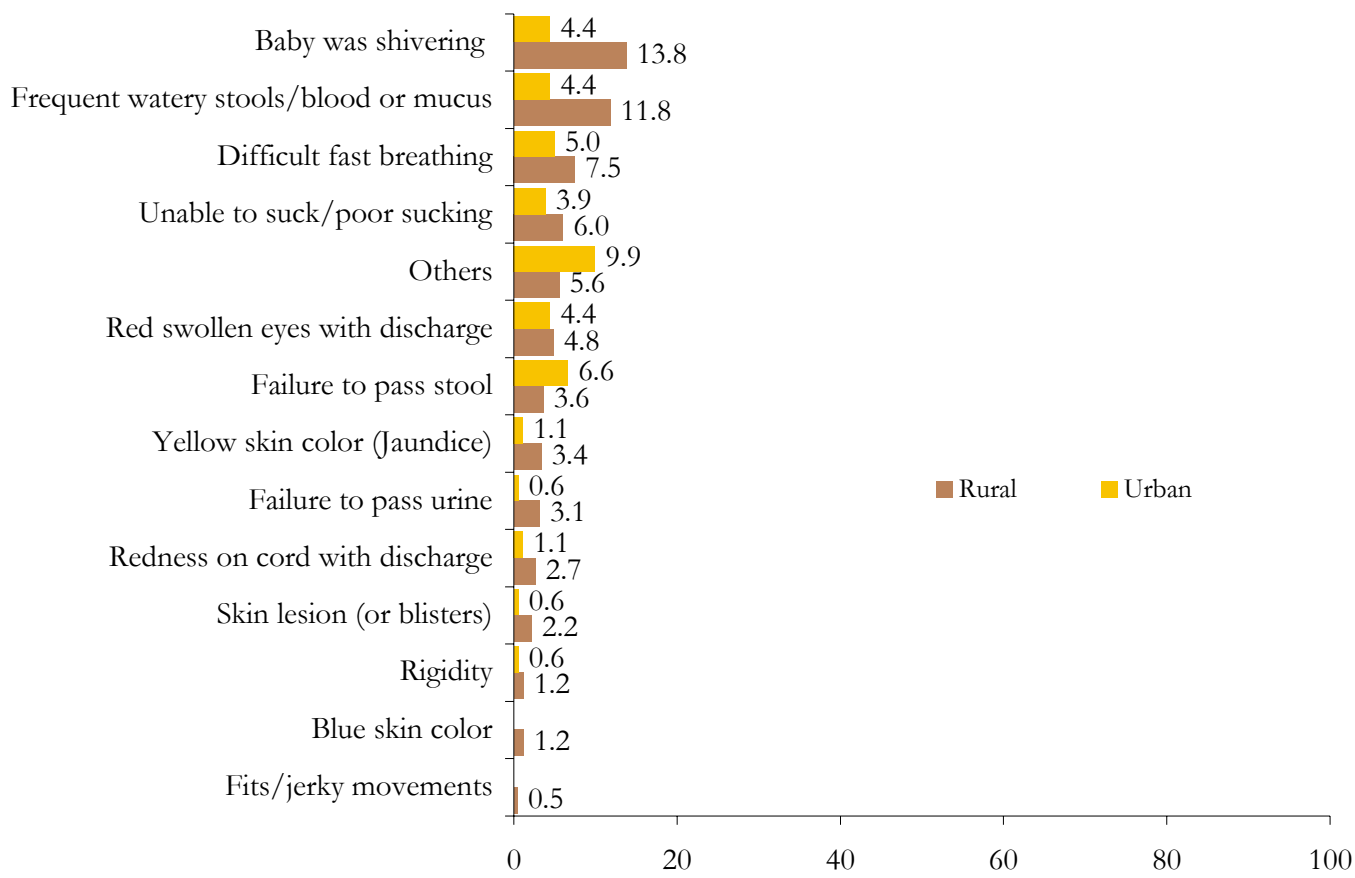

Respondents were asked to indicate the measures they took to get their newborn treated once the symptoms mentioned above were noted. The highest percentage of women indicated that they took their children to a private hospital or clinic to seek treatment (32 percent and 54 percent in rural and urban areas respectively). However, a sizable portion of both urban and rural women (25 percent and 43 percent respectively) failed to get any treatment at all.

Figure 7.22: $\quad$ Place where treatment was sought for newborn complications

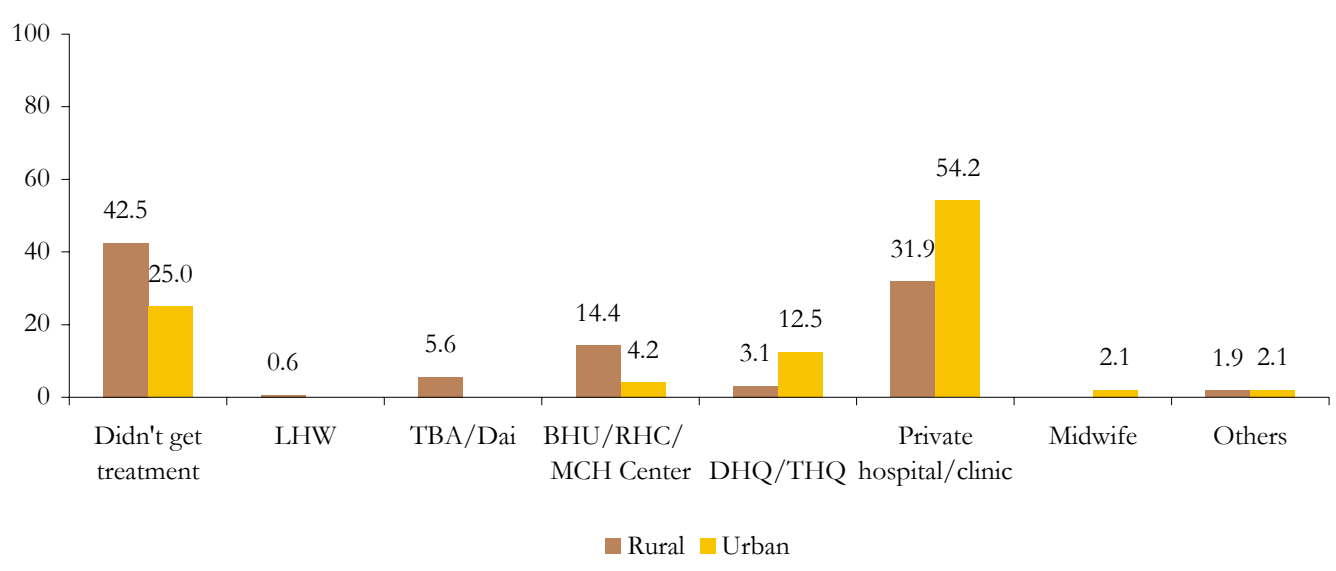


Finally, respondents were asked to indicate the status of health of their last child. Over 96 percent of the children were still alive in both urban and rural Lasbela. More than 65 percent of the respondents in rural Lasbela and 73 percent in urban areas were still breastfeeding their children at the time of the survey.

Figure 7.23: $\quad$ Status and bealth of last live birth

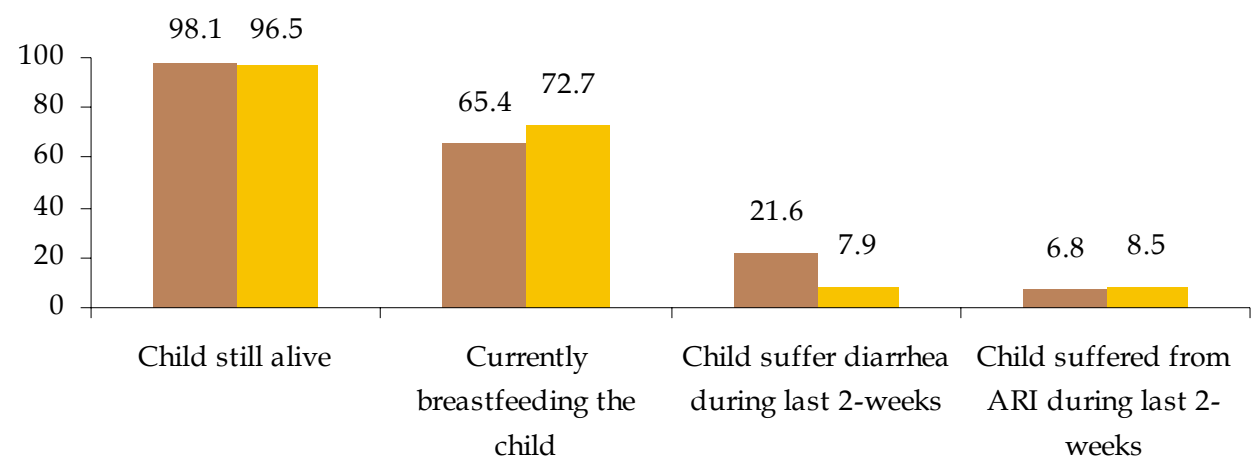

Rural Urban

A large proportion of respondents indicated that their children had been healthy during the last two weeks and had not suffered from acute respiratory illnesses. However, 22 percent of the respondents in rural areas and 8 percent in urban areas indicated that their children had had at least one episode of diarrhea within the two weeks preceding the survey. About 7 percent in rural areas and 9 percent in urban areas also indicated that their children suffered from ARI during the two weeks preceding the survey. 


\section{Chapter (8)}

\section{Conclusions}

The baseline household survey conducted in Lasbela is an essential tool in the process of understanding the different attitudes towards, and misconceptions regarding pregnancy and neonatal care. Since PAIMAN is intended to improve the health of all pregnant women as well as their newborn children, it is important to understand the obstacles that stand in the way of good health. The baseline survey is based largely on the opinions and experiences of married women of reproductive age (MWRA); the information obtained is from the very individuals who are to be the primary recipients of the work carried out by PAIMAN.

The sex ratio in the baseline survey is 105 males per 100 females. The sex ratio obtained in 1998 Population Census was 115 males per 100 females. This may be due to the improvement in the overall enumeration of the female population in individual households. Another sign of improvement since the 1998 Population Census can be noted in the marital status of women, which clearly demonstrates a delay in the age at marriage for females. However, women still tend to get married earlier than men. On average in Lasbela, women have 3.8 live births and 3.5 living children.

Findings also show that 29 percent of the population in the district of Lasbela has access to some sort of media; whether it is television, radio or newspapers. However, the 71 percent of the population without access to any sort of media would need to be reached through other channels. A majority of the women interviewed believed that television was the most trustworthy form of media.

Regarding antenatal care, an overwhelming majority believed it necessary for women to receive antenatal check-ups. Findings show that more than 46 percent of all pregnant women in rural Lasbela, and almost 69 percent of the women in urban Lasbela went for an antenatal check during their last pregnancy. However, less than one-quarter of married women in rural areas and one-third in urban areas went for three or more antenatal checkups. Therefore, it is quite clear that while many women do want to receive antenatal check-ups, and feel that it is a necessary part of neonatal care, many are not able to access this service on a regular basis. Findings show that all the major issues were discussed with a sizeable portion of the women during their antenatal visits. However, only 24 percent of the pregnant women were informed of the danger signs that may appear during pregnancy.

Respondents were asked to indicate which complications they believed were dangerous and required medical attention. Surprisingly, a very small percentage believed that most complications required a doctor's care. The findings show that 53 percent of the married women in rural areas knew three or more danger signs during pregnancy, compared to more than 45 percent in urban areas. However, approximately 15 percent of the respondents were unable to name a single complication that may appear during pregnancy. 
Over 28 percent of the married women in rural areas, and 55 percent in urban areas indicated that they did in fact receive at least two TT shots during their last pregnancy. A very large portion of the rural respondents (57 percent) and urban respondents (38 percent) indicated that they took no iron or folate supplements during their pregnancy.

Findings also show that even though a majority of the women believe that services during childbirth should be obtained from a hospital, more than 63 percent of the deliveries in Lasbela are carried out by TBAs/Dais. Not all women are allowed or able to deliver with the help of SBA even if they want to. One reason, which explains why some women still want to deliver at home, is that they are not always able to make decisions independently. Often, women are dependant upon their husbands or in-laws when it comes to major decisions. However, most of the respondents claimed that they had arranged for transport, money, and hospital fees etc. prior to the time of delivery, therefore eradicating any major delays.

Caesarean section deliveries make up less than 7 percent and 1 percent of the deliveries in urban and rural areas respectively. About 40 percent of the respondents in rural areas indicated that they experienced excruciatingly abnormal pain during their last delivery, while 34 percent in urban centers reported the same. Bleeding before labor began, prolonged/obstructed labor and fever were some other complications that were reported.

Married women in Lasbela generally undervalue the importance of postnatal care. Most respondents believed that only some women in their area received postnatal care.

As in the case of pregnancy, many women are not aware of the complications that may arise during delivery. Survey findings show that only 24 percent of the women in rural areas and 18 percent in urban areas were able to name at least three danger signs during delivery. Deliveries can only be made safe if married women are educated regarding the danger signs that may be noted during the delivery, so that they can decide when to seek treatment. Innovative approaches are therefore needed to make these communities more aware of issues regarding maternal and newborn health.

Although baseline survey findings indicate that excessive vaginal bleeding is the most known danger sign during the postpartum period, not all women were aware of this fact. The postpartum period is a critical time for mother and newborn. More than 74 percent of the population in both rural and urban areas received no postnatal check-up. Among those who went for postnatal care, 17.6 percent went within 24 hours after the childbirth.

A very large percentage in both urban and rural areas indicated that they received their pregnancyrelated information from their family members, in-laws and friends. Only 9 percent in rural Lasbela and 14 percent in urban Lasbela indicated that a Lady Health Worker was the source of their information. District Headquarter Hospital and Tehsil Headquarter Hospitals were also a source of information for approximately 9 percent of the rural respondents and 21 percent of the urban respondents in Lasbela.

Arrangement of transport to a health facility is a major cause of delay and can often lead to maternal and newborn mortality. It is very important to arrange transport ahead of time in order to eliminate that delay. Unfortunately, many households are unable to do so due to a lack of transportation in their communities. Most communities do not have any arrangement for transport, provision of blood and finances for women at the time of need during delivery. This is a major obstacle to safe birth practices, and birth preparedness promotes the arrangement of such aspects. 
We hope that this data may be used by health officials, NGOs, and other concerned stakeholders to improve the situation regarding maternal and newborn health in Lasbela. PAIMAN will use this information to guide its own interventions and to monitor its progress. 


\section{References}

Caldwell, J., Routes to Low Mortality in Poor Countries. Population and Development Review, Vol. 12, No. 2. (Jun., 1986), pp. 171-220.

Federal Bureau of Statistics, "Socio-Economic Indicators at District Level, Punjab," Statistics Division, Government of Pakistan, (2002).

Hollander, D., Antenatal Education Helps Turkish Women Adopt Health-Promoting Behaviour. International Family Planning Perspectives, Vol. 30, No. 1. (Mar., 2004), pp. 45-46.

JHPIEGO/Maternal and Neonatal Health Program, "Monitoring Birth Preparedness and Complication Readiness: Tools and Indicators for Maternal and Newborn Health,” (2004).

Mahmood, Arshad, Determinants of Neonatal and Post-Neonatal Mortality in Pakistan. The Pakistan Development Review, Vol. 41, No. 4, Part II (Winter 2002), pp. 723-744.

Mahmood, Arshad, Socioeconomic Factors, Personal Illness Control and Infant and Child Mortality in Pakistan. Pakistan Population Review, Vol. 3, No. 1 (1992), pp. 67-86.

Martin, Linda G.; J. Trussell; Florentina Reyes Salvail; Nasra M. Shah, Co-variates of Child Mortality in the Philippines, Indonesia, and Pakistan: An Analysis Based on Hazard Models. Population Studies, Vol. 37, No. 3. (Nov., 1983), pp. 417-432.

Nawaz, Shuja, The Mass Media and Development in Pakistan. Asian Survey, Vol. 23, No. 8. (Aug., 1983), pp. 934-957.

Ringheim, Karin, When the Client is Male: Client-Provider Interaction from a Gender Perspective, International Family Planning Perspectives, Vol. 28, No. 3 (Sept., 2002), pp. 170-175.

Robbins, P.T., Global Approaches to Development. Sociology of Development, University of London, (2001), pp. 29-37.

Sathar, Zeba; Nigel Crook; Christine Callum; Shahnaz Kazi, Women's Status and Fertility Change in Pakistan. Population and Development Review, Vol. 14, No. 3. (Sep., 1988), pp. 415432.

Simmons, George B., Family Planning Programs or Development: How Persuasive is the New Wisdom? International Family Planning Perspectives, Vol. 5, No. 3. (Sep., 1979), pp. $101-110$.

Syed, Sabiha H., Communications Channels and Family Planning in Pakistan. Studies in Family Planning, Vol. 10, No. 2. (Feb., 1979), pp. 53-60.

www.unesco.org 